\title{
THE POTENTIAL FOR ENERGY EFFICIENCY IN THE STATE OF IOWA
}

S. W. Hadley

June 2001

Sponsored by

The Iowa Energy Center

2521 Elwood Drive

Suite 124

Ames, Iowa 50010-8263

OAK RIDGE NATIONAL LABORATORY

Oak Ridge, Tennessee 37831

managed by

UT-BATTELLE, PLC

for the

U.S. DEPARTMENT OF ENERGY

under contract No. DE-AC05-00OR22725 



\section{TABLE OF CONTENTS}

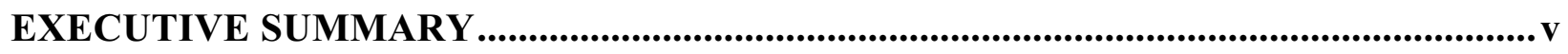

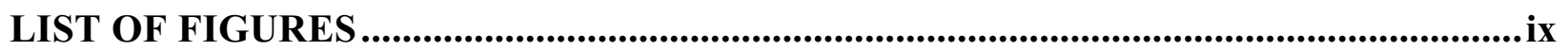

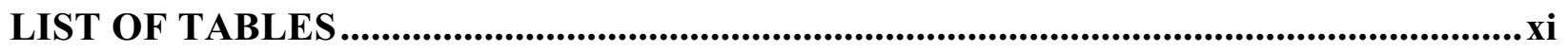

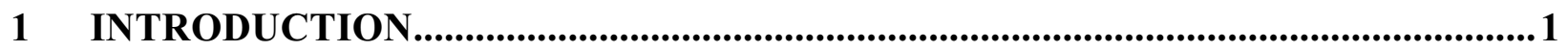

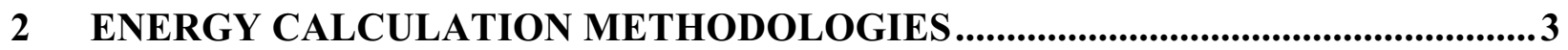

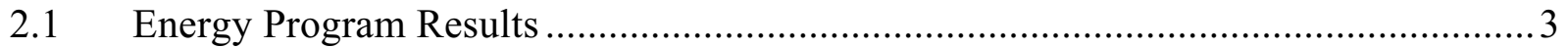

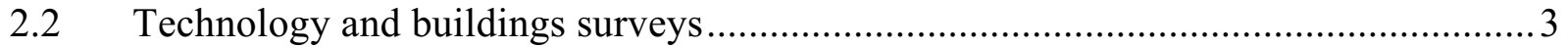

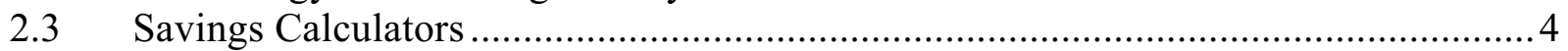

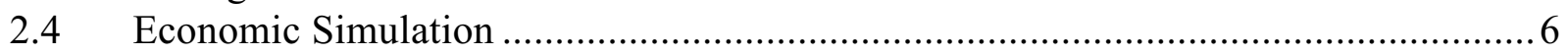

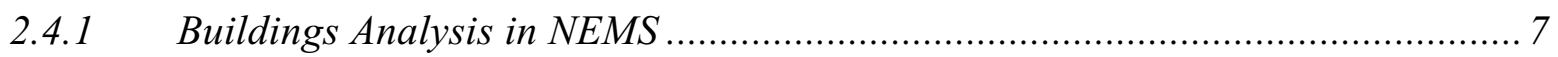

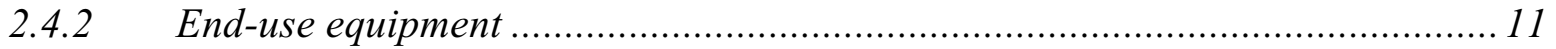

3 ENERGY USE ...................................................................................................... 13

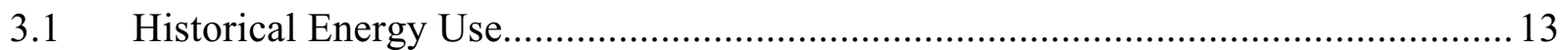

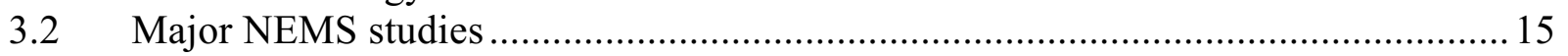

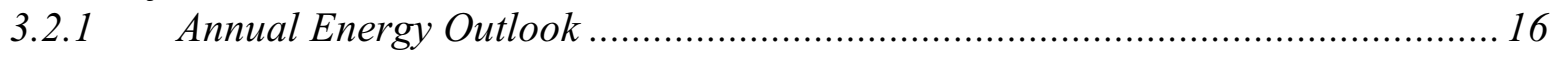

3.2.2 Clean Energy Futures............................................................................ 17

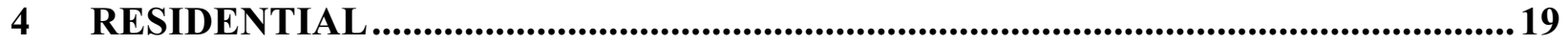

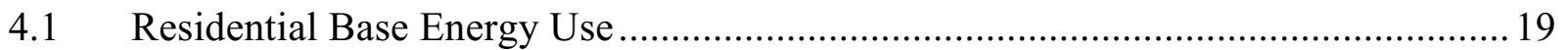

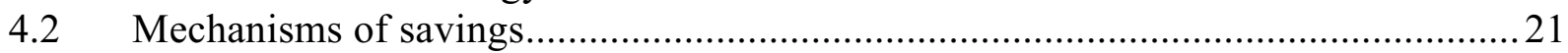

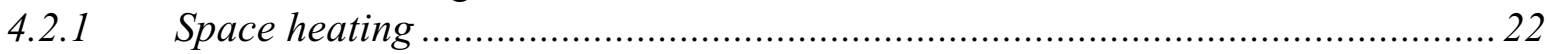

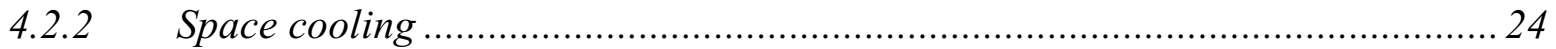

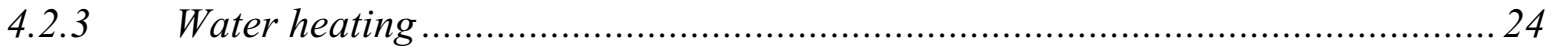

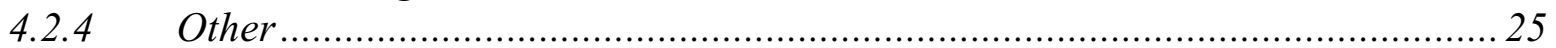

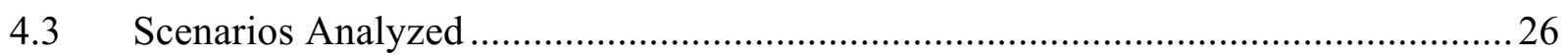

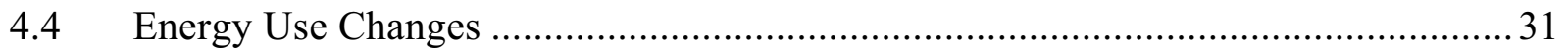

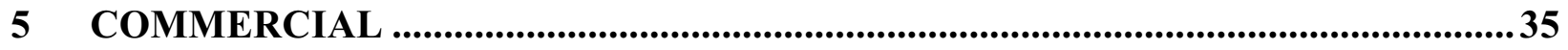

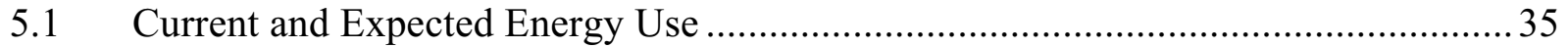

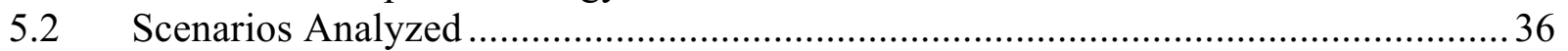

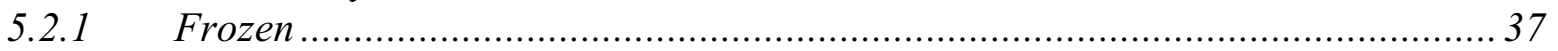

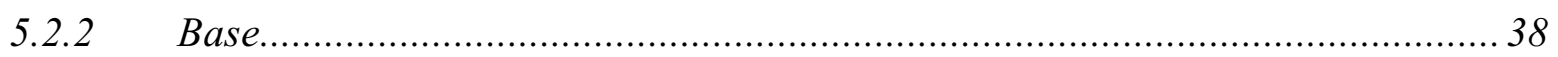

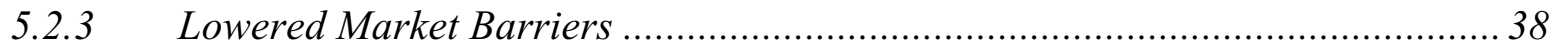

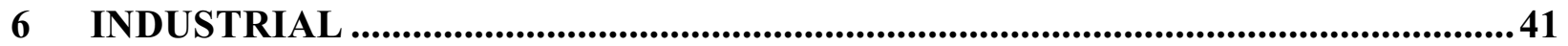

7 SUMMARY

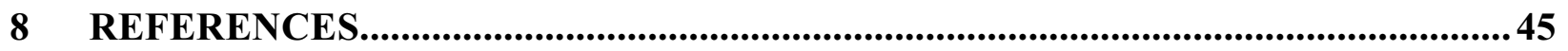




\section{APPENDIX: BUILDINGS IMPLEMENTATION PATHWAYS FROM THE CLEAN \\ ENERGY FUTURES STUDY ...........................................................................................}

1 POLICY IMPLEMENTATION PATHWAYS............................................................... 1

1.1 Barriers to Adoption of Cost-Effective Efficiency Technologies.................................... 1

1.1.1 Barriers faced by energy users..................................................................

1.1.2 Barriers faced by manufacturers, builders, designers, and suppliers.................... 3

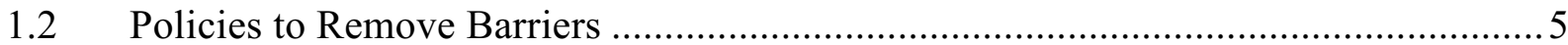

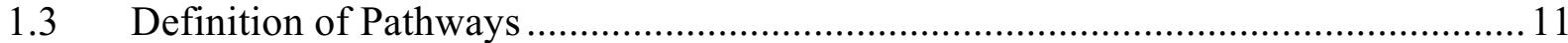

2 METHODOLOGY FOR ANALYZING IMPACTS ……................................................. 11

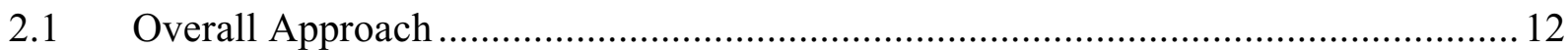

2.2 Details of the Analysis of Policies Outside of CEF-NEMS ………………................ 13

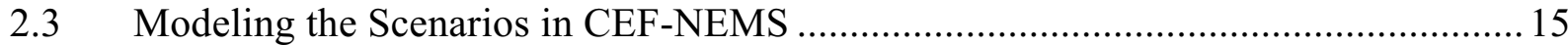

$3 \quad$ APPENDIX REFERENCES...................................................................................... 16

Iowa Energy Efficiency Potential iv 


\section{EXECUTIVE SUMMARY}

The purpose of this study was to do an initial estimate of the potential for energy savings in the state of Iowa. Several methods for determining savings were examined, including existing programs, surveys, savings calculators, and economic simulation. Each method has advantages and disadvantages, trading off between detail of information, accuracy of results, and scope. This paper concentrated on using economic simulation (the NEMS model (EIA 2000a)) to determine market potential for energy savings for the residential and commercial sectors. The results of surveys were used to calculate the economic potential for savings in the industrial sector.

The NEMS model is used by the Energy Information Administration to calculate twenty-year projections of energy use for every region of the country. The results of the Annual Energy Outlook 2000 were used as the Base case (EIA 1999a). Two alternative cases were created to simulate energy savings policies. Voluntary, market-related programs were simulated by lowering the effective discount rates that end-users use when making decisions on equipment purchases. Standards programs in the residential sector were simulated by eliminating the availability of low efficiency equipment in future years. The parameters for these programs were based on the Moderate scenario from the DOE Clean Energy Futures study (Interlaboratory Working Group 2000), which assumed increased concern by society on energy efficiency but not to the point of fiscal policies such as taxes or direct subsidies.

The study only considered a subset of the various programs, policies, and technologies that could reduce energy use. The major end-uses in the residential sector affected by the policies were space cooling (20\% savings by 2020$)$ and water heating (14\% savings by 2020 .) Figure S-1 shows the space cooling savings when voluntary programs and minimum efficiency standards were implemented. Refrigerators, freezers, and clothes dryers saw slight improvements. The study did not involve changes to the building shell (e.g., increased insulation) or residential lighting improvements. Nevertheless, the residential sector's market potential for electrical energy savings was calculated to be $5.3 \%$ of expected electrical use, representing $850 \mathrm{GWh}$ by 2020. Natural gas savings could be $2.4 \%$ of expected gas use, representing 2.1 trillion Btus. Using expected prices for energy in that year, these represent savings of $\$ 47$ million and $\$ 12$ million per year.

In the commercial sector, the study only considered voluntary market-based policies for some of the technologies. The most notable savings were in ventilation ( $12 \%$ savings by 2020$)$, lighting ( $12 \%$ savings), refrigeration ( $7 \%$ savings), water heating ( $6 \%$ savings), and space heating ( $5 \%$ savings by 2020 ) (Figure S-2). The commercial sector's market potential for electrical energy savings based on the programs modeled was calculated to be $5.1 \%$ of its total expected electrical use, representing $605 \mathrm{GWh}$ of power by 2020. Natural gas savings were 2.3 trillion Btu, $3.7 \%$ of use. Using the same prices as the residential sector $(5.5 \phi / \mathrm{kWh}$ and $\$ 5.74 / \mathrm{MBtu}$ ), the savings represent $\$ 33$ million and $\$ 13$ million per year, respectively. 
Figure S-1: Iowa residential space cooling energy use with various policies implemented

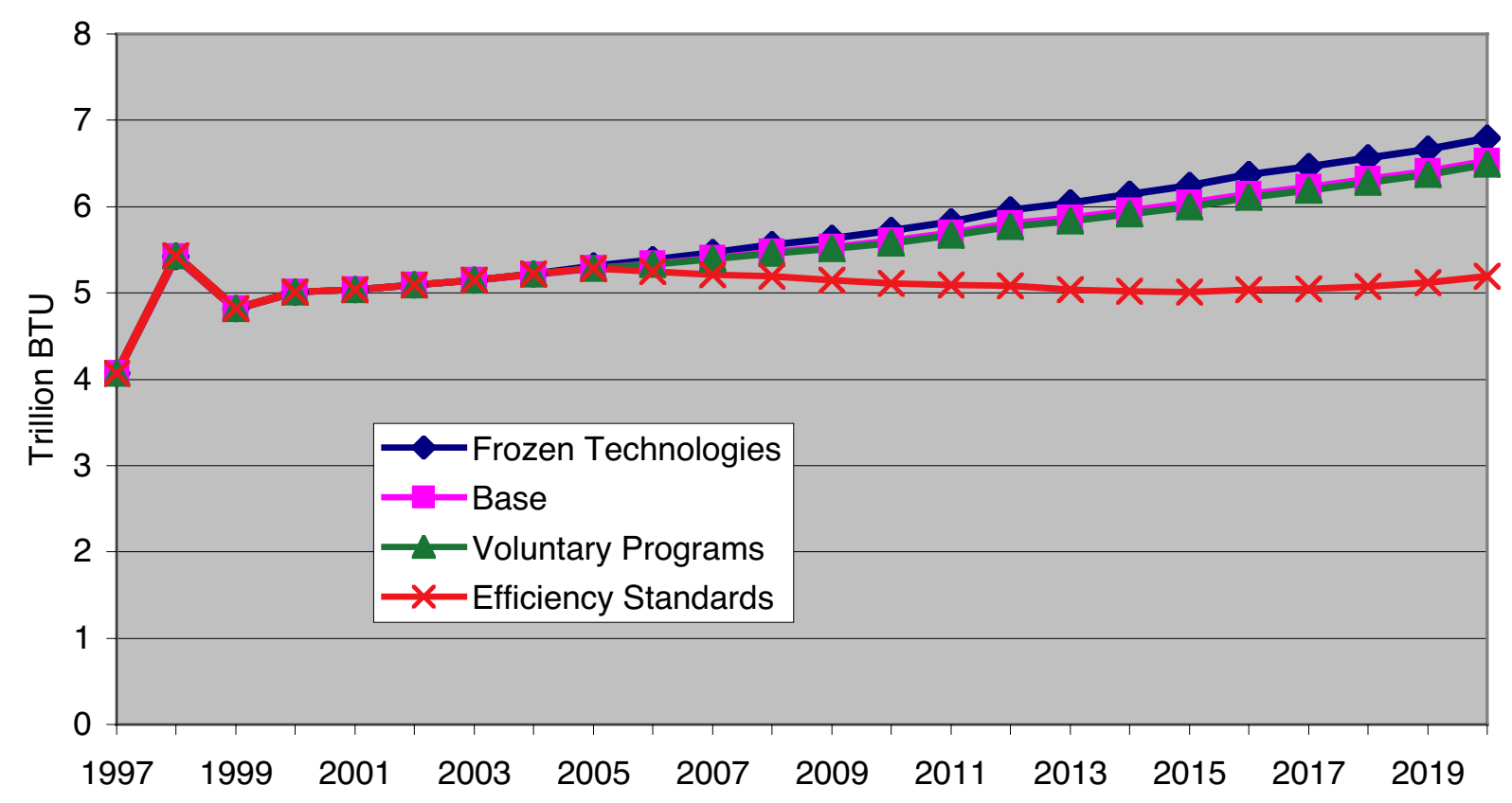

Figure S-2: Energy savings by 2020 for the Iowa commercial sector with programs studied

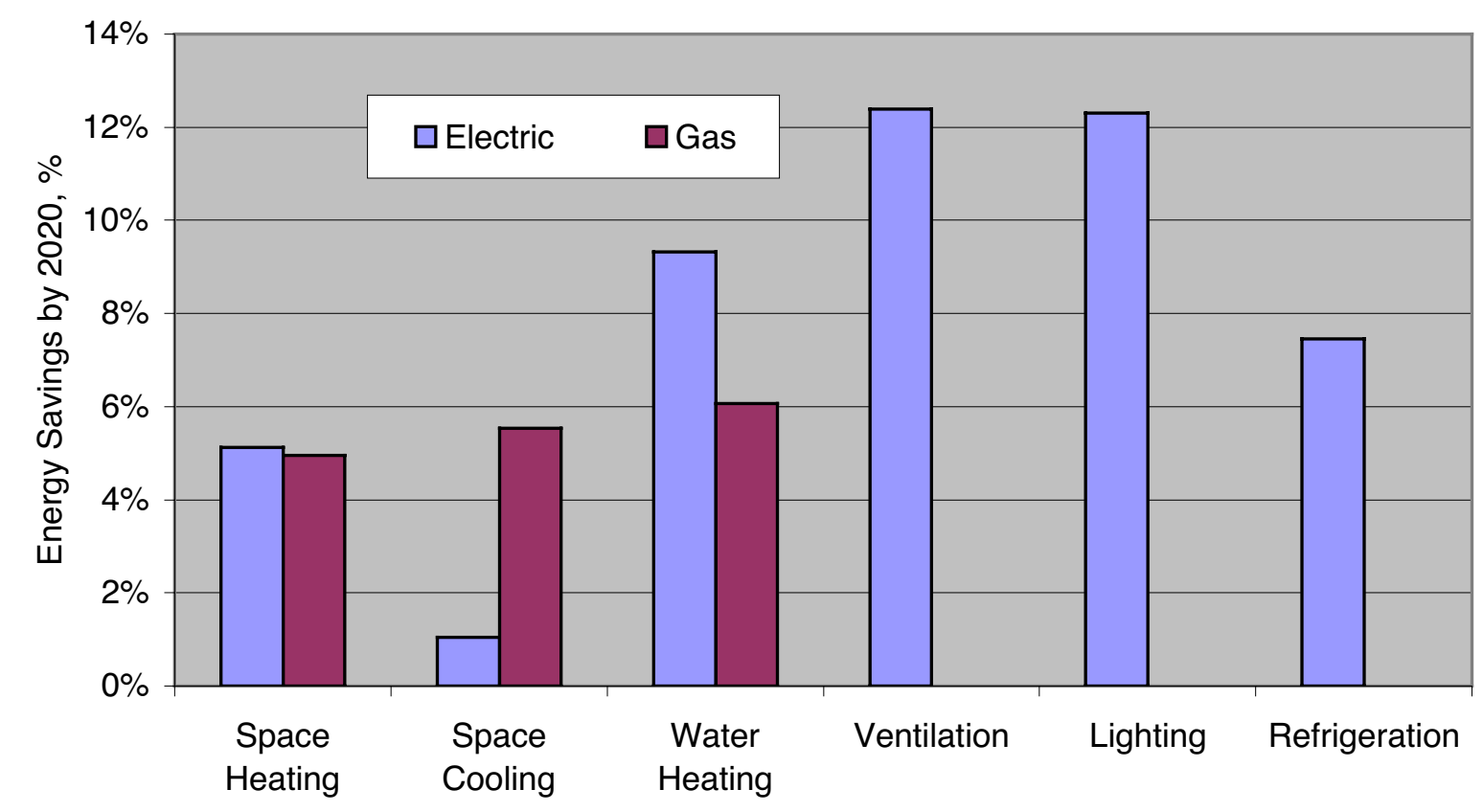

Instead of performing a market simulation of the Industrial sector, a survey of potential savings from motor drive system improvements was used to calculate the economic potential savings. It found that motor systems are roughly $40 \%$ of electrical use within the industrial 
sector, and that $14 \%$ of this amount could be saved, or a total of $6 \%$ of industrial electrical use. This represents possible savings of $930 \mathrm{GWh}$, or $\$ 46$ million per year at $5 \mathrm{c} / \mathrm{kWh}$.

In all three sectors only some of the potential savings were examined. For example, lighting and building envelope improvements in the residential sector, efficiency standards in commercial equipment, and distributed energy resources in the industrial sector were not examined. Expansion of studies into these areas may be useful in the future. Also, the growth of miscellaneous other energy uses such as electronics makes these a significant fraction of future demands and may warrant further investigation. Energy savings programs specific to these uses (such as Energy Star) may be helpful in slowing their growth.

Overall, there is a good potential for saving at least 5\% of energy use in Iowa through a combination of market programs and standards, representing over $\$ 100$ million per year. 



\section{LIST OF FIGURES}

Figure S-1: Iowa residential space cooling energy use with various policies implemented...........vi Figure S-2: Energy savings by 2020 for the Iowa commercial sector with programs studied ......vi

Figure 1-1: Iowa Investor-Owned Utility annual energy savings - Potential vs. Actual ................2

Figure 2-1: Screenshot of energy savings for typical Des Moines home from the Home Energy Savers website 6

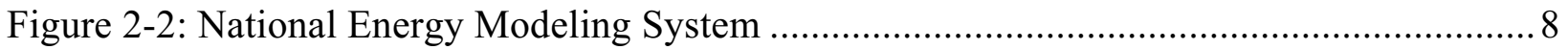

Figure 2-3: Residential demand module structure within NEMS ................................................ 9

Figure 2-4: Commercial demand module structure within NEMS ............................................ 10

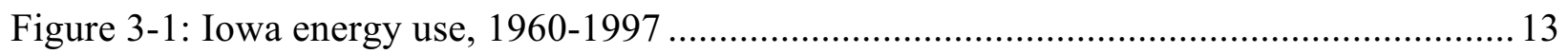

Figure 3-2: 1997 Iowa Energy Use by Sector...................................................................... 14

Figure 3-3: Fuel price projections 1999-2020: AEO2000 and AEO2001 compared (EIA 2000) 16

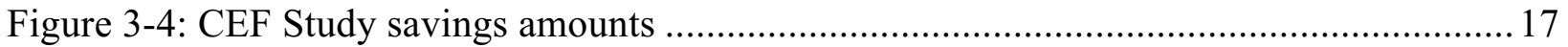

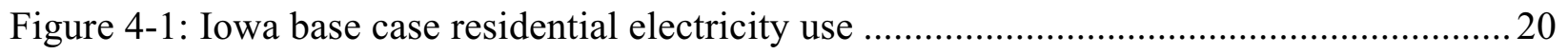

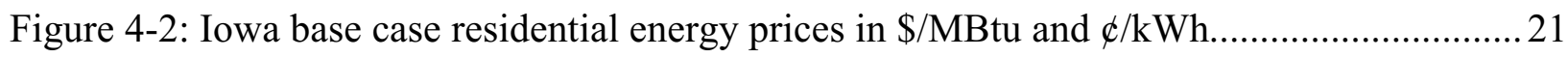

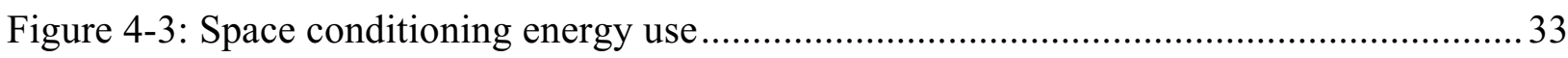

Figure 4-4: Water heating energy use .................................................................................. 33

Figure 5-1: West-North-Central commercial energy use.............................................................. 35

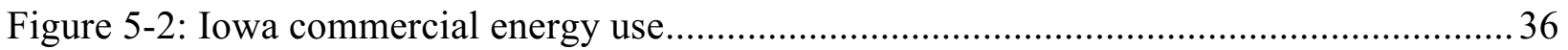

Figure 5-3: Iowa commercial electricity use

Figure 5-4: Percentage of commercial customers with varying discount rates.............................39

Iowa Energy Efficiency Potential ix 



\section{LIST OF TABLES}

Table 2-1: Percentage energy savings for different improvements from the ORNL SEP model...5

Table 2-2: Services and Equipment in the NEMS Residential Sector Demand Module. 12

Table 2-3: Building types and end-use services in NEMS Commercial Demand Module ..... 12

Table 3-1: 1997 Iowa Energy Use by Fuel and Sector in Billion Btus from SEDS (EIA 1997).. 14

Table 3-2: Percentage of Iowa energy use to seven-state total from SEDS (EIA 1997)............. 15

Table 3-3: Housing units for Iowa and 7-state region from 1990 U.S. Census ......................... 15

Table 4-1: Iowa Base Case Total Residential Energy Use ............................................... 19

Table 4-2: Iowa base case residential electricity use ............................................................. 20

Table 4-3: Heat pump costs and efficiencies in the AEO2000 ..........................................22

Table 4-4: Space heating technologies in the AEO2000 (except heat pumps) .........................23

Table 4-5: Air conditioner costs and efficiencies in the AEO2000........................................24

Table 4-6: Water heating costs and efficiencies in the AEO2000.......................................25

Table 4-7: Refrigerator and freezer technologies within NEMS ........................................26

Table 4-8: Average equipment efficiencies in Frozen case ...............................................2 27

Table 4-9: Percentage changes in average efficiency between Base case and Frozen case .........28

Table 4-10: Base case and Lowered Rate case implicit discount rates ...................................29

Table 4-11: Percent increase in average efficiency of Lowered Rate case versus Base Case...... 30

Table 4-12: Minimum residential efficiency standards from CEF .......................................... 30

Table 4-13: Percentage change in average efficiency Standards versus Base case ................... 31

Table 4-14: Iowa 2020 residential energy use (Trillion Btu).............................................. 32

Table 5-1: Commercial equipment efficiency in Frozen case (Btu Out/Btu In) ........................3 37

Table 5-2: Commercial equipment efficiency improvements with lowered discount rates (Btu

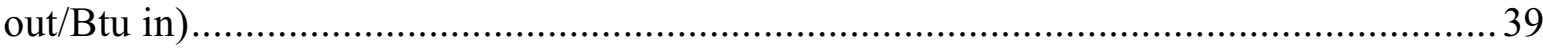

Table 5-3: Iowa 2020 commercial energy use from Frozen, Base, and Lowered Discount Rate

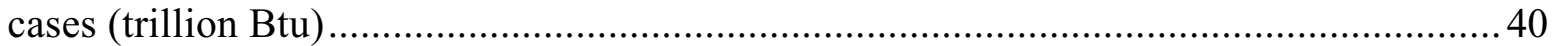

Table 6-1: Iowa industrial motor energy use and potential savings .................................... 42

Iowa Energy Efficiency Potential 



\section{Introduction}

Iowa has a long history of being active in the promotion of energy efficiency. Over the years, the state has collected funds for funding energy-related programs through surcharges on electricity and gas rates. Examples of programs funded include low-income heating assistance, energy efficiency programs, and renewable energy development. Future funding in these areas is being debated, as to both the amount and the allocation. One question that arises is what are the potential results of funding the different types of programs. What is the potential for energy efficiency or for renewable power, and what would be accomplished given the amount of funding provided?

The purpose of this project is to provide an initial estimate of the potential for energy efficiency programs in Iowa. It concentrates on the residential, commercial, and industrial sectors of the economy, especially on electric energy savings through improvements in equipment. Savings in buildings can include improvements to space conditioning as well as improvements to lighting or other appliances. Industrial savings could include improvements to motors and drives or changes to industrial efficiency.

Estimates of potential energy savings available in a given population of facilities generally distinguish between different conceptual approaches (McElhaney and Jallouk 1999). These can be summarized as follows:

- Technical potential denotes energy savings that can be achieved by applying proven energy efficiency technologies to all available opportunities for their use in the population, regardless of the relationship between implementation and cost.

- Economic potential denotes energy savings that can be achieved through a subset of the technically feasible efficiency improvements that meet specified economic criteria. Energy efficiency measures should pass an economic screen (incremental cost versus avoided energy and capacity savings) with a "societal test" benefit cost ratio of greater than 1.20 to allow for administrative costs to conduct the program.

- Market potential denotes the energy savings that can be achieved by a subset of economically cost-effective measures that analysts believe the market can deliver during the time horizon of the analysis.

Supply-side constraints on the achievement of economic potential include the lack of awareness of energy efficiency measures and design practices among engineers and conflicting economic incentives for manufacturers or distributors who are principally interested in equipment sales. On the demand side, constraints arise from the competing priorities for capital expenditures and plant maintenance resources.

Differences in the approach used in reporting savings can lead to confusion on the amount of savings actually available. While technical or economic potential savings may be high, the market barriers such as customer inertia, long lives of existing equipment, and limitations in 
institutional structures will generally greatly lower the amount of savings that will actually occur and slow the penetration of new technologies. As an example, Dunn has summarized the savings potential from Iowa investor-owned utilities as reported by Barakat \& Chamberlin (Dunn 1999). Figure 1-1 indicates the technical savings potential, the economic potential if immediately implemented, and the savings if phased-in over time.

Figure 1-1: Iowa Investor-Owned Utility annual energy savings - Potential vs. Actual (Dunn 1999)

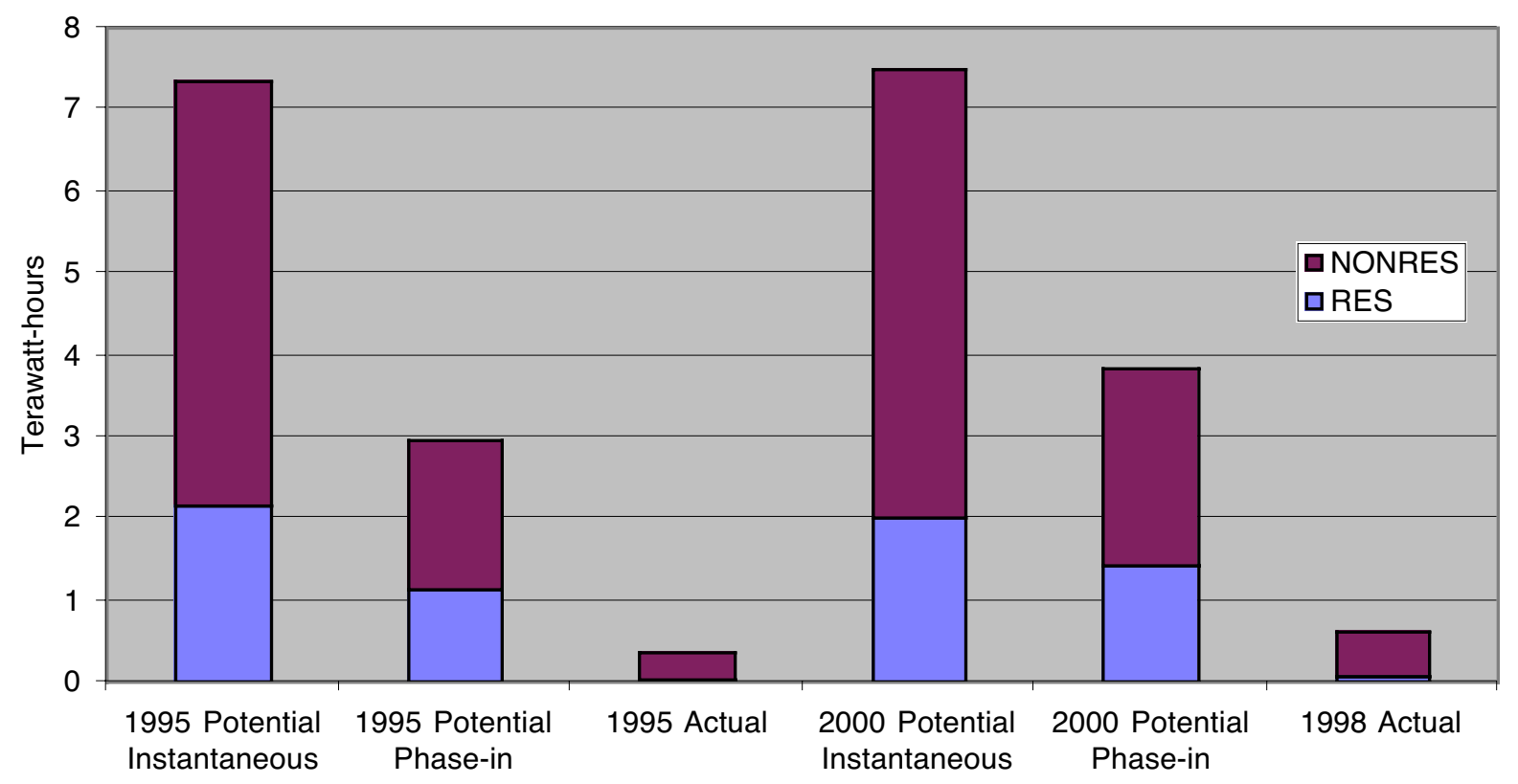

This paper is organized as follows: Section 2 describes the methodologies that can be used to calculate energy savings potentials. Section 3 describes the current and projected amount of energy use in Iowa. Section 4 describes energy savings potentials in the residential sector, Section 5 the commercial sector, and Section 6 the industrial sector. Section 7 summarizes the report and Section 8 gives the references used. 


\section{Energy Calculation Methodologies}

Statewide energy savings potential cannot be directly measured but must be calculated. First, the word "potential" means that the savings have not occurred yet. Second, the savings are often only indirectly measured by estimating what energy use there would have been without the changes in technology or behavior. Calculations through sampling and statistical analysis or by simulation, are a necessary part of any mechanism to determine energy savings potential.

There are currently several methods for calculating savings. Extrapolation of savings achieved from specific programs, surveys of existing building stock or energy-using activities, computer calculations of representative building types, and economic simulations all provide insight into the amount of energy that could be saved.

\subsection{Energy Program Results}

Many states and utilities have implemented demand side management programs over the past ten to twenty years. Under these programs, energy savings practices or technologies are implemented in a given region or end-use customer sector. With the advent of electricity restructuring and low energy prices, many of these programs lost steam, but persisted. Iowa's programs through the Department of Natural Resources' Energy Bureau have long been a success. Over the years, the Energy Bureau's Energy Bank has funded $\$ 150$ million in improvements to schools, hospitals, colleges, local governments, and state agencies. These improvements are estimated to save $\$ 25$ million per year for these organizations. Newer programs such as Rebuild Iowa (part of the DOE Rebuild America program) have funded over $\$ 7$ million with good success as well.

The utilities within Iowa have also been very active in energy efficiency and load management programs. For example, Alliant Energy has spent over $\$ 87$ million in energy programs over the past decade with annual savings calculated at almost $\$ 30$ million per year.

One requirement of many of the demand-side management programs is verification of savings. Utilities or other organizations running these programs must verify the amount of savings in order to be compensated. This provides detailed information on the savings for those houses or businesses that were part of the program. Some difficulty arises, however, in extrapolating the results to the entire state. Information on the state's housing stock, as compared to that in the program, must be found. Assumptions must then be made on the fraction of the state that could benefit from such a program and the amount of energy saved.

\subsection{Technology and buildings surveys}

Numerous technologies show the potential to greatly reduce energy use in buildings and industry. Advances in heat pumps, refrigeration, lighting, motor systems, clothes washers, and water heaters can greatly reduce the amount of energy needed for these end-uses. Technology surveys provide information on the types of equipment that could be available, as well as the existing equipment being used. 
Surveys of different end-use sectors can provide information on the energy-saving potential within their activities. Surveys answer the problem posed in the section above, what is the current stock of energy-using equipment within buildings, be it residential, commercial, or industrial. The Department of Energy's Energy Information Administration (EIA) periodically conducts national surveys of the residential and commercial building energy use. The most recent residential survey is A Look at Residential Energy Consumption in 1997 (EIA 1999) (commonly called RECS) and the most recent commercial survey, A Look at Commercial Buildings in 1995: Characteristics, Energy Consumption, and Energy Expenditures (EIA 1998), is often called CBECS. These surveys provide details on the type of equipment used, age, building characteristics, occupants, energy use, and other information to provide a portrait of building stock across the US. However, the data provided by the survey is only at the regional, rather than state level, making it difficult to apply to Iowa. Overcoming this problem will be discussed in section 3.1.

Industrial sector surveys are also available for providing information on the energy-saving potential within various industries. These can be focused on certain end-uses such as motor systems, or on broader industry "best practices". Section 6 describes the results of one such survey on industrial motor systems.

\subsection{Savings Calculators}

Savings calculators provide individuals or energy program administrators the ability to calculate the potential savings under a variety of energy projects. Based on information of the house or business (its size, current set of equipment, number of occupants, location, prices, etc.) the energy savings by introducing new equipment, doing certain repairs, or changing behaviors can be calculated. There are a number of models available, some focusing on specific actions (such as adding insulation), some on certain building types (such as residential single-family homes), while some are broader in scope. Examples include:

ORNL Building Thermal Envelope System and Materials Program insulation calculator http://www.ornl.gov/roofs+walls/calculators/index.html

ORNL National Energy Audit (NEAT) calculator http://weatherization.ornl.gov/Neatmhea.htm

LBL Home Energy Saver website http://hes.lbl.gov/hes/vh.html 
The models typically show extensive savings potential. One model, the SEP model (ORNL $1998 \mathrm{draft}$ ) provides estimates based on type of building, fuel type, and state. It calculates savings based on RECS and CBECS data for prices, energy use, and typical equipment efficiencies. Table 2-1 shows examples of the percentage of savings for various building improvements. Applying these to the amount of energy consumed by the buildings for these end-uses provides an estimate of the energy savings potential. Some of the savings are simply from replacing older equipment with modern equipment that meets minimum federal standards. These savings will eventually occur over time, although energy efficiency programs could accelerate the changeover.
Table 2-1: Percentage energy savings for different improvements from the ORNL SEP model.

\begin{tabular}{|l|c|}
\hline Technology & Percent Savings \\
\hline Central AC & 20 \\
Clothes dryer & 21 \\
Clothes Washer & 26 \\
Dishwasher & 12 \\
Lighting & 33 \\
Refrigerator & 21 \\
Insulation & 34 \\
Water Heating (gas) & 31 \\
\hline
\end{tabular}

As another example, using the default settings for a typical Des Moines home in the Home Energy Savers model, annual energy bills could be reduced from $\$ 1383$ to $\$ 714$, a $48 \%$ improvement (Figure 2-1). However, the savings from the model are based on implementing a number of actions that are economic, but have very long payback times. These calculators show "technical" or "economic" potential for savings rather than "market" potential. They demonstrate what could be saved on an individual or sector-specific basis, rather than state-wide average savings. Also, as mentioned above, some of the savings will occur as older equipment is replaced with new equipment, regardless of energy programs.

The impact of new energy efficiency programs is dependent on how much savings occur over and above what would occur normally. Technology improvements over time mean that simply replacing older equipment with the latest will improve the energy efficiency. In some cases, federal or state energy standards mandate the minimum efficiency levels. In other cases, manufacturers have simply improved the energy efficiency of the equipment as part of the competitive market. Even if there were no further improvements in technology, average efficiencies would improve as part of capital turnover. A key requirement in knowing the potential for energy efficiency programs is determining the amount of savings that would occur through ordinary market forces and technology development. 
Figure 2-1: Screenshot of energy savings for typical Des Moines home from the Home Energy Savers website (LBL 2000)

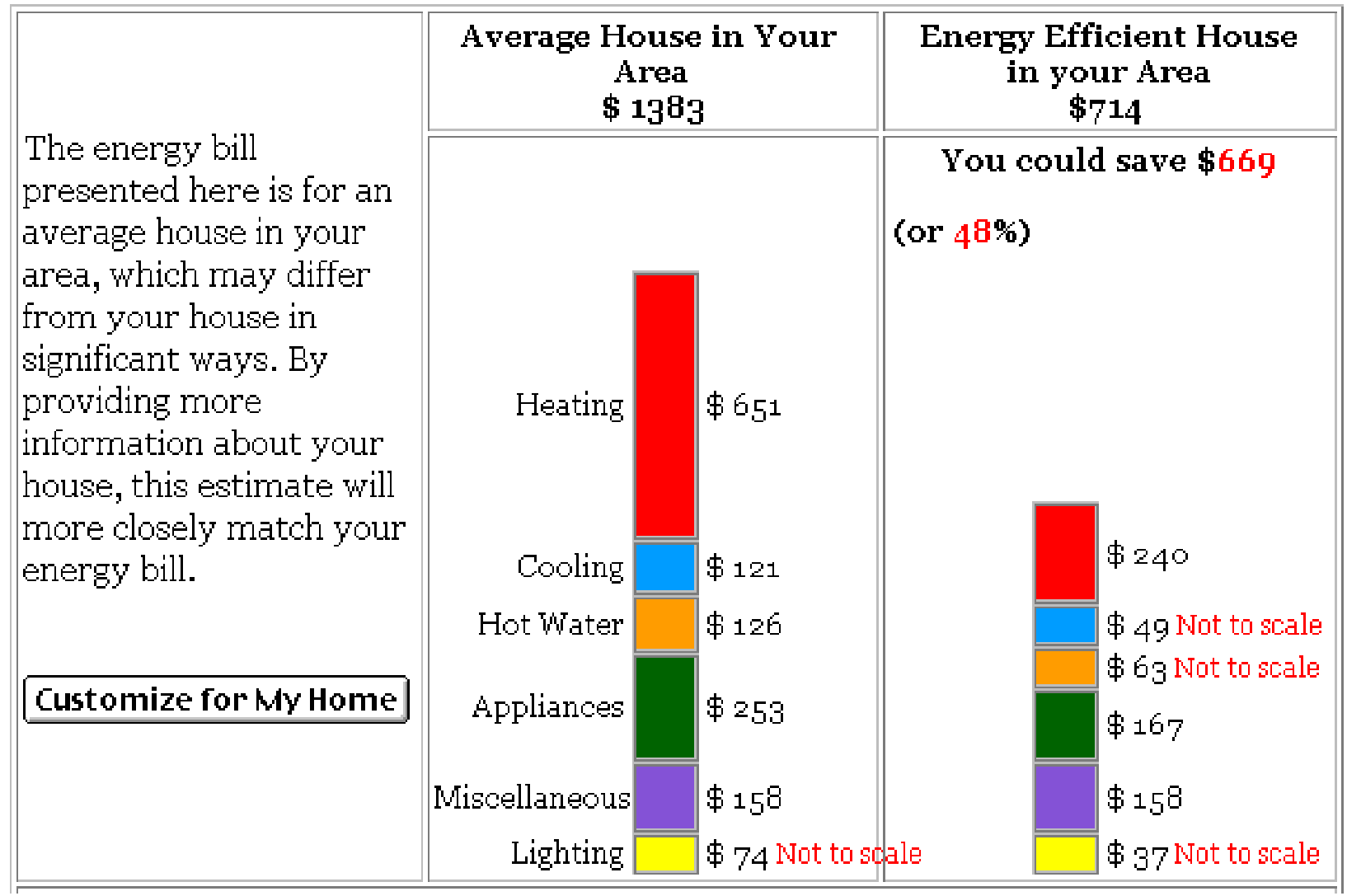

\subsection{Economic Simulation}

Economic simulation involves modeling the economic decision-making of an energy-using sector or entire region. The stock of existing buildings and equipment, data on options available, decision procedures, energy prices, etc. need to be available for the model to attempt to realistically simulate the purchase behavior of people. Even with adequate data, there will always be disagreements on some of the more subjective criteria, such as importance of energy efficiency versus other product characteristics, or market inertia of consumers towards changing consumer preferences. Nevertheless, this method of calculation is necessary to determine the market potential of energy savings equipment and technologies.

The most widely recognized economic simulation model is the National Energy Modeling System (NEMS). The EIA developed this model to forecast national and regional energy supply and demand through 2020. The model allows a wide variety of parameters to be altered to determine their impact on overall fuel use. Examples include changes in equipment efficiencies, costs, fuel supplies, economic growth, and consumer preferences. Detailed information on the model can be found in the National Energy Modeling System: An Overview 2000 (EIA 2000), on their website at http://www.eia.doe.gov/oiaf/aeo/overview/index.html. 
NEMS models the major end-use sectors of the economy: residential, commercial, industrial, and transportation. Within the energy sector it models the

Figure 2-2: West-North-Central Census Region

electricity sector, oil, gas, and coal production, and renewable energy. It separates the nation into nine geographical regions. Iowa is part of the WestNorth-Central region, which includes Kansas, Nebraska, South Dakota, North Dakota, Minnesota, and Missouri as well (Figure 2-2).

\subsubsection{Buildings Analysis in NEMS}

The residential and commercial sectors are largely defined by the types of buildings used. The residential sector is split between single-family dwellings, multi-family dwellings, and mobile homes. The commercial sector is separated by the type of activities. NEMS models eleven different businesses: assembly, education, food sales, food service, health care, lodging, large office, small office, mercantile \& service, warehouse, and other. For each type of building NEMS maintains

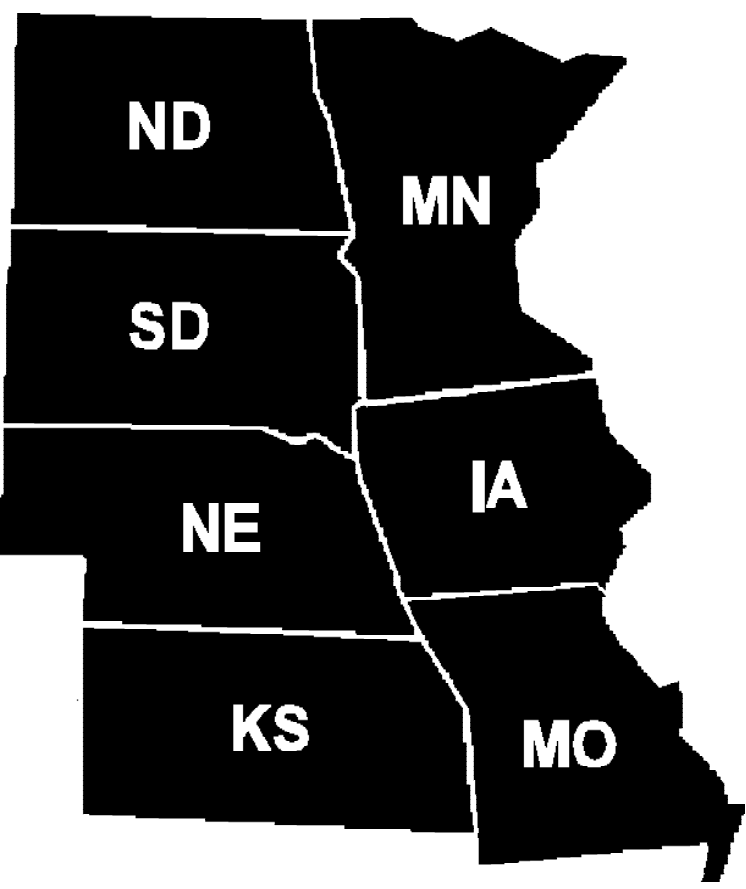
information on end-use service, fuel, equipment used, energy prices, customer purchasing preferences, age distribution of buildings, etc.

Figure 2-2 from the NEMS Overview shows the overall flow of the NEMS model between the various sectors. Each module uses inputs from data sets provided by the user along with calculated values from the other modules in order to calculate its results. Because of the feedback between supply and demand, some iteration is required. Key results can be stored from runs to allow for repetition of cases without having to run the full model. For this study, most of the modules were not recalculated, relying on their values from the AEO2000 stored case. Only the residential and commercial demand modules were modified and rerun, thereby saving recalculation time. Energy prices are consequently kept constant between all scenarios. 
Figure 2-2: National Energy Modeling System

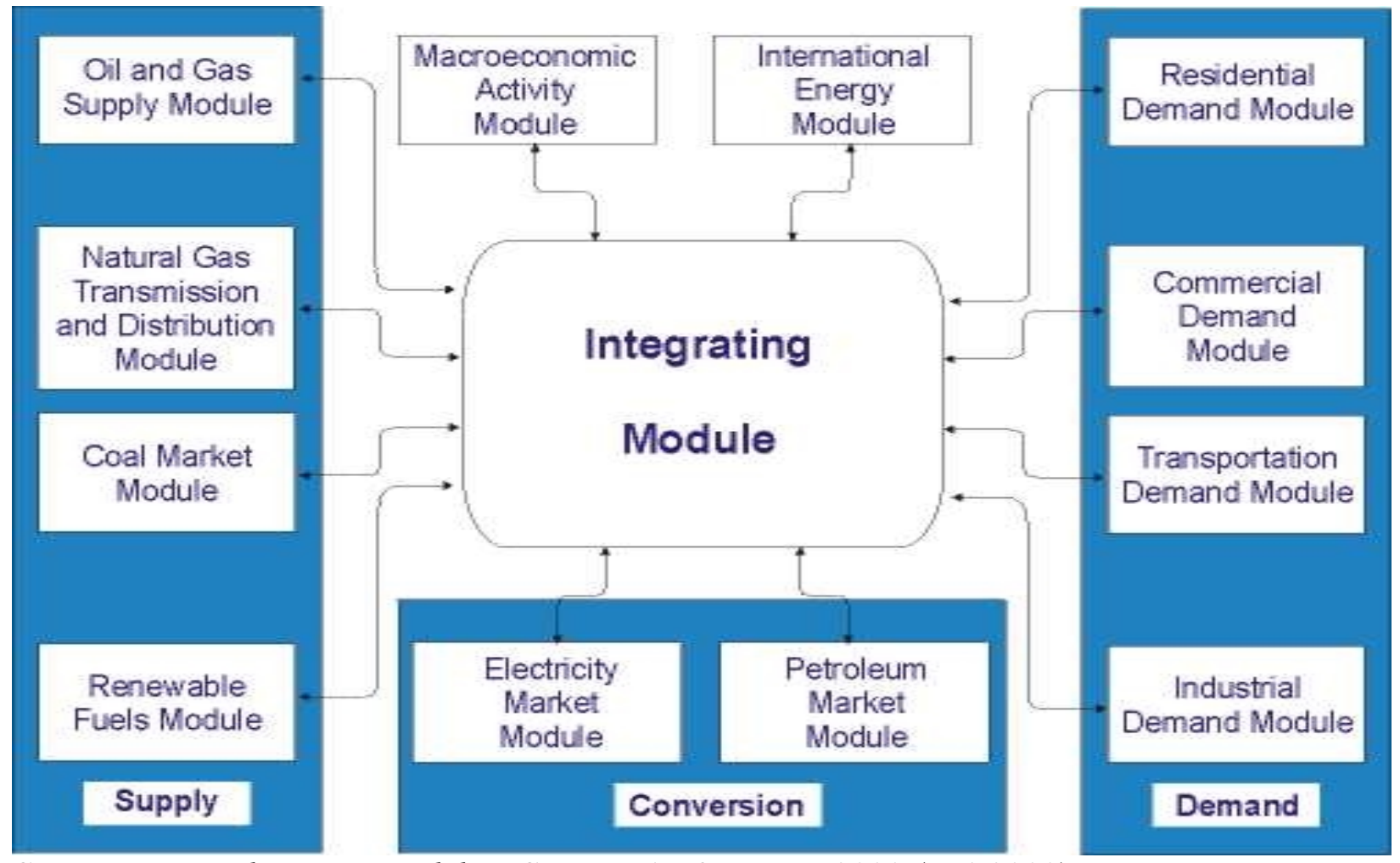

Source: National Energy Modeling System: An Overview 2000 (EIA 2000)

Figure 2-3 shows the structure within the residential module. Base year housing data, appliance types and efficiencies, and other data are provided by inputs from the user. Other NEMS modules provide information such as energy prices and economic growth. The module calculates housing stock, appliance needs, and distributed energy use to determine energy demands. These are then fed back to the other modules if they are to be called upon for recalculation, and to the output reports. 


\section{Figure 2-3: Residential demand module structure within NEMS}

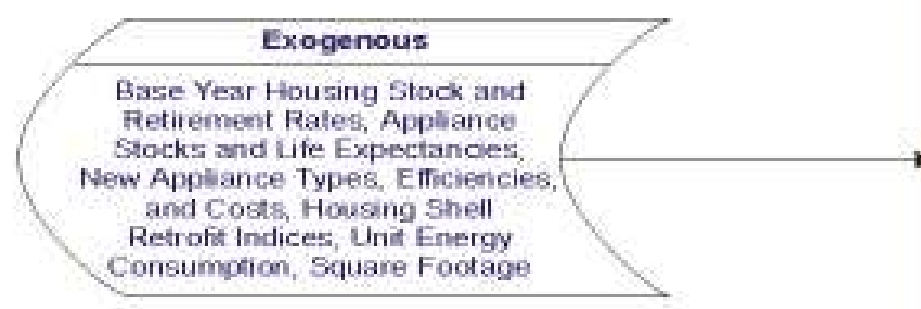

\section{Residential Demand Module}

Base Year

w Applance Types, Efficiencies,

Consumption, Square Footage

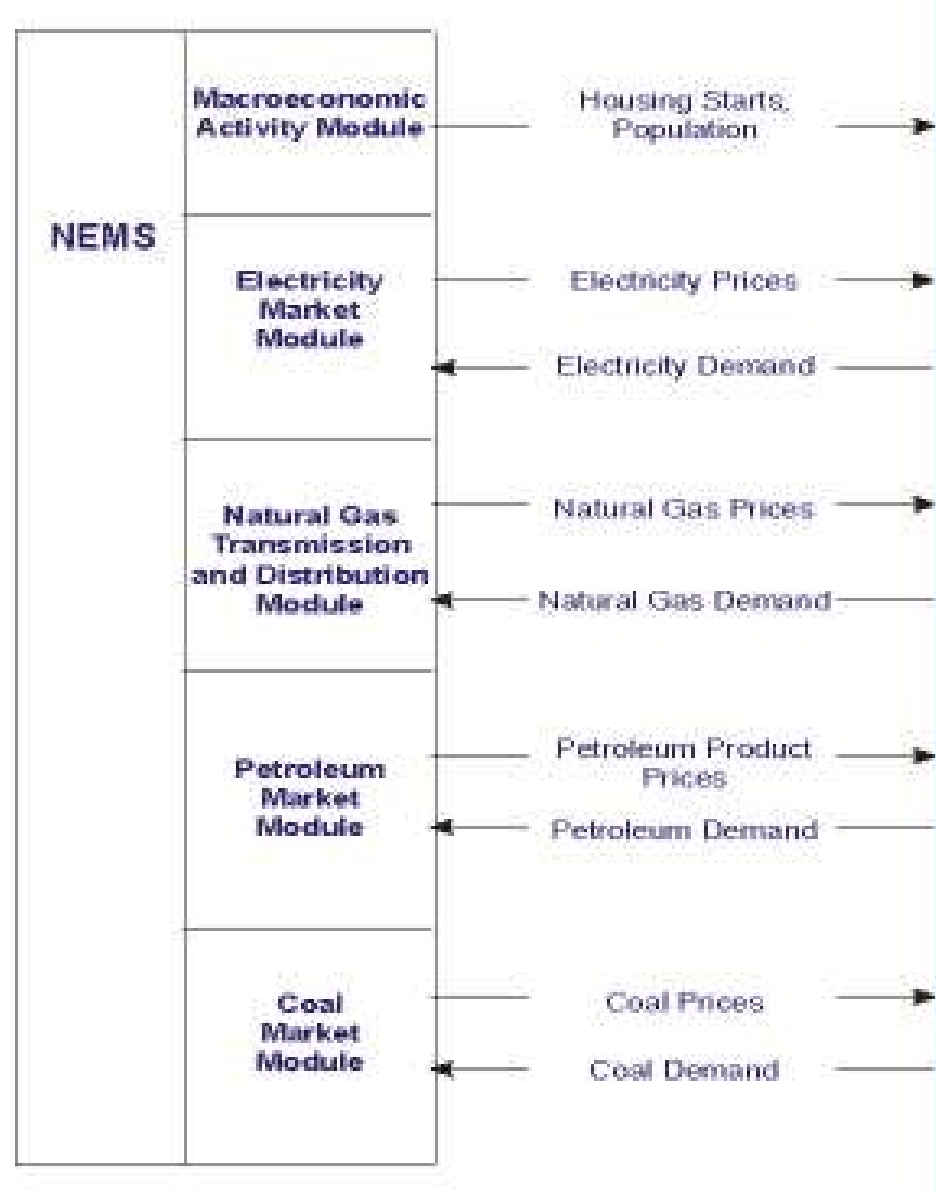

Stock of Structures by Type and Wntage

Housing

Stock

Submodule

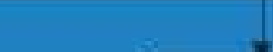

Source: National Energy Modeling System: An Overview 2000 (EIA 2000)

Figure 2-4 shows the structure within the commercial module. As with the residential module, exogenous data is provided by the user and calculated values from the other modules. Floorspace and consequent end-services calculations are made. Technology choices are determined, resulting in the energy use for each region and commercial building type. 
Figure 2-4: Commercial demand module structure within NEMS

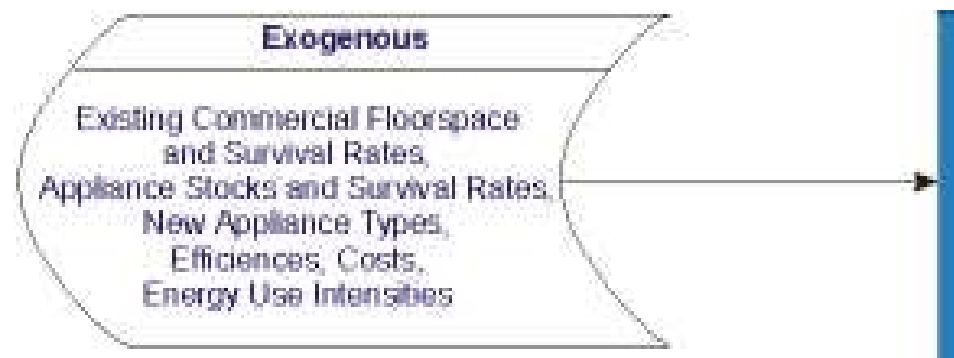

\section{Commercial Dernand Module}

Eficiences Costs.

Energy Use Intensities

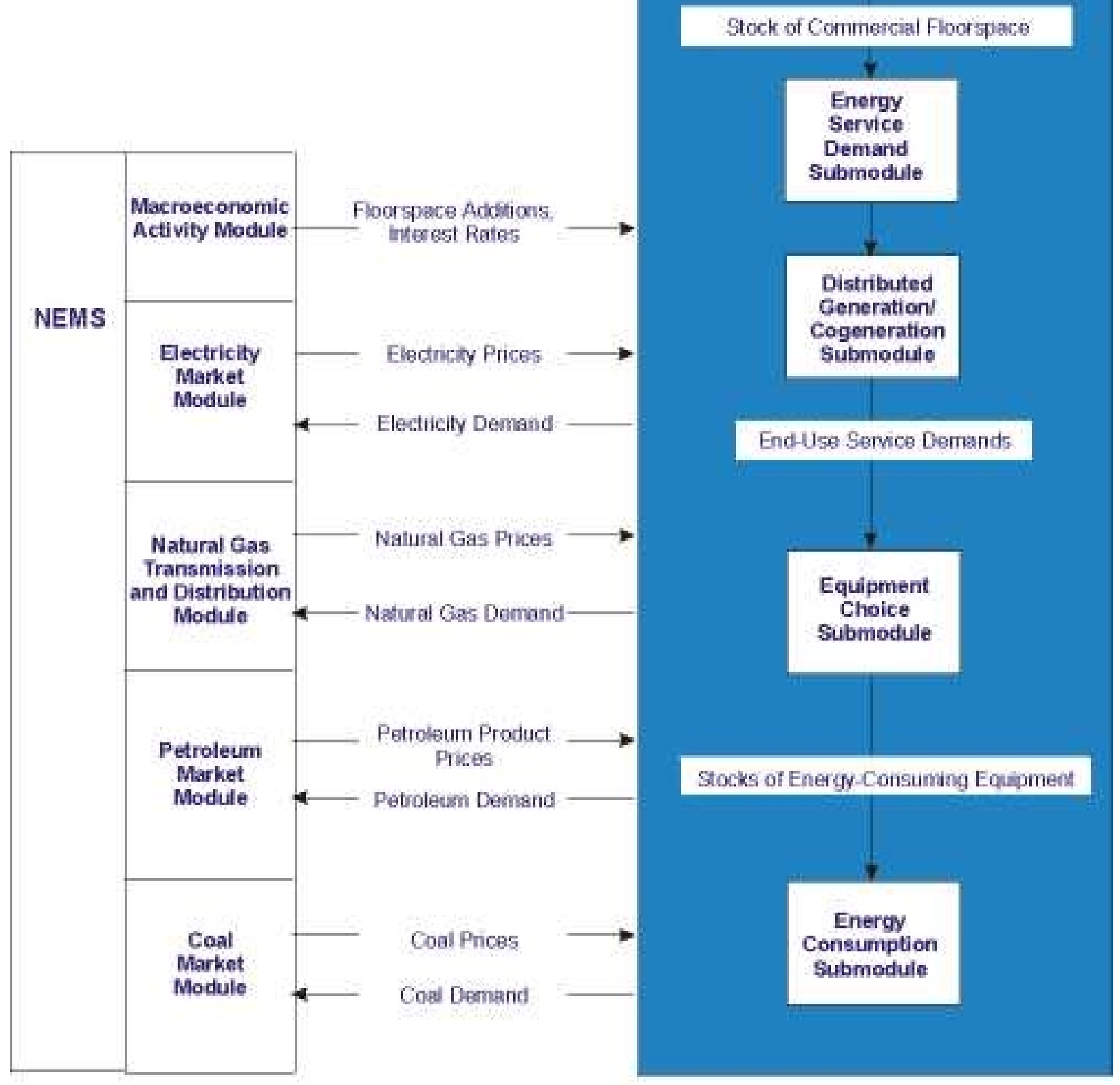

Source: National Energy Modeling System: An Overview 2000 (EIA 2000) 
For each type of end-use service (heating, cooling, water heating, etc.) different technologies are available. The model maintains data on capital cost, efficiency, type of fuel used, purchase preference criteria, and dates of availability for each type of equipment. This allows the model to bring on new equipment and retire older equipment throughout the study period. To bring on new equipment it calculates the life cycle cost of each technology, and selects a mixture based on the relative cost of each. The life cycle cost includes the capital (or replacement) cost plus future costs of the energy needed discounted using an input discount rate. The rates are higher than just the cost of money to reflect customer resistance or insensitivity to ongoing costs versus initial cost. In addition, the model places limits on the amount of technology or fuel switching for various types of customers, based on historical survey data from RECS and CBECS.

\subsubsection{End-use equipment}

Residential and commercial sectors have a number of end-uses modeled (Table 2-2 and Table 2-3). Each major end-use has a number of different technologies available. Within each technology (e.g., natural gas furnace) there may be many different types of equipment available at a variety of costs and efficiencies. Values for these equipment are listed in Section 4.1.

Besides the major end-uses modeled within NEMS, a "Miscellaneous Other" category is included. The Other category in the residential sector includes a variety of smaller end-uses, including, personal computers, color televisions, furnace fans, small kitchen appliances, other home electronics, and all of the other unidentified energy end-uses. It also includes adjustments to ensure that each region and sector's energy-use matches the totals as reported in EIA's State Energy Data Report (SEDS)(EIA 1997).

Within the commercial sector, the "Other" category contains transformers, traffic lights, exit signs, district services, automated teller machines, telecommunications equipment, medical equipment, and other unidentified end-uses. It also includes an adjustment term to ensure that the total commercial sector energy use adds up to the totals reported in EIA's SEDS (EIA 1997). 
Table 2-2: Services and Equipment in the NEMS Residential Sector Demand Module

\begin{tabular}{|ll|}
\hline Space Heating Equipment & Cookstoves \\
Electric Furnace & Natural Gas \\
Electric Air-Source Heat Pump & LPG \\
Natural Gas Furnace & Electric \\
Natural Gas Other (Hydronic) & \\
Kerosene Furnace & Clothes Dryers \\
LPG Furnace & Natural Gas \\
Distillate Furnace & Electric \\
Distillate Other (Hydronic) & \\
Wood Stove & Refrigerators \\
Electric Ground-Source Heat Pump & 18 cubic-foot Top Mounted Freezer \\
Natural Gas Heat Pump & 24 cubic-foot Side-by-Side with \\
& Through-the-Door Features \\
Space Cooling Equipment & \\
Electric Room Air Conditioner & Water Heaters \\
Central Air Conditioner & Natural Gas \\
Electric Air-Source Heat Pump & Electric Resistance / Heat Pump \\
Electric Ground-Source Heat Pump & Distillate \\
Natural Gas Heat Pump & LPG \\
Freezers & Solar Thermal \\
Chest Manual Defrost & \\
Upright Manual Defrost & Lighting \\
Clothes Washers & Incandescent \\
Vertical Axis & Compact Fluorescent \\
Horizontal Axis & Halogen Tochiere \\
\end{tabular}

Table 2-3: Building types and end-use services in NEMS Commercial Demand Module

\begin{tabular}{|l|l|}
\hline Building Types & End-Use Services \\
\hline Assembly & Space Heating \\
Education & Space Cooling \\
Food Sales & Water Heating \\
Food Service & Ventilation \\
Health Care & Cooking \\
Lodging & Lighting \\
Office - Large & Refrigeration \\
Office - Small & Office Equipment - PCs \\
Mercantile \& Service & Office Equipment - Other \\
Warehouse & Other \\
\hline
\end{tabular}




\section{Energy Use}

State-specific energy use data is available for each state for the years 1960 through 1997 from the Combined State Energy Data System by the Energy Information Administration. This data is available from their website and was used in the report State Energy Data Report 1997, Consumption Estimates (EIA 1997). Further details of energy use are provided in the database, especially information on petroleum and renewable energy use. Projections of future energy use are also available from various studies that have been done by EIA, most notably the Annual Energy Outlook 2000 (EIA 1999) that was used as the basis for much of this study.

\subsection{Historical Energy Use}

Iowa energy use can be broken down by source of power and by sector. In Figure 3-1 the historical amounts of energy by end-use sector is shown. Figure 3-2 and Table 3-1 show the 1997 energy use by source for the various end-use sectors. Electricity use in the end-use sectors is divided between actual end-use and the losses associated with the electricity production. The final column shows the primary energy use in the Electricity sector. Its total matches the sum of the electricity end-use from the other sectors and the losses associated with making electricity.

Figure 3-1: Iowa energy use, 1960-1997

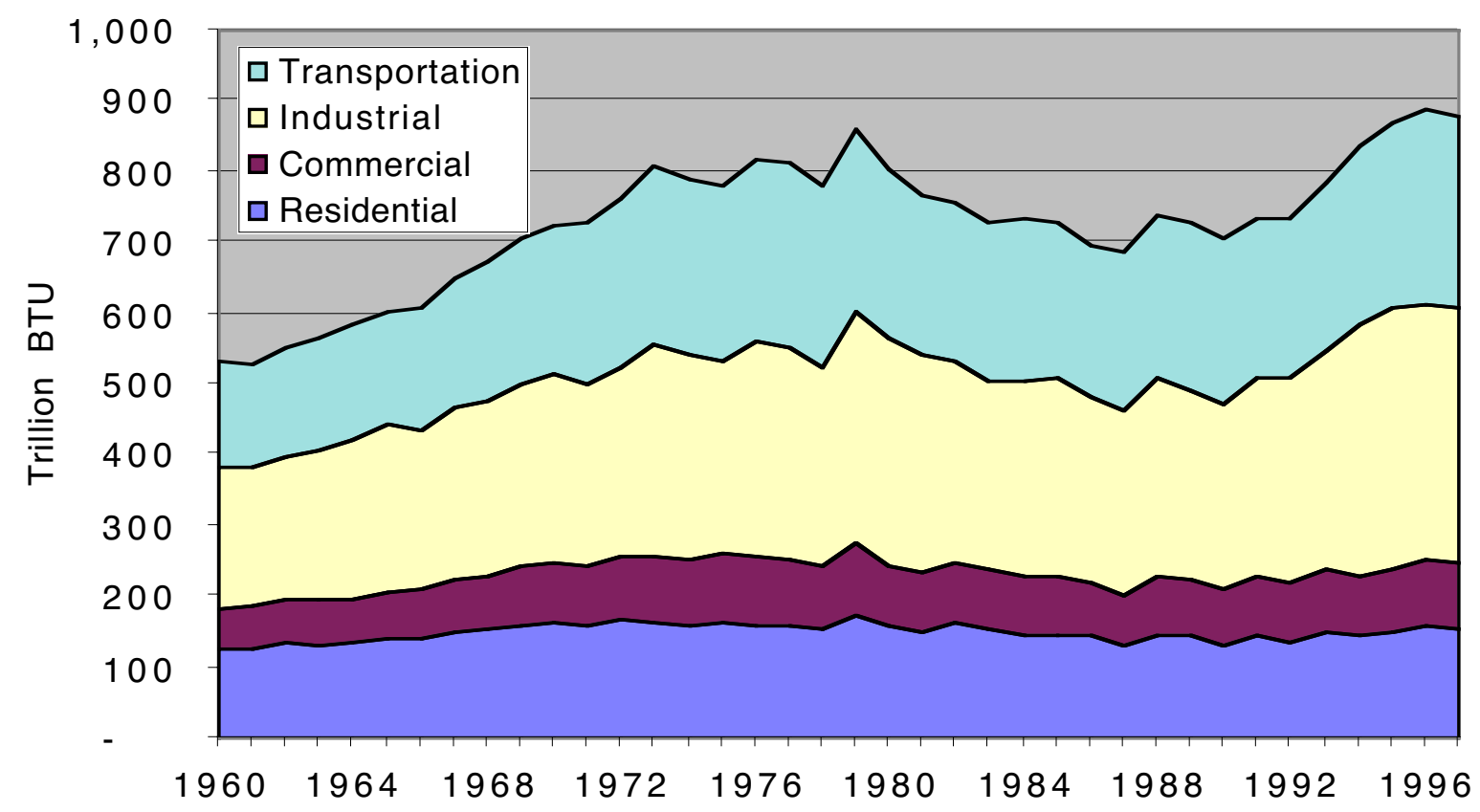


Figure 3-2: 1997 Iowa Energy Use by Sector. Electrical sector use is shown separately. The consequent delivered electricity (after conversion losses) is shown in each end-use sector. (EIA 1997)

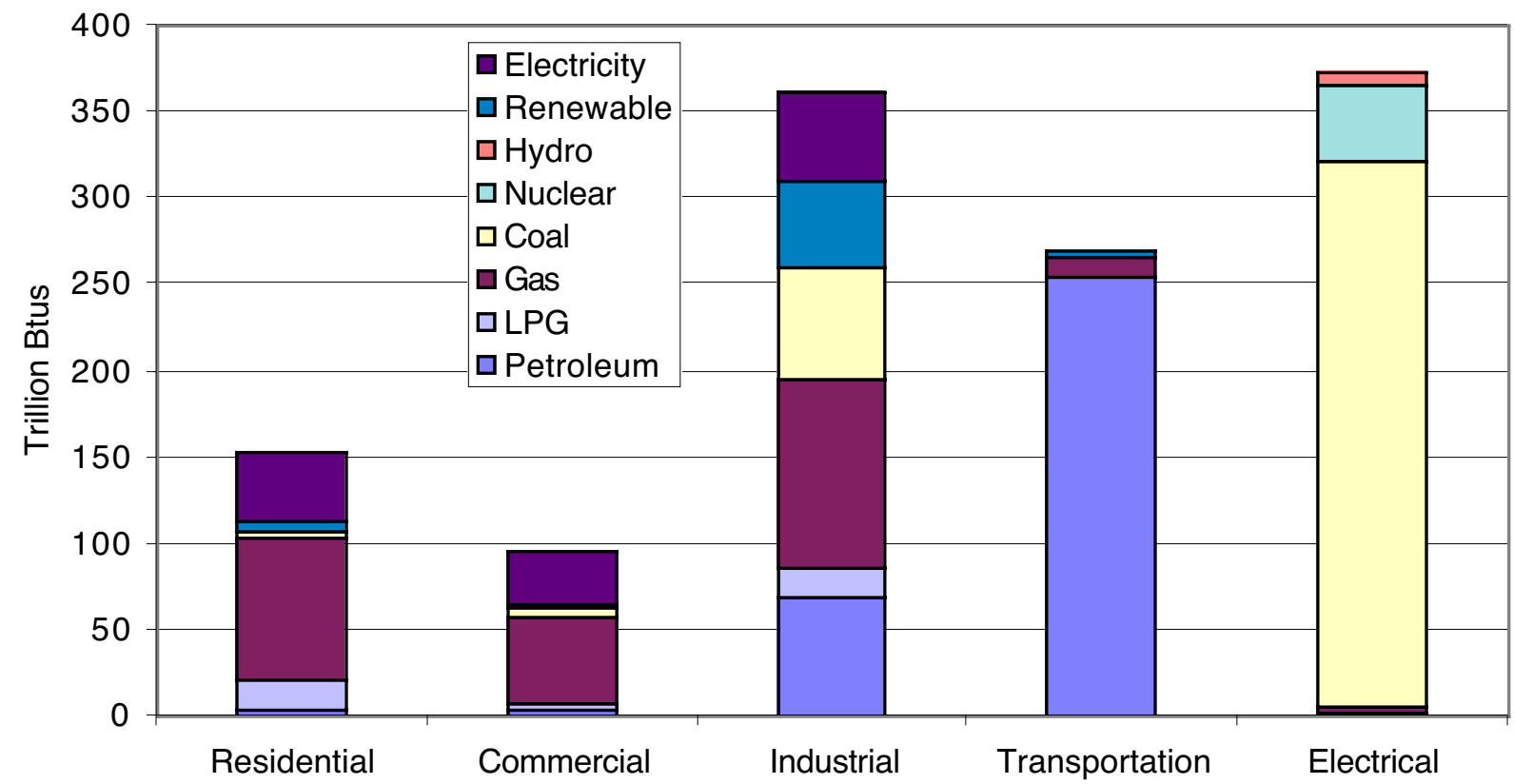

Table 3-1: 1997 Iowa Energy Use by Fuel and Sector in Billion Btus from SEDS (EIA 1997)

\begin{tabular}{|l|rrrrrr|}
\hline \multicolumn{1}{|c|}{ FuellSector } & Residential & Commercial & Industrial & Transport & Electrical & Total \\
\hline Petroleum & 21,689 & 7,371 & 85,910 & 254,676 & 1,231 & 369,646 \\
Gas & 82,439 & 50,648 & 108,441 & 11,414 & 4,136 & 257,078 \\
Coal & 3,081 & 5,722 & 65,962 & - & 315,216 & 389,981 \\
Nuclear & & & & 44,076 & 44,076 \\
Electricity & 39,830 & 30,516 & 52,991 & - & - & 123,337 \\
Hydro & & & 106 & & 8,195 & 8,301 \\
Other Renewable & 5,131 & 650 & 49,048 & 4,591 & 232 & 59,651 \\
\cline { 2 - 7 }$\quad$ Net Total & 152,170 & 94,906 & 362,459 & 270,681 & 373,086 & 880,215 \\
Electric losses & 82,717 & 63,374 & 110,050 & - & 16,392 & 256,141 \\
\cline { 2 - 7 }$\quad$ Total & 234,887 & 158,279 & 472,509 & 270,681 & 379,478 & $1,136,356$ \\
\hline
\end{tabular}

${ }^{1}$ Electricity imports value makes up difference between electricity generation and total end-use plus losses.

As mentioned earlier, the RECS and CBECS energy use surveys, and consequently NEMS results, do not separate out information at the state level, but rather provide regional data. To approximate the values for Iowa, we combined the values for all seven states from the Combined State Energy Data System used above. We then found the ratio of energy use by fuel and sector for Iowa as compared to the total for all seven states (Table 3-2). Applying the resulting percentages to regional energy use from NEMS gives an approximate amount for Iowa. 
Table 3-2: Percentage of Iowa energy use to seven-state total from SEDS (EIA 1997)

\begin{tabular}{|l|cccccc|}
\hline \multicolumn{1}{r|}{ FuellSector } & Residential & Commercial & Industrial & Transport & Electrical & Total \\
\hline Petroleum & 14 & 13 & 14 & 14 & 8 & 14 \\
Gas & 17 & 16 & 20 & 13 & 9 & 18 \\
Coal & 42 & 42 & 29 & - & 15 & 17 \\
Nuclear & - & - & - & - & 10 & 10 \\
Electricity & 14 & 13 & 20 & - & - & 16 \\
Hydro & - & - & 3 & - & 3 & 3 \\
Other Renewable & 15 & 16 & 38 & 20 & 5 & 30 \\
\cline { 2 - 7 }$\quad$ Net Total & 17 & 15 & 21 & 14 & 13 & 17 \\
Electric losses & 14 & 13 & 20 & - & $(1)$ & 16 \\
\cline { 2 - 7 }$\quad$ Total & 16 & 14 & 20 & 14 & - & 17 \\
\hline \multicolumn{1}{r}{} & & & & & & \\
\hline
\end{tabular}

The residential values can be corroborated by examining the amount of housing listed in the 1990 U.S. Census (Table 3-3). Total housing units in Iowa were 1.14 million in 1990, 15.3\% of the total for the region. This compares to the $17 \%$ of residential net energy shown in Table 3-2. Most of the fuels categories in Table 3-2 show the same rough percentages as the net total. Coal use is proportionately higher in Iowa than the others; but its total is still very small compared to the other fuels, as seen in Table 3-1.

Table 3-3: Housing units for Iowa and 7-state region from 1990 U.S. Census

\begin{tabular}{|l|ccc|}
\hline Housing units & lowa & Total & lowa \% total \\
\hline 1, detached & 852,993 & $5,174,761$ & $16.5 \%$ \\
1, attached & 17,735 & 210,517 & $8.4 \%$ \\
$\mathbf{2}$ & 42,017 & 275,481 & $15.3 \%$ \\
$\mathbf{3}$ or $\mathbf{4}$ & 44,939 & 293,354 & $15.3 \%$ \\
$\mathbf{5}$ to $\mathbf{1 0}$ & 40,745 & 252,951 & $16.1 \%$ \\
$\mathbf{1 0}$ to $\mathbf{9 9}$ & 36,097 & 291,386 & $12.4 \%$ \\
$\mathbf{2 0}$ to $\mathbf{4 9}$ & 28,701 & 237,788 & $12.1 \%$ \\
$\mathbf{5 0}$ or more & 11,963 & 182,194 & $6.6 \%$ \\
Mobile home or trailer & 56,857 & 478,395 & $11.9 \%$ \\
Other & 11,622 & 67,925 & $17.1 \%$ \\
\hline Total & $1,143,669$ & $7,464,752$ & $15.3 \%$ \\
\hline
\end{tabular}

According to the RECS, total housing within the region in 1997 was 7.2 million, which corroborates to the U.S. Census values.

\subsection{Major NEMS studies}

The NEMS model has been used for a number of studies by both EIA and others. The two of most relevance to this paper are the Annual Energy Outlook 2000 (EIA 1999) and the Clean Energy Futures (CEF) study (Interlaboratory Working Group 2000). This study uses the regional results from the AEO2000 as its baseline estimate of energy use for the region. We then applied 
some of the policies from the CEF study to understand the impacts of these energy conservation efforts on Iowa.

\subsubsection{Annual Energy Outlook}

Every year the EIA releases a report that presents midterm forecasts of the energy supply, demand, and prices through 2020. They develop a reference scenario that includes expectations of future changes in demands, supplies, technologies, and prices. Only existing government policies are modeled. Sensitivities on economic growth, energy prices, and other factors are also examined. Energy prices are calculated internally based on oil and gas exploration technologies, coal mining practices, and power plant modeling, rather than as exogenous inputs. Short-term price fluctuations can be entered but only on the basis of known data.

This study is based on the results of the AEO2000. In December 2000, the EIA released the AEO2001 with revised data on various parameters. Many of the results were only slightly changed, although near-term energy prices did show a marked change (Figure 3-3). This is due to the recent run-up in gas and oil prices, although the model shows that the expectation is for these prices to decline back to similar prices as before.

Figure 3-3: Fuel price projections 1999-2020: AEO2000 and AEO2001 compared (EIA 2000)

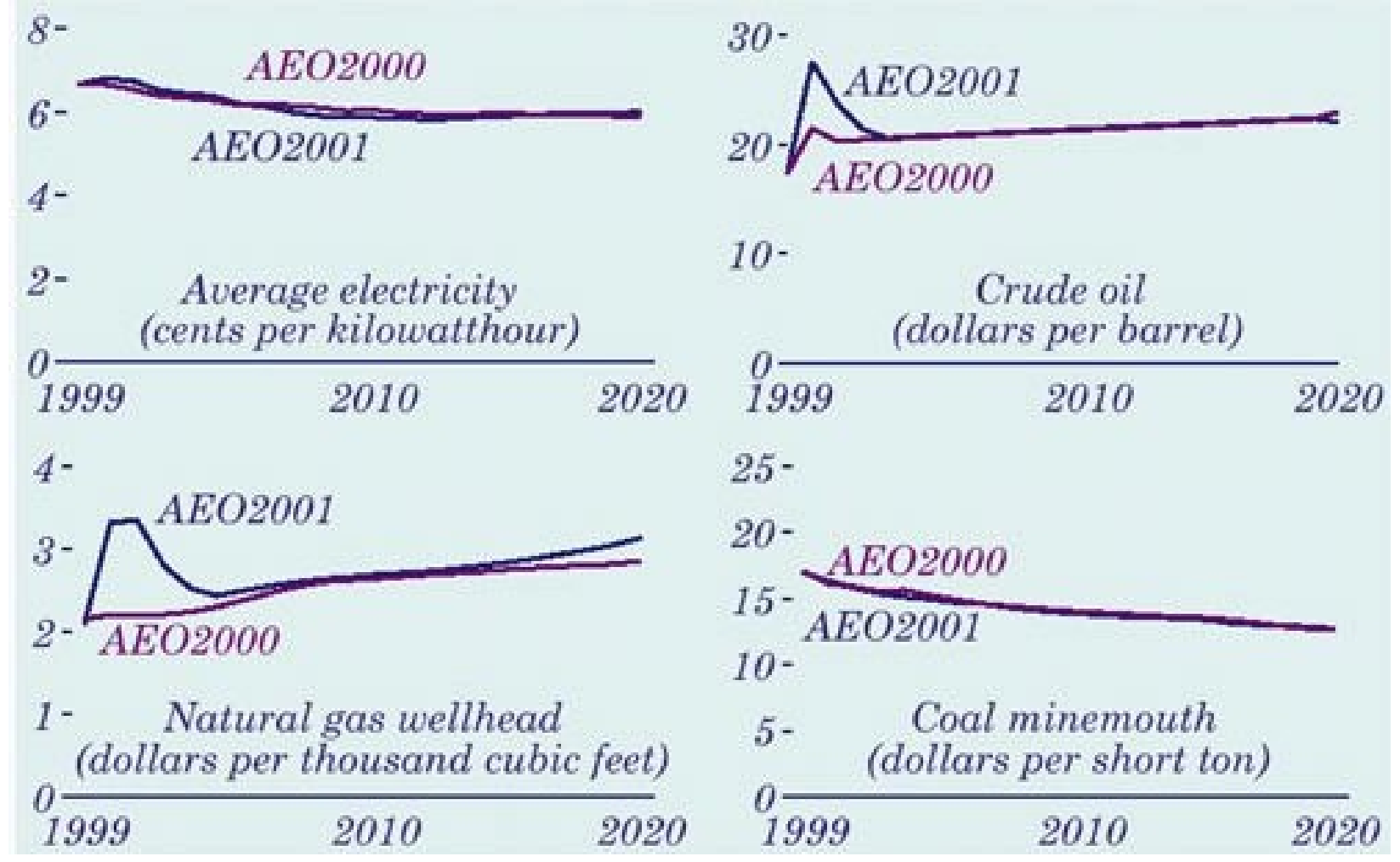




\subsubsection{Clean Energy Futures}

During 1999 and 2000 a major study was commissioned by DOE on the effects of possible policies to reduce energy use or emissions. The resulting report, Scenarios for a Clean Energy Future (also known as the CEF study) (Interlaboratory Working Group 2000) used a modified version of the NEMS model to integrate the analysis of policy impacts on the various sectors of the economy. Three main scenarios were developed: a Business as Usual scenario that was similar to the AEO1999 but with minor changes due to improved data; a Moderate scenario with policies that did not involve major cost burdens on the economy; and an Advanced scenario that included more far-reaching policies such as a carbon cap and trade system. The study concentrated on national results rather than regional impacts. Consequently, little data is available on the impact of these policies on Iowa or the upper Midwest.

National energy savings from the policies within the CEF study are shown in Figure 3-4. Moderate scenario savings are around $8 \%$ of the Business-As-Usual energy use by 2020 . The additional policies of the Advanced scenario save even more, to where total energy use actually declines. However, this study of Iowa only considered a subset of the Moderate scenario policies. Consequently, total savings were around $5 \%$, as described later.

\section{Figure 3-4: CEF Study savings amounts}

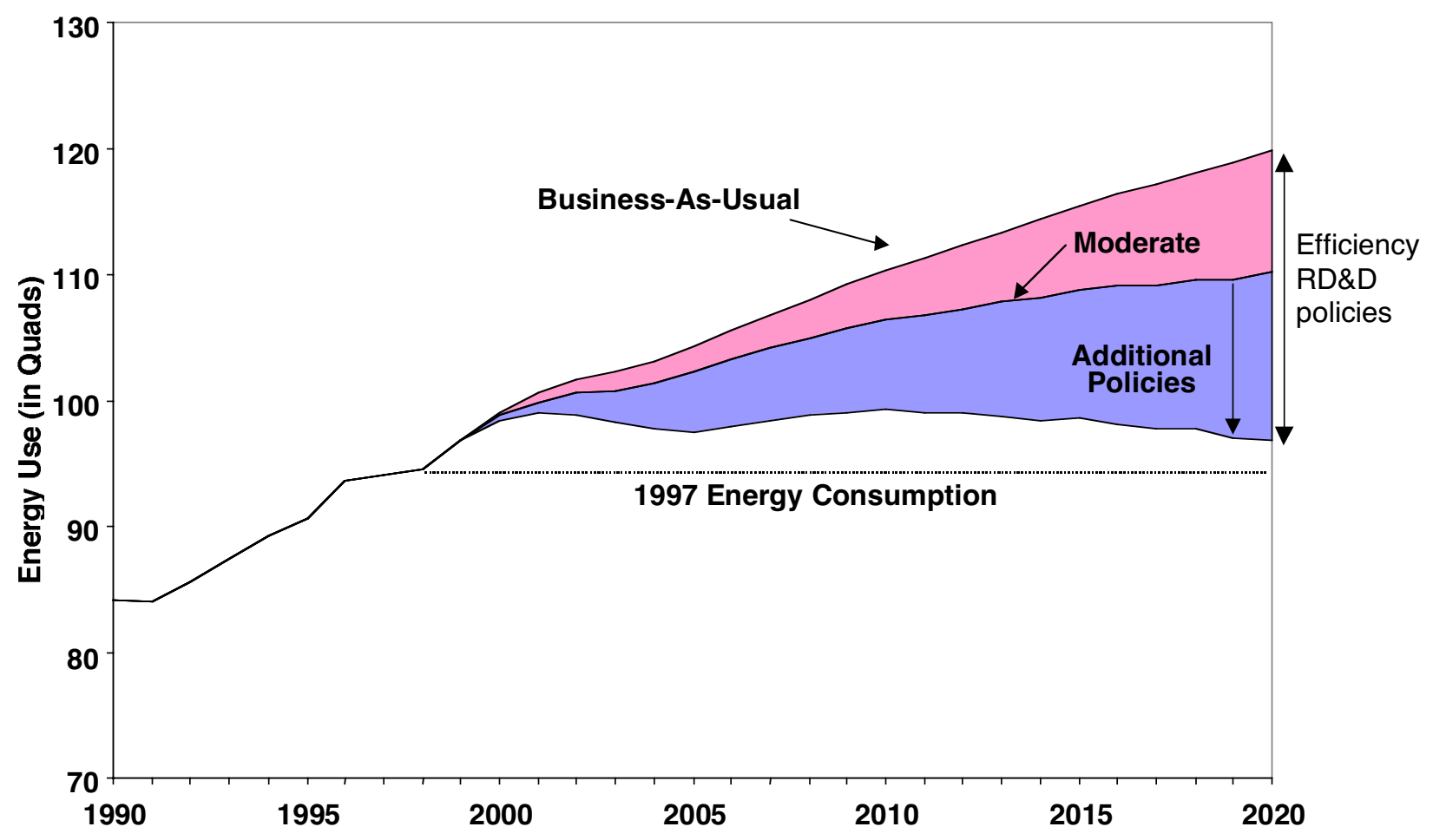





\section{Residential}

\subsection{Residential Base Energy Use}

The residential end-use sector represents $17 \%$ of total end-use consumption (Table 3-1). While the most readily visible energy using sector, it is not the largest. Space heating makes up the bulk of energy use in the sector, with water heating being the next largest (Table 4-1). These services are largely performed by natural gas, with some energy provided by electricity, LPG, and distillate fuels.

Table 4-1: Iowa Base Case Total Residential Energy Use

\begin{tabular}{|c|c|c|c|c|c|c|}
\hline & $\begin{array}{c}2000 \text { Energy } \\
\text { Use } \\
\text { TBtu }\end{array}$ & $\begin{array}{c}\% \text { of Total } \\
\text { Energy }\end{array}$ & $\begin{array}{c}\% \text { of Total } \\
\text { Gas } \\
\end{array}$ & $\begin{array}{c}\% \text { of Total } \\
\text { Electric }\end{array}$ & $\begin{array}{c}\% \text { of Each } \\
\text { End-use }\end{array}$ & $\begin{array}{c}\text { Annual } \\
\text { Growth Rate } \\
2000-2020 \\
\end{array}$ \\
\hline Space Heating & 81.8 & $56 \%$ & & & & $0.0 \%$ \\
\hline Electric & 3.5 & & & $8 \%$ & $4 \%$ & $1.3 \%$ \\
\hline Gas & 62.2 & & $76 \%$ & & $76 \%$ & $0.3 \%$ \\
\hline Distillate & 4.9 & & & & $6 \%$ & $-1.9 \%$ \\
\hline LPG & 11.2 & & & & $14 \%$ & $-1.6 \%$ \\
\hline Space Cooling & 5.0 & $3 \%$ & & & & $1.3 \%$ \\
\hline Electric & 5.0 & & & $11 \%$ & $99 \%$ & $1.1 \%$ \\
\hline Gas & 0.0 & & $0 \%$ & & $1 \%$ & $10.8 \%$ \\
\hline Water Heating & 23.8 & $16 \%$ & & & & $0.1 \%$ \\
\hline Electric & 4.0 & & & $9 \%$ & $17 \%$ & $-0.1 \%$ \\
\hline Gas & 17.0 & & $21 \%$ & & $71 \%$ & $0.4 \%$ \\
\hline Distillate & 0.2 & & & & $1 \%$ & $-2.3 \%$ \\
\hline LPG & 2.7 & & & & $11 \%$ & $-1.7 \%$ \\
\hline Refrigeration & 4.6 & $3 \%$ & & $11 \%$ & & $-1.8 \%$ \\
\hline Cooking & 3.6 & $2 \%$ & & & & $0.9 \%$ \\
\hline Electric & 1.2 & & & $3 \%$ & $33 \%$ & $0.5 \%$ \\
\hline Gas & 1.7 & & $2 \%$ & & $47 \%$ & $1.7 \%$ \\
\hline LPG & 0.7 & & & & $20 \%$ & $-1.1 \%$ \\
\hline Clothes Drying & 3.8 & $3 \%$ & & & & $1.2 \%$ \\
\hline Electric & 2.8 & & & $6 \%$ & $74 \%$ & $0.9 \%$ \\
\hline Gas & 1.0 & & $1 \%$ & & $26 \%$ & $1.9 \%$ \\
\hline Freezers & 1.8 & $1 \%$ & & $4 \%$ & & $-1.5 \%$ \\
\hline Lighting & 3.7 & $3 \%$ & & $9 \%$ & & $1.0 \%$ \\
\hline Other & 17.3 & $12 \%$ & & $40 \%$ & & $2.1 \%$ \\
\hline Total & 145.3 & $100 \%$ & & & & $0.4 \%$ \\
\hline Electric & 43.7 & $30 \%$ & & & & $1.1 \%$ \\
\hline Gas & 81.9 & $56 \%$ & & & & $0.4 \%$ \\
\hline Distillate & 5.1 & $3 \%$ & & & & $-1.9 \%$ \\
\hline LPG & 14.6 & $10 \%$ & & & & $-1.6 \%$ \\
\hline
\end{tabular}

A further breakdown of the electricity use is shown in Figure 4-1 and Table 4-2. The "Other" category is subdivided into personal computers (CPU and monitor), color televisions, furnace 
fans, other household electronics, heating coils (such as toasters or coffeepots), and small motors. There is also an adjustment factor to benchmark the calculated total to the amounts from the SEDS (EIA 1997). The "Other" category is not as well represented within NEMS and needs further research. Newer versions of NEMS may provide more details on these categories.

Figure 4-1: Iowa base case residential electricity use

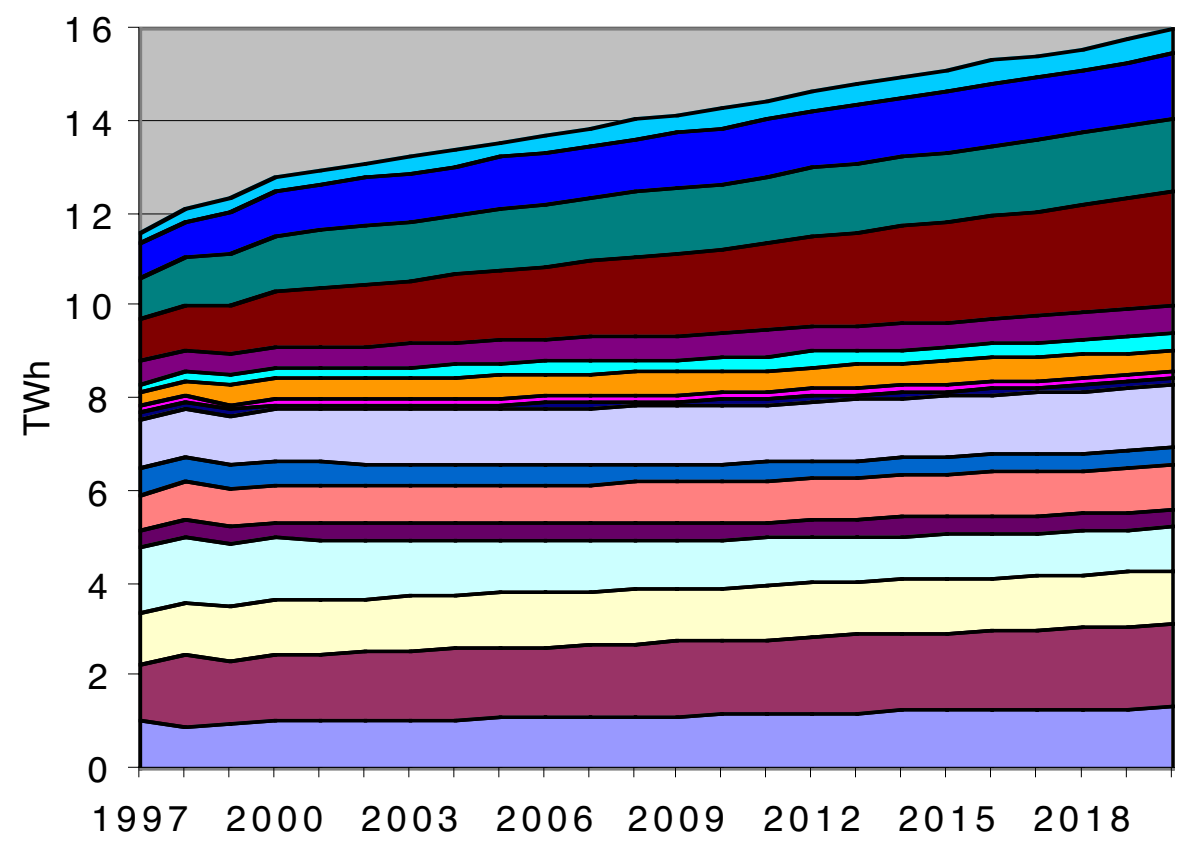

Adjustment

Motors

$\square$ Heating Elements

- Other Electronics

Furnace Fans

$\square$ PC Monitor and CPU

$\square$ Color Televisions

- Dishwashers

Clothes Washers

Lighting

Freezers

$\square$ Clothes Dryers

Cook Stoves

$\square$ Refrigeration

$\square$ Water Heating

Space Cooling

$\square$ Space Heating

Table 4-2: Iowa base case residential electricity use

\begin{tabular}{|l|ccc|}
\hline \multicolumn{1}{|c}{$\begin{array}{c}\text { 2000 Electricity } \\
\text { Use, TWh }\end{array}$} & \% of Total & $\begin{array}{r}\text { Annual Growth } \\
\text { Rate 2000-2020 }\end{array}$ \\
\hline Space Heating & 1.02 & $8 \%$ & $1.1 \%$ \\
Space Cooling & 1.46 & $11 \%$ & $1.9 \%$ \\
Water Heating & 1.16 & $9 \%$ & $-0.1 \%$ \\
Refrigeration & 1.35 & $11 \%$ & $-1.9 \%$ \\
Cook Stoves & 0.35 & $3 \%$ & $0.5 \%$ \\
Clothes Dryers & 0.81 & $6 \%$ & $0.9 \%$ \\
Freezers & 0.52 & $4 \%$ & $-1.8 \%$ \\
Lighting & 1.09 & $9 \%$ & $1.1 \%$ \\
Clothes Washers & 0.11 & $1 \%$ & $0.9 \%$ \\
Dishwashers & 0.14 & $1 \%$ & $0.4 \%$ \\
Color Televisions & 0.41 & $3 \%$ & $1.6 \%$ \\
PC & 0.24 & $2 \%$ & $5.1 \%$ \\
Furnace Fans & 0.46 & $4 \%$ & $0.4 \%$ \\
Misc. Electronics & 1.22 & $10 \%$ & $4.4 \%$ \\
Misc. Heating & 1.20 & $9 \%$ & $2.5 \%$ \\
Misc. Motors & 0.97 & $8 \%$ & $2.8 \%$ \\
Adjustment & 0.31 & $2 \%$ & $3.3 \%$ \\
\hline Total & 12.82 & & $1.1 \%$ \\
\hline
\end{tabular}


Note that the expected growth rates for most electrical end-uses are below $2 \%$; some are even negative. Many of these major end-uses have been the focus of energy efficiency improvements over the past thirty years. Higher efficiency equipment have been introduced into the market and are expected to make significant contributions to keeping demand growth low. Also, these markets are largely saturated, with growth increasing in step with economic and/or population growth. The large growth rates for PC's and miscellaneous electronics reflect the surge in demand for these items. High growth rates for the other miscellaneous categories are likely due to less attention on energy savings for these smaller types of equipment. Energy use is less of a deciding parameter in their manufacture and purchase.

The expected energy prices for the Iowa residential sector are shown in Figure 4-2. As mentioned earlier the AEO2000 was prepared before the recent run-up in natural gas prices. As of this writing, prices have declined substantially, although still higher than prices of two years ago. The EIA expects that prices will continue to subside to more closely reflect the long-term expectations of the AEO2000 (Figure 3-3).

\section{Figure 4-2: Iowa base case residential energy prices in $\$ / M B t u$ and $\mathfrak{c} / \mathbf{k W h}$}

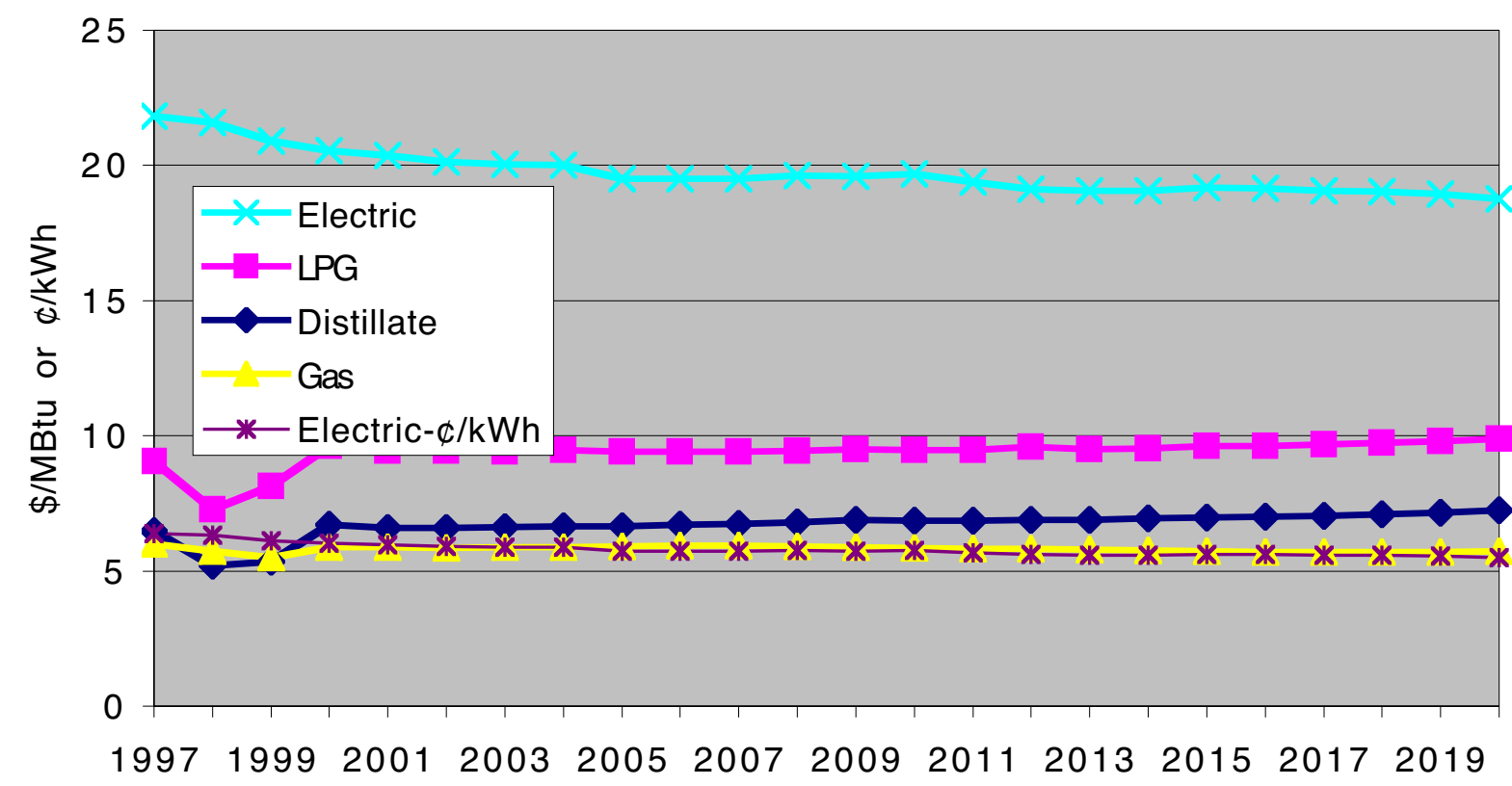

\subsection{Mechanisms of savings}

Natural gas provides over 55\% of energy needs in the residential sector, while electricity only provides $27 \%$. As a consequence, energy savings that focus on electricity may miss the bulk of savings. On the other hand, there may be more potential for energy saving policies or technologies from electrical equipment than from gas equipment. 


\subsubsection{Space heating}

The NEMS data includes heat pumps (electric, gas, and ground-source), furnaces (gas, distillate, kerosene, and electric), radiators, and wood stoves. Table 4-3 shows the initial installation cost, replacement cost, efficiency, and years available for the heat pump technologies. Table 4-4 shows those values for the other space heating technologies. One reviewer has noted that gas-fired furnaces actually have a gap in published efficiencies between roughly $84 \%$ and $90 \%$ and that only small furnaces $(<50,000 \mathrm{Btu} / \mathrm{hr})$ have efficiencies above $96 \%$. NEMS tries to simulate actual performance so derates some of the higher efficiency equipment. EIA has been notified of this concern so may change the parameters for future analysis.

Table 4-3: Heat pump costs and efficiencies in the AEO2000

\begin{tabular}{|c|c|c|c|c|c|c|}
\hline \multirow[b]{2}{*}{ Name } & \multicolumn{2}{|c|}{ Capital Cost, 1998\$ } & \multicolumn{2}{|c|}{ Efficiency } & \multirow[b]{2}{*}{ Start Date } & \multirow[b]{2}{*}{ End Date } \\
\hline & Installed & Retail & $\begin{array}{l}\text { Heating } \\
\text { Btu Out/ln }\end{array}$ & $\begin{array}{c}\text { Cooling } \\
\text { SEER }\end{array}$ & & \\
\hline ELEC_HP1 & 4100 & 3400 & 1.99 & 10.0 & 1997 & 2020 \\
\hline ELEC_HP2 & 4400 & 3700 & 2.20 & 12.0 & 1997 & 2020 \\
\hline ELEC_HP3 & 4950 & 4150 & 2.43 & 14.8 & 1997 & 2020 \\
\hline ELEC_HP4 & 5555 & 4600 & 2.75 & 17.7 & 1997 & 2014 \\
\hline ELEC_HP4 & 5155 & 4200 & 2.75 & 17.7 & 2015 & 2020 \\
\hline ELEC_HP5 & 4815 & 4000 & 2.50 & 13.0 & 2005 & 2014 \\
\hline ELEC_HP5 & 4615 & 3800 & 2.50 & 13.0 & 2015 & 2020 \\
\hline ELEC_HP6 & 5320 & 4400 & 2.93 & 18.0 & 2015 & 2020 \\
\hline GEO_HP1 & 8000 & 3000 & 3.40 & 13.5 & 1997 & 2020 \\
\hline GEO_HP2 & 12000 & 5300 & 4.00 & 21.0 & 1997 & 2004 \\
\hline GEO_HP2 & 10800 & 4800 & 4.10 & 21.0 & 2005 & 2020 \\
\hline GEO_HP3 & 5850 & 3500 & 3.80 & 15.0 & 2015 & 2020 \\
\hline GEO_HP4 & 8300 & 4800 & 4.20 & 21.0 & 2015 & 2020 \\
\hline NG_HP & 8000 & 8000 & 14.00 & 15.6 & 1997 & 2004 \\
\hline NG_HP & 7500 & 7500 & 14.00 & 15.6 & 2005 & 2014 \\
\hline NG_HP & 6500 & 6500 & 14.00 & 15.6 & 2015 & 2020 \\
\hline
\end{tabular}


Table 4-4: Space heating technologies in the AEO2000 (except heat pumps)

\begin{tabular}{|c|c|c|c|c|c|}
\hline \multirow[b]{2}{*}{ Name } & \multicolumn{2}{|c|}{ Capital Cost, $1998 \$$} & \multicolumn{2}{|l|}{ Efficiency } & \multirow[b]{2}{*}{ End Date } \\
\hline & Installed & Retail & Btu Out/ln & Start Date & \\
\hline ELEC_RAD & 1350 & 750 & 1.00 & 1997 & 2020 \\
\hline NG_FA\#1 & 1300 & 680 & 0.78 & 1997 & 2020 \\
\hline NG_FA\#2 & 1350 & 750 & 0.80 & 1997 & 2004 \\
\hline NG_FA\#2 & 1300 & 750 & 0.80 & 2005 & 2014 \\
\hline NG_FA\#2 & 1300 & 750 & 0.80 & 2015 & 2020 \\
\hline NG_FA\#3 & 1687 & 1062 & 0.84 & 1997 & 2004 \\
\hline NG_FA\#3 & 1387 & 812 & 0.84 & 2005 & 2014 \\
\hline NG_FA\#3 & 1375 & 787 & 0.84 & 2015 & 2020 \\
\hline NG_FA\#4 & 2025 & 1375 & 0.88 & 1997 & 2004 \\
\hline NG_FA\#4 & 1475 & 875 & 0.88 & 2005 & 2014 \\
\hline NG_FA\#4 & 1450 & 825 & 0.88 & 2015 & 2020 \\
\hline NG_FA\#5 & 2700 & 2000 & 0.96 & 1997 & 2004 \\
\hline NG_FA\#5 & 1650 & 1300 & 0.96 & 2005 & 2014 \\
\hline NG_FA\#5 & 1600 & 900 & 0.96 & 2015 & 2020 \\
\hline NG_RAD\#1 & 4845 & 2145 & 0.78 & 1997 & 2020 \\
\hline NG_RAD\#2 & 5631 & 2931 & 0.80 & 1997 & 2004 \\
\hline NG_RAD\#2 & 5422 & 2850 & 0.80 & 2005 & 2014 \\
\hline NG_RAD\#2 & 5297 & 2600 & 0.80 & 2015 & 2020 \\
\hline NG_RAD\#3 & 6418 & 3718 & 0.95 & 1997 & 2004 \\
\hline NG_RAD\#3 & 6000 & 3500 & 0.95 & 2005 & 2014 \\
\hline NG_RAD\#3 & 5750 & 3000 & 0.95 & 2015 & 2020 \\
\hline KERO_FA1 & 2052 & 1000 & 0.65 & 1997 & 2020 \\
\hline KERO_FA2 & 2660 & 1600 & 0.70 & 1997 & 2020 \\
\hline KERO_FA3 & 4217 & 2200 & 0.80 & 1997 & 2020 \\
\hline LPG_FA\#1 & 1300 & 680 & 0.78 & 1997 & 2020 \\
\hline LPG_FA\#2 & 1350 & 750 & 0.80 & 1997 & 2004 \\
\hline LPG_FA\#2 & 1300 & 750 & 0.80 & 2005 & 2014 \\
\hline LPG_FA\#2 & 1300 & 750 & 0.80 & 2015 & 2020 \\
\hline LPG_FA\#3 & 2025 & 1375 & 0.88 & 1997 & 2004 \\
\hline LPG_FA\#3 & 1475 & 875 & 0.88 & 2005 & 2014 \\
\hline LPG_FA\#3 & 1450 & 825 & 0.88 & 2015 & 2020 \\
\hline LPG_FA\#4 & 2700 & 2000 & 0.96 & 1997 & 2004 \\
\hline LPG_FA\#4 & 1650 & 1300 & 0.96 & 2005 & 2014 \\
\hline LPG_FA\#4 & 1600 & 900 & 0.96 & 2015 & 2020 \\
\hline DIST_FA1 & 2000 & 1000 & 0.80 & 1997 & 2020 \\
\hline DIST_FA2 & 2624 & 1400 & 0.83 & 1997 & 2020 \\
\hline DIST_FA3 & 2939 & 1800 & 0.87 & 1997 & 2020 \\
\hline DISTRAD1 & 4845 & 2145 & 0.78 & 1997 & 2020 \\
\hline DISTRAD2 & 5631 & 2931 & 0.80 & 1997 & 2004 \\
\hline DISTRAD2 & 5422 & 2850 & 0.80 & 2005 & 2014 \\
\hline DISTRAD2 & 5297 & 2600 & 0.80 & 2015 & 2020 \\
\hline DISTRAD3 & 6418 & 3718 & 0.95 & 1997 & 2004 \\
\hline DISTRAD3 & 6000 & 3500 & 0.95 & 2005 & 2014 \\
\hline DISTRAD3 & 5750 & 3000 & 0.95 & 2015 & 2020 \\
\hline WOOD_HT & 1700 & 1000 & 1.00 & 1997 & 2020 \\
\hline
\end{tabular}




\subsubsection{Space cooling}

Cooling technologies include the heat pumps as listed above, plus five room air conditioners and five central air conditioners (Table 4-5).

Table 4-5: Air conditioner costs and efficiencies in the AEO2000.

\begin{tabular}{|l|ccccc|}
\hline \multicolumn{7}{|c}{$\begin{array}{c}\text { Capital Cost, } 1998 \$ \\
\text { Name }\end{array}$} & $\begin{array}{c}\text { Efficiency } \\
\text { SEER }\end{array}$ & Start Date & End Date \\
\hline RM_AIR\#1 & 450 & 350 & 8.7 & 1997 & 2000 \\
RM_AIR\#1 & 450 & 350 & 9.7 & 2001 & 2020 \\
RM_AIR\#2 & 500 & 400 & 10.0 & 1997 & 2004 \\
RM_AIR\#2 & 490 & 390 & 10.0 & 2005 & 2020 \\
RM_AIR\#3 & 760 & 660 & 11.7 & 1997 & 2020 \\
RM_AIR\#4 & 760 & 660 & 12.0 & 2005 & 2020 \\
RM_AIR\#5 & 600 & 500 & 11.0 & 2015 & 2020 \\
CT_AIR\#1 & 2500 & 1800 & 10.0 & 1997 & 2020 \\
CT_AIR\#2 & 2800 & 2100 & 12.0 & 1997 & 2004 \\
CT_AIR\#2 & 2700 & 1800 & 12.0 & 2005 & 2020 \\
CT_AIR\#3 & 3200 & 2500 & 15.1 & 1997 & 2004 \\
CT_AIR\#3 & 3000 & 2100 & 15.1 & 2005 & 2020 \\
CT_AIR\#4 & 3600 & 2700 & 18.1 & 1997 & 2004 \\
CT_AIR\#4 & 3400 & 2500 & 18.1 & 2005 & 2014 \\
CT_AIR\#4 & 3200 & 2300 & 18.1 & 2015 & 2020 \\
CT_AIR\#5 & 3100 & 2000 & 16.6 & 2015 & 2020 \\
\hline
\end{tabular}

\subsubsection{Water heating}

Water heating can be provided by gas (both natural gas and LPG), distillate, and electric water heaters (Table 4-6). The LPG heaters are not listed in the table but have the same costs and efficiencies as the natural gas water heaters. 
Table 4-6: Water heating costs and efficiencies in the AEO2000

\begin{tabular}{|c|c|c|c|c|c|}
\hline \multirow[b]{2}{*}{ Name } & \multicolumn{2}{|c|}{ Capital Cost, $1998 \$$} & \multicolumn{2}{|l|}{ Efficiency } & \multirow[b]{2}{*}{ End Date } \\
\hline & Installed & Retail & Btu Out/ln & Start Date & \\
\hline NG_WH\#1 & 340 & 190 & 0.54 & 1997 & 2020 \\
\hline NG_WH\#2 & 370 & 220 & 0.58 & 1997 & 2020 \\
\hline NG_WH\#3 & 400 & 300 & 0.60 & 1997 & 2004 \\
\hline NG_WH\#3 & 375 & 225 & 0.60 & 2005 & 2020 \\
\hline NG_WH\#4 & 2360 & 2200 & 0.86 & 1997 & 2004 \\
\hline NG_WH\#4 & 2000 & 1800 & 0.86 & 2005 & 2014 \\
\hline NG_WH\#4 & 1800 & 1500 & 0.86 & 2015 & 2020 \\
\hline NG_WH\#5 & 450 & 350 & 0.63 & 2005 & 2014 \\
\hline NG_WH\#5 & 425 & 325 & 0.63 & 2015 & 2020 \\
\hline NG_WH\#6 & 500 & 400 & 0.70 & 2015 & 2020 \\
\hline ELEC_WH1 & 350 & 225 & 0.86 & 1997 & 2020 \\
\hline ELEC_WH2 & 350 & 225 & 0.88 & 1997 & 2020 \\
\hline ELEC_WH3 & 575 & 450 & 0.95 & 1997 & 2020 \\
\hline ELEC_WH4 & 1025 & 825 & 2.60 & 1997 & 2020 \\
\hline ELEC_WH5 & 2600 & 2100 & 2.00 & 1997 & 2020 \\
\hline ELEC_WH6 & 350 & 225 & 0.89 & 2005 & 2020 \\
\hline ELEC_WH7 & 475 & 300 & 0.96 & 2005 & 2020 \\
\hline ELEC_WH8 & 900 & 500 & 2.00 & 2005 & 2020 \\
\hline ELEC_WH9 & 400 & 250 & 0.90 & 2015 & 2020 \\
\hline ELEC_WH10 & 425 & 300 & 0.96 & 2015 & 2020 \\
\hline ELEC_WH11 & 800 & 400 & 2.20 & 2015 & 2020 \\
\hline DIST_WH1 & 725 & 525 & 0.53 & 1997 & 2020 \\
\hline DIST_WH2 & 779 & 579 & 0.58 & 1997 & 2020 \\
\hline
\end{tabular}

\subsubsection{Other}

Other technologies for the residential sector with input cost and efficiency parameters include cooking stoves, refrigerators, freezers, dishwashers, clothes washers, and dryers. Table 4-7 shows the cost and efficiency values for refrigerators and freezers modeled in NEMS. Energy demands for lighting, personal computers, color televisions, furnace fans, miscellaneous other electronic equipment, small motors, and heating elements (such as toasters) are calculated within the model based on penetration and other data from RECS. Also, the Other category contains an adjustment factor to equilibrate the calculated total demands to the known values from SEDS. 
Table 4-7: Refrigerator and freezer technologies within NEMS

\begin{tabular}{|lccccc|}
\hline Name & \multicolumn{2}{c}{ Capital Cost, $1998 \$$} & Efficiency & & \\
Installed & Retail & KWh/year & Start Date & End Date \\
\hline Ref\#1 & 530 & 480 & 690 & 1997 & 2001 \\
Ref\#1 & 530 & 480 & 478 & 2002 & 2020 \\
Ref\#2 & 550 & 500 & 660 & 1997 & 2001 \\
Ref\#2 & 550 & 500 & 460 & 2002 & 2020 \\
Ref\#3 & 850 & 800 & 518 & 1997 & 2001 \\
Ref\#3 & 550 & 500 & 460 & 2002 & 2020 \\
Ref\#4 & 700 & 700 & 400 & 2005 & 2020 \\
Ref- Thru the Door & 1314 & 1314 & 843 & 1997 & 2001 \\
Ref- Thru the Door & 1314 & 1314 & 577 & 2002 & 2020 \\
Freez\#1 & 381 & 381 & 472 & 1997 & 2001 \\
Freez\#1 & 381 & 381 & 394 & 2002 & 2020 \\
Freez\#2 & 420 & 420 & 350 & 1997 & 2020 \\
Freez\#3 & 500 & 500 & 302 & 1997 & 2020 \\
FRZR-Upright & 381 & 381 & 617 & 1997 & 2001 \\
FRZR-Upright & 381 & 381 & 520 & 2002 & 2020 \\
\hline
\end{tabular}

\subsection{Scenarios Analyzed}

In order to understand the potential changes in energy use due to changes in the technologies or market, we ran four separate NEMS scenarios. The Base case is the AEO2000 results. Its results are displayed in the graphs above. A Frozen case was run where no improvements in technologies beyond 2000 were made. This provides information on the amount of change based on expected improvements contained in the Base case. A Lowered Rate case was run that reduced the rates used by consumers to compare future costs to upfront costs during purchase decisions. This was to simulate the impact of market programs that either reduce the risk or market barriers to consumers. Fourth, we ran a Standards case that eliminated certain low efficiency technologies as choices in the future.

The Frozen case, despite no improvements in technologies beyond today, still shows gradual improvements in the average efficiency of various technologies (Table 4-8). The currently available technologies have higher efficiencies than the average mix already in place. As new housing is built, this technology will be used and raise the average efficiencies. Secondly, older equipment has a given lifetime and must be replaced. Currently available technology will be used that has higher efficiencies than the retired equipment. 
Table 4-8: Average equipment efficiencies in Frozen case

\begin{tabular}{|l|rrrr|}
\hline RESIDENTIAL END-USES & $\mathbf{1 9 9 7}$ & $\mathbf{2 0 0 0}$ & $\mathbf{2 0 1 0}$ & $\mathbf{2 0 2 0}$ \\
\hline Main Space Heaters & & & & \\
Electric Heat Pumps (HSPF) & 6.9 & 7.2 & 7.3 & 7.3 \\
Natural Gas Heat Pumps (HSPF) & 14.0 & 14.0 & 14.0 & 14.0 \\
Geothermal Heat Pumps (COP) & 3.4 & 3.4 & 3.4 & 3.4 \\
Natural Gas Furnace (AFUE) & 0.74 & 0.76 & 0.81 & 0.82 \\
Distillate Furnace (AFUE) & 0.77 & 0.79 & 0.81 & 0.82 \\
Space Cooling & & & & \\
Electric Heat Pumps (SEER) & 10.1 & 10.9 & 11.5 & 11.4 \\
Natural Gas Heat Pumps (SEER) & 15.6 & 15.6 & 15.6 & 15.6 \\
Geothermal Heat Pumps (EER) & 13.5 & 13.5 & 13.5 & 13.5 \\
Cent Air Conditioners (SEER) & 10.0 & 10.3 & 10.7 & 10.7 \\
Room Air Conditioners (EER) & 8.4 & 8.7 & 9.1 & 9.1 \\
Water Heaters & & & & \\
Electric (EF) & 0.86 & 0.87 & 0.87 & 0.87 \\
Natural Gas (EF) & 0.53 & 0.54 & 0.56 & 0.56 \\
Distillate (EF) & 0.53 & 0.53 & 0.54 & 0.53 \\
Liquid Petroleum Gas (EF) & 0.53 & 0.54 & 0.56 & 0.57 \\
Other Appliances (kWh/yr) & & & & \\
Refrigerators & 976 & 882 & 745 & 725 \\
Freezers & 770 & 632 & 504 & 495 \\
\hline
\end{tabular}

As shown in the tables above, the Base case contains expected improvements in technologies beyond 2000. As a result, the average efficiencies improve beyond what occurs in the Frozen case (Table 4-9). Electric-based space heating and cooling equipment improve between 5\% and $8 \%$, but gas-fired space heating equipment, which is the major energy user, improves less (3\%). Water heating efficiencies improve little, with only slight improvements in the basic technology. Refrigerators and freezer efficiencies improve dramatically, as more improved equipment became available early in this decade (Table 4-7). 
Table 4-9: Percentage changes in average efficiency between Base case and Frozen case

\begin{tabular}{|l|cc|}
\hline & $\mathbf{2 0 1 0}$ & $\mathbf{2 0 2 0}$ \\
\hline Main Space Heaters & 2 & 6 \\
Electric Heat Pumps (HSPF) & 1 & 3 \\
Natural Gas Furnace (AFUE) & & \\
Space Cooling & 1 & 7 \\
Electric Heat Pumps (SEER) & 2 & 5 \\
Cent Air Conditioners (SEER) & 5 & 8 \\
Room Air Conditioners (EER) & & \\
Water Heaters & 0 & 2 \\
Electric (EF) & 1 & 2 \\
Natural Gas (EF) & 1 & 2 \\
Liquid Petroleum Gas (EF) & & \\
Other Appliances & 17 & 29 \\
Refrigerators & 5 & 11 \\
Freezers &
\end{tabular}

For the CEF study, several methods were used to model policy changes to improve efficiency. Outside calculations were done to estimate the impact of various energy saving programs (e.g., Energy Star appliances and homes, Rebuild America) on energy use. The results from field studies and simulations were used to project savings on a broader scale if the programs were more fully implemented. As one method to model the different energy policies, various parameters within the inputs or programming for the CEF-NEMS model were changed to replicate the results of these outside calculations. (The CEF study used a modified version of the NEMS program as used in the AEO1999. Consequently, it was named CEF-NEMS to avoid confusion.)

Many energy efficient technologies are cost-effective on a life cycle basis despite their higher initial cost. The lower operating costs due to higher efficiencies offset the higher initial cost. Market barriers, lack of knowledge about future costs, or simply customer emphasis on lowest initial cost lead to lack of acceptance of these cost-effective options. NEMS models this resistance by using a high discount rate (or a weighted bias between capital and discounted operating costs) and thereby making future costs less important in the decision process. The model uses a log-linear function that incorporates other factors in the decision process such as consumer preference parameters, besides just capital cost and energy savings. Table 4-10 shows the discount rates in the Base and Lowered Rate cases for key technologies. 
Table 4-10: Base case and Lowered Rate case implicit discount rates

\begin{tabular}{|l|ccc|}
\hline Technology & $\begin{array}{c}\text { Base Case } \\
\text { Discount Rates }\end{array}$ & $\begin{array}{c}\text { Lowered Rate } \\
\text { Discount Rates }\end{array}$ & Period \\
\hline Elec waterheater & $83 \%$ & $20 \%$ & $2001-2020$ \\
Gas waterheater & $47 \%$ & $15 \%$ & $2001-2020$ \\
Distillate waterheater & $150 \%$ & $15 \%$ & $2001-2020$ \\
Air source HP cooling & $38 \%$ & $15 \%$ & $2001-2020$ \\
Room air conditioners & $142 \%$ & $15 \%$ & $2001-2020$ \\
Central air conditioners & $36 \%$ & $15 \%$ & $2001-2020$ \\
Air/ground source HP heating & $38 \%$ & $15 \%$ & $2001-2020$ \\
Clothes washers & $391 \%$ & $15 \%$ & $2001-2020$ \\
Elec clothes dryers & $90 \%$ & $15 \%$ & $2001-2020$ \\
Gas dryers & $47 \%$ & $15 \%$ & $2001-2020$ \\
Refrigerators & $19 \%$ & $15 \%$ & $2001-2020$ \\
Freezers & $37 \%$ & $15 \%$ & $2001-2020$ \\
\hline
\end{tabular}

This analysis used the discount rate changes from the Moderate scenario of the CEF study. It did not include changes to the costs of technologies or internal coding changes that modified technologies such as lighting or others. Technology cost changes are dependent on policies such as improved R\&D that are beyond the scale of a single state to affect. Alternatively, lowered costs can imply a subsidy from the state on the capital cost of the equipment, but then it requires outside calculations using the projected energy prices to determine whether the subsidies are worthwhile from a societal perspective. Lowering the discount rate, but still keeping it at or above the cost of capital, represents a lowering of the risks, real or perceived, and transaction costs to consumers. Any purchase decisions are still cost-effective if barriers or information gaps are reduced. A $15 \%$ rate, while lower than some credit card rates for consumer purchases, is still higher than typical mortgages or home improvement loans.

Because of the lowered rates, electric heat pumps see a $12 \%$ improvement in average efficiency (Table 4-11). However, heat pump penetration is low within Iowa ( $1.2 \%$ of total heating units) so that little impact is made on total heating and cooling loads. Electric water heaters see an even larger increase in efficiency because heat pump water heaters become more cost-effective than standard electric water heaters. Other equipment (air conditioners, refrigerators, freezers, and others) see little change despite the lowered discount rate. Low firstcost but low efficiency equipment are still most frequently cost-effective. 
Table 4-11: Percent increase in average efficiency of Lowered Rate case versus Base Case

\begin{tabular}{|l|cc|}
\hline & $\mathbf{2 0 1 0}$ & $\mathbf{2 0 2 0}$ \\
\hline Space Heaters & & \\
$\quad$ Electric Heat Pumps (HSPF) & 9.6 & 12.0 \\
Space Cooling & & \\
Electric Heat Pumps (SEER) & 11.1 & 12.1 \\
Cent Air Conditioners (SEER) & 0.4 & 0.5 \\
Room Air Conditioners (EER) & 0.2 & 0.5 \\
Water Heaters & & \\
Electric (EF) & 11.4 & 27.0 \\
Natural Gas (EF) & 3.0 & 6.0 \\
Other Appliances & & \\
Refrigerators & 0.1 & 0.2 \\
Freezers & 0.4 & 0.6 \\
\hline
\end{tabular}

Finally, we considered a scenario assuming a phase-in of minimum efficiency standards similar to those used in the CEF study (Table 4-12). These are applied post 2004 to give manufacturers the opportunity to change their production facilities yet are currently achievable. The lower discount rates are applied to this case as well.

Table 4-12: Minimum residential efficiency standards from CEF

\begin{tabular}{|l|cc|}
\hline Technology & Efficiency & Start Date \\
\hline Clothes washers & Horizontal axis & 2006 \\
Gas water heaters & $0.60 \mathrm{EF}$ & 2004 \\
Elec water heaters & $0.95 \mathrm{EF}$ & 2004 \\
Room air conditioners & 10.5 SEER & 2010 \\
Central air conditioners & 13 SEER & 2006 \\
Elec. air-source heat pumps & 13 SEER/7.6 HSPF & 2006 \\
\hline
\end{tabular}

Air conditioning has a large impact from applying minimum standards (Table 4-13). With the relatively small amount of cooling required in the West North Central region, high efficiency is less important and so low efficiency equipment maintains a relatively large market share. When standards eliminate these low efficiency products, the high efficiency equipment are purchased and raise the average efficiency. Water heaters also see a large change, partly because of the standards and partly because of the lower discount rates. 
Table 4-13: Percentage change in average efficiency Standards versus Base case

\begin{tabular}{|l|rr|}
\hline & $\mathbf{2 0 1 0}$ & $\mathbf{2 0 2 0}$ \\
\hline Main Space Heaters & & \\
$\quad$ Electric Heat Pumps (HSPF) & 8.9 & 10.4 \\
Space Cooling & & \\
Electric Heat Pumps (SEER) & 14.3 & 16.0 \\
Cent Air Conditioners (SEER) & 13.8 & 36.8 \\
Room Air Conditioners (EER) & 1.6 & 11.1 \\
Water Heaters & & \\
Electric (EF) & 18.2 & 39.9 \\
$\quad$ Natural Gas (EF) & 3.7 & 6.6 \\
Other Appliances & & \\
$\quad$ Refrigerators & 0.1 & 0.2 \\
Freezers & 0.4 & 0.6 \\
\hline
\end{tabular}

\subsection{Energy Use Changes}

Table 4-14 shows the amount of energy used in trillion Btu for the various end-use services under the different cases. It also breaks down the usage by fuel. Percentage changes in energy use between the Lower Discount Rate and Base cases, and between the Standards and Base cases, show which technologies were affected most by the policies modeled. Space cooling and water heating were most affected, dropping by $20.5 \%$ and $14.2 \%$, respectively (Figure $4-3$ and Figure 4-4). These two were largely influenced by reductions in the electric versions of the technologies, although gas-fired water heaters also showed savings. Overall, electric savings totaled $5.3 \%$ and gas savings $2.4 \%$. 
Table 4-14: Iowa 2020 residential energy use (Trillion Btu)

\begin{tabular}{|c|c|c|c|c|c|c|}
\hline & Frozen & Base & $\begin{array}{c}\text { Lower } \\
\text { Discount } \\
\text { Rate } \\
\end{array}$ & $\begin{array}{c}\text { \%change, } \\
\text { Lower Rate } \\
\text { from Base }\end{array}$ & Standards & $\begin{array}{l}\% \text { change, } \\
\text { Standards } \\
\text { from Base }\end{array}$ \\
\hline Space Heating & 84.3 & 82.6 & 82.5 & $-0.1 \%$ & 82.5 & $-0.1 \%$ \\
\hline Electric & 4.7 & 4.5 & 4.4 & $-1.2 \%$ & 4.4 & $-1.0 \%$ \\
\hline Gas & 67.7 & 66.7 & 66.7 & $0.0 \%$ & 66.7 & $0.0 \%$ \\
\hline Distillate & 3.4 & 3.3 & 3.3 & $0.0 \%$ & 3.3 & $0.0 \%$ \\
\hline LPG & 8.6 & 8.1 & 8.1 & $0.0 \%$ & 8.1 & $0.0 \%$ \\
\hline Space Cooling & 6.8 & 6.5 & 6.5 & $-0.5 \%$ & 5.2 & $-20.5 \%$ \\
\hline Electric & 6.5 & 6.2 & 6.2 & $-0.6 \%$ & 4.9 & $-21.6 \%$ \\
\hline Gas & 0.3 & 0.3 & 0.3 & $0.0 \%$ & 0.3 & $0.0 \%$ \\
\hline Water Heating & 24.8 & 24.4 & 22.6 & $-7.6 \%$ & 20.9 & $-14.2 \%$ \\
\hline Electric & 4.0 & 3.9 & 3.1 & $-20.2 \%$ & 2.7 & $-32.0 \%$ \\
\hline Gas & 18.7 & 18.5 & 17.4 & $-5.8 \%$ & 16.4 & $-11.5 \%$ \\
\hline Distillate & 0.1 & 0.1 & 0.1 & $1.1 \%$ & 0.1 & $-3.8 \%$ \\
\hline LPG & 2.0 & 1.9 & 1.9 & $-0.2 \%$ & 1.8 & $-5.0 \%$ \\
\hline Refrigeration & 4.4 & 3.2 & 3.2 & $-0.2 \%$ & 3.2 & $-0.2 \%$ \\
\hline Cooking & 4.3 & 4.3 & 4.3 & $0.0 \%$ & 4.3 & $0.0 \%$ \\
\hline Electric & 1.3 & 1.3 & 1.3 & $0.0 \%$ & 1.3 & $0.0 \%$ \\
\hline Gas & 2.4 & 2.4 & 2.4 & $0.0 \%$ & 2.4 & $0.0 \%$ \\
\hline LPG & 0.6 & 0.6 & 0.6 & $0.0 \%$ & 0.6 & $0.0 \%$ \\
\hline Clothes Drying & 4.7 & 4.7 & 4.7 & $-1.4 \%$ & 4.7 & $-1.4 \%$ \\
\hline Electric & 3.3 & 3.3 & 3.2 & $-1.9 \%$ & 3.2 & $-1.9 \%$ \\
\hline Gas & 1.4 & 1.4 & 1.4 & $-0.4 \%$ & 1.4 & $-0.4 \%$ \\
\hline Freezers & 1.5 & 1.3 & 1.3 & $-0.6 \%$ & 1.3 & $-0.6 \%$ \\
\hline Lighting & 4.6 & 4.6 & 4.6 & $0.0 \%$ & 4.6 & $0.0 \%$ \\
\hline Other & 26.2 & 26.2 & 26.1 & $-0.5 \%$ & 26.0 & $-0.7 \%$ \\
\hline Total & 161.5 & 157.8 & 155.6 & $-1.4 \%$ & 152.7 & $-3.3 \%$ \\
\hline Electric & 56.5 & 54.5 & 53.4 & $-2.0 \%$ & 51.6 & $-5.3 \%$ \\
\hline Gas & 90.4 & 89.3 & 88.2 & $-1.2 \%$ & 87.2 & $-2.4 \%$ \\
\hline Distillate & 3.5 & 3.4 & 3.4 & $0.0 \%$ & 3.4 & $-0.1 \%$ \\
\hline LPG & 11.2 & 10.6 & 10.6 & $0.0 \%$ & 10.5 & $-0.9 \%$ \\
\hline
\end{tabular}

Bold numbers indicate end-uses studied with significant savings

The Lower Discount Rate case by itself lowered energy use most dramatically in the water heating end-use. Clothes drying, freezers, and Other also saw some improvement. Total energy savings were $1.4 \%$ from the Base case.

A savings of 2.9 trillion Btus of electricity equals $850 \mathrm{GWh}$. At $5.5 \mathrm{c} / \mathrm{kWh}$ (the 2020 value in $1998 \$$ ) this represents savings of $\$ 47$ million per year. The amount of electricity saved represents the output of a $150 \mathrm{MW}$ power plant. In addition, a savings of 2.1 TBtus of natural gas, at $\$ 5.74 / \mathrm{MBtu}$ means savings of $\$ 12$ million per year. 
Figure 4-3: Space conditioning energy use

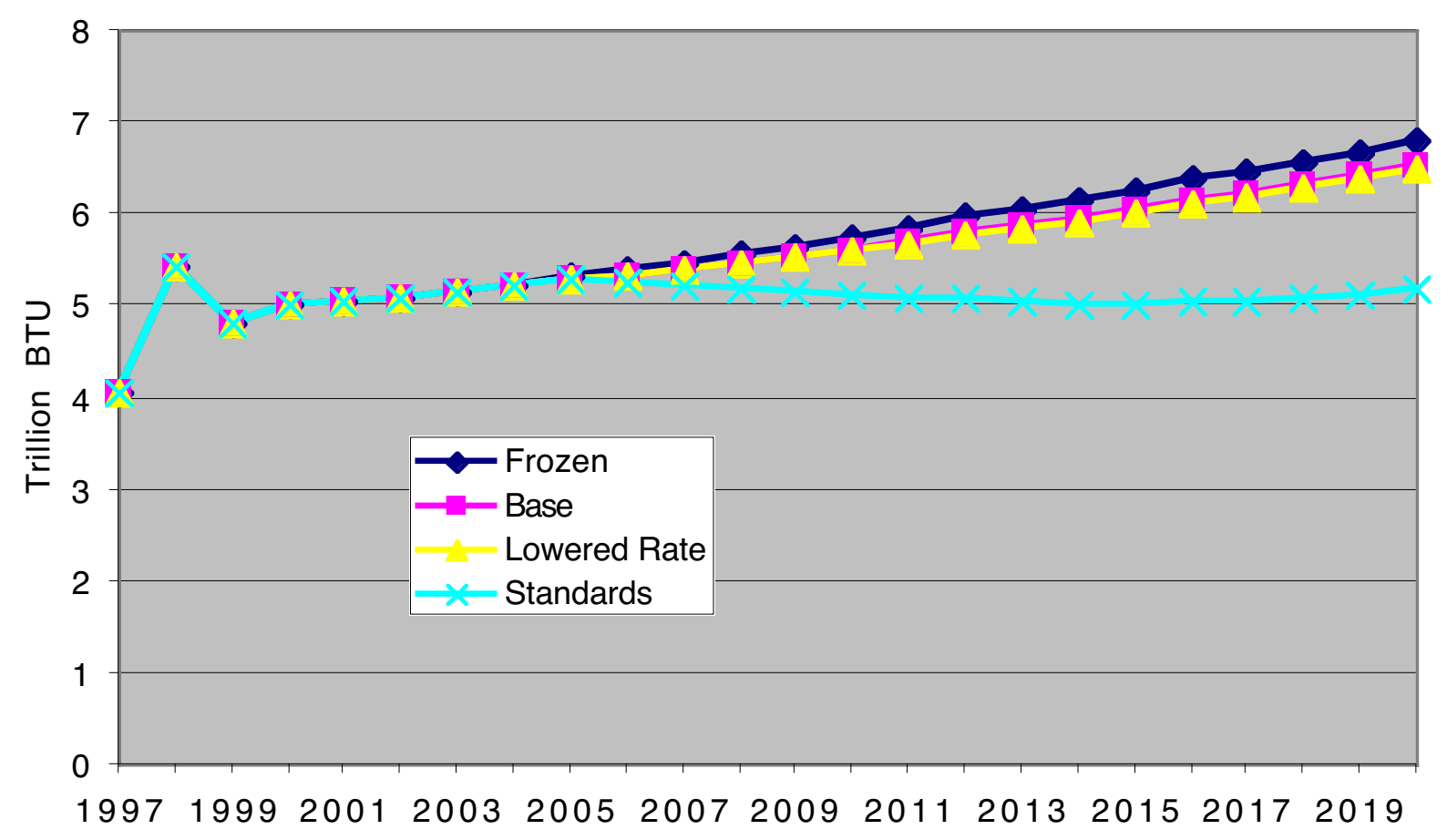

Figure 4-4: Water heating energy use

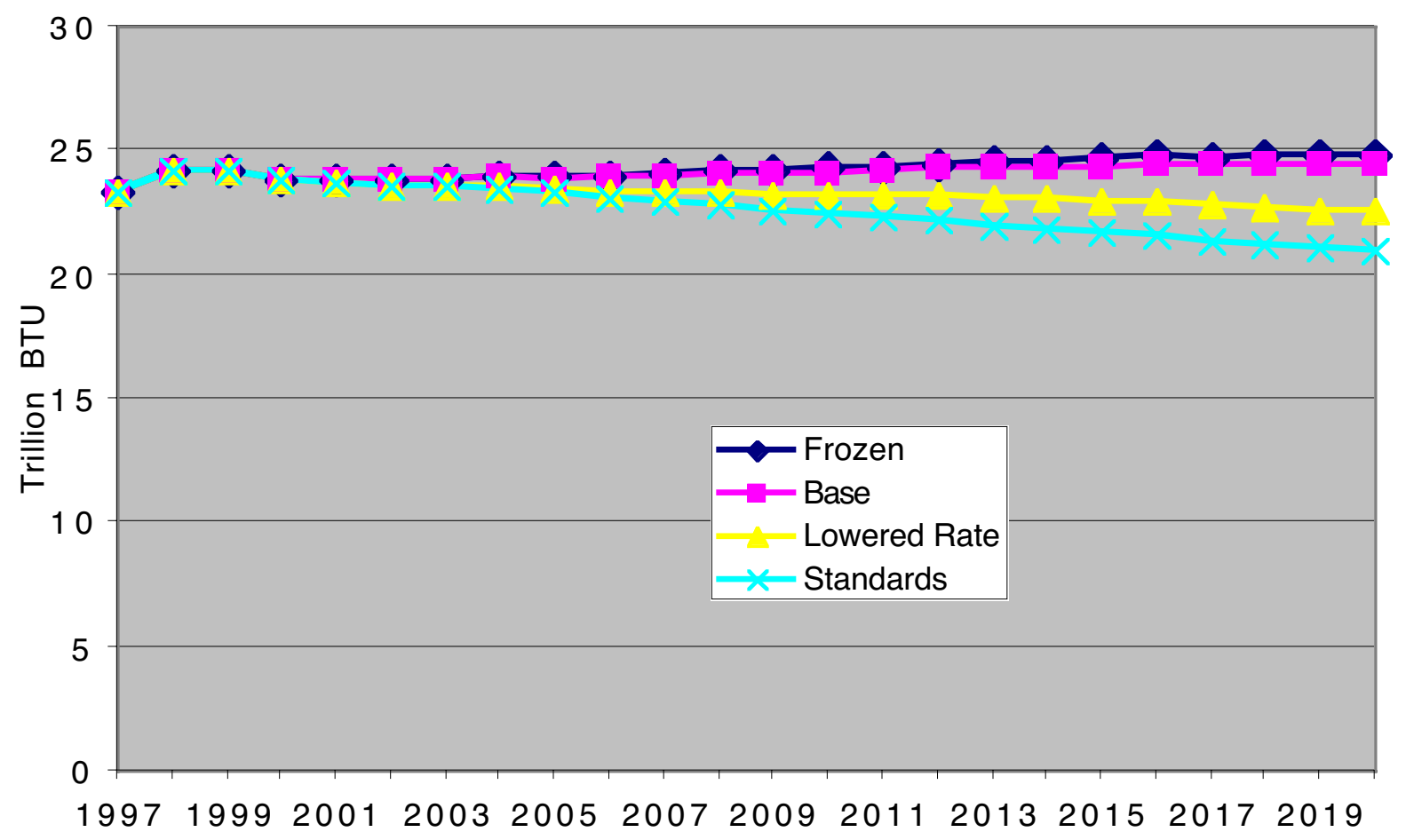





\section{Commercial}

\subsection{Current and Expected Energy Use}

The commercial end-use sector represents $11 \%$ of total end-use consumption (Table $3-1$ ). This is the smallest of the four end-use sectors. It can be further separated by the type of commercial activity (Figure 5-1). The largest activity has to do with mercantile/service businesses. As with the residential sector, space heating makes up the bulk of energy use in the sector (Figure 5-2). There is also a large "Other" category. A large portion of this is the energy used in cogeneration, where the energy from natural gas is used both for heat or process steam as well as to make electricity for use by the business. Lighting is also a large end-use, with water heating being the next largest.

\section{Figure 5-1: West-North-Central commercial energy use}

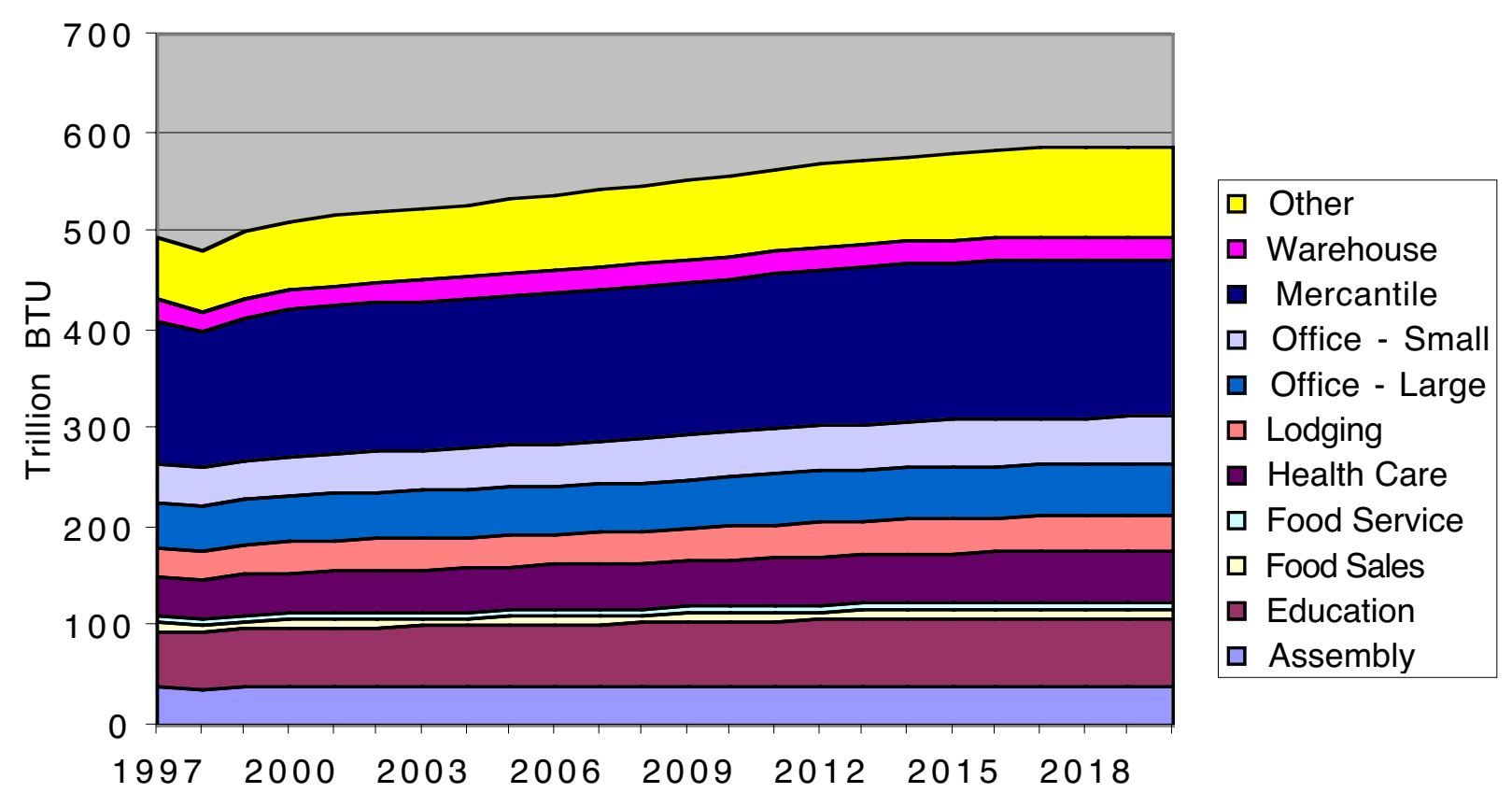

Of the commercial electricity use, lighting is the largest end-use, representing $38 \%$ of total electricity in 1997 (Figure 5-3). The Other category within electricity contains transformers, traffic lights, exit signs, automated teller machines, telecommunications equipment, medical equipment, and other unidentified end-uses. It also includes an adjustment term to ensure that the total commercial sector energy use adds up to the totals reported in EIA's State Energy Data Report. 


\section{Figure 5-2: Iowa commercial energy use}

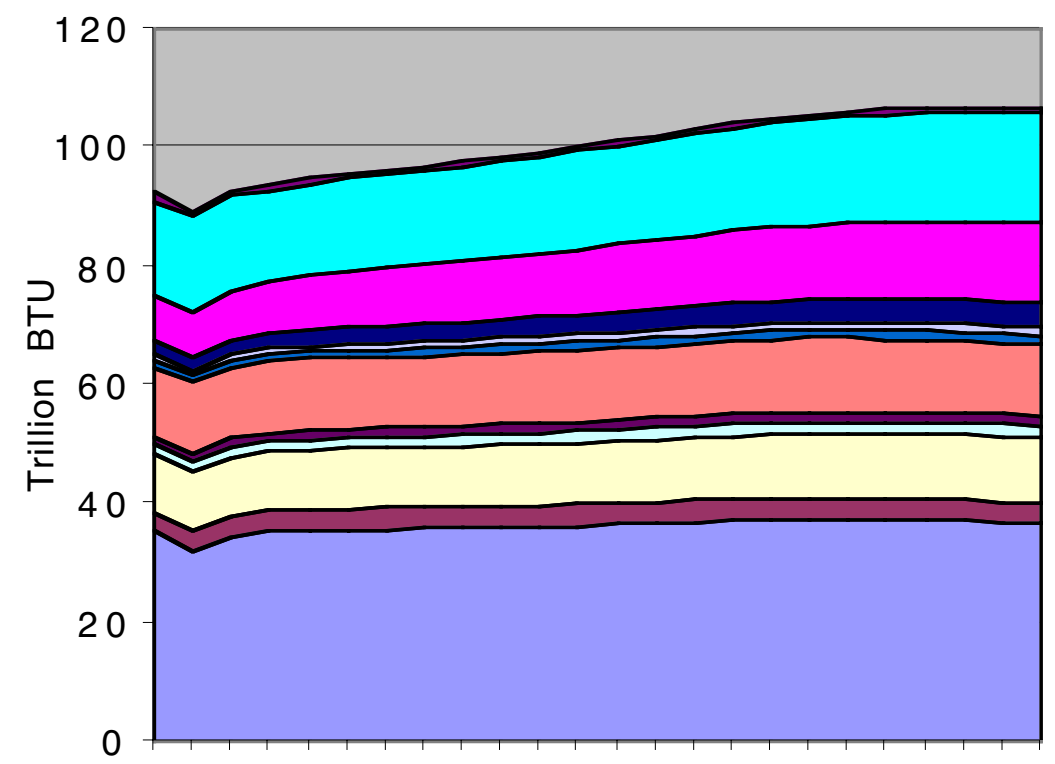

- Other Use-Other fuels

$\square$ Other Use-Gas

$\square$ Other Use-Electric

- Office Equipment (non-PC)

$\square$ Office Equipment (PC)

$\square$ Refrigeration

- Lighting

$\square$ Cooking

$\square$ Ventilation

$\square$ Water Heating

$\square$ Space Cooling

$\square$ Space Heating

19972000200320062009201220152018

Figure 5-3: Iowa commercial electricity use

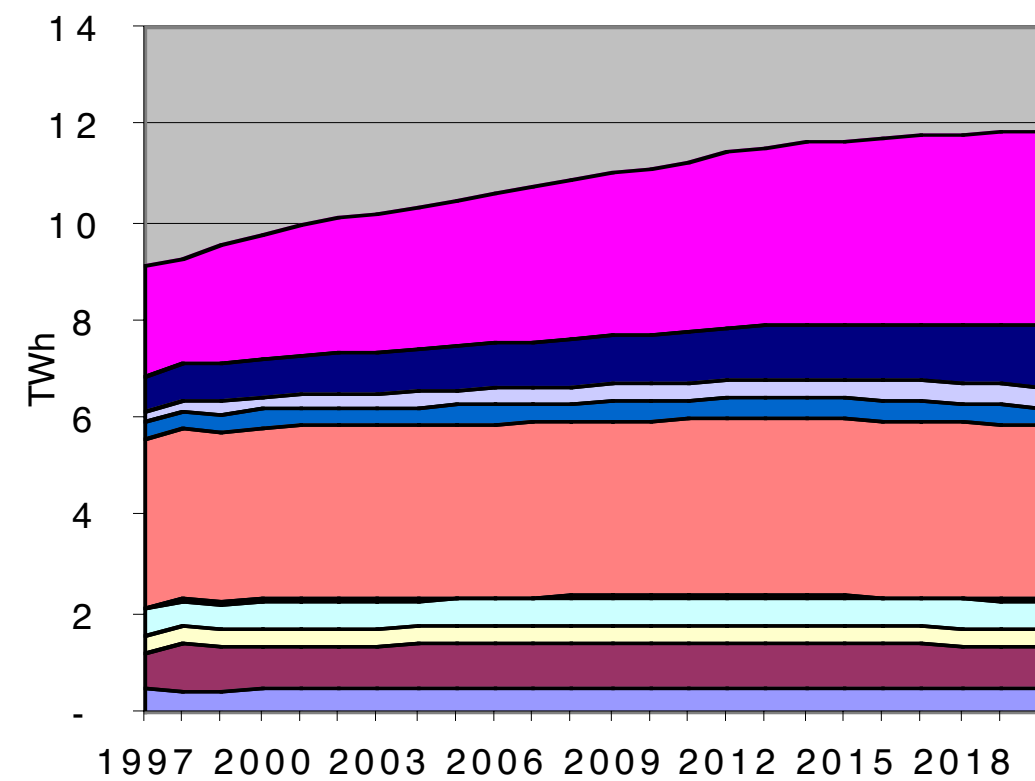

$\square$ Other Uses

- Office Equipment (non-PC)

$\square$ Office Equipment (PC)

$\square$ Refrigeration

$\square$ Lighting

$\square$ Cooking

$\square$ Ventilation

$\square$ Water Heating

$\square$ Space Cooling

$\square$ Space Heating

\subsection{Scenarios Analyzed}

Three cases were run using NEMS for the Commercial sector. As with the residential sector, a Frozen case was run with no technologies available post-2000. This case shows the gradual change in efficiency simply from the retirement of older equipment and the addition of new 
facilities into the mix of energy use. Comparing this to the Base case shows the amount of savings to be expected from the availability of newer technologies, even with no new policies. Finally, a case was run where the discount rates were lowered within each business sector in line with the values identified in the CEF study.

\subsubsection{Frozen}

A gradual improvement in efficiencies occurred in the Frozen case, as shown in Table 5-1. Space cooling shows the most improvement in efficiency. This is due to increased penetration of commercial sector with cooling (so current technology is used) as well as the improvements in equipment already available but not widespread yet. Lighting also shows a large improvement in average efficiency, with the continued conversion of commercial facilities to current lighting technology.

Table 5-1: Commercial equipment efficiency in Frozen case (Btu Out/Btu In)

\begin{tabular}{|c|c|c|c|c|}
\hline & 1997 & 2000 & 2010 & 2020 \\
\hline \multicolumn{5}{|l|}{ Space Heating } \\
\hline Electricity & 1.17 & 1.18 & 1.18 & 1.16 \\
\hline Natural Gas & 0.73 & 0.75 & 0.78 & 0.79 \\
\hline Distillate & 0.74 & 0.75 & 0.77 & 0.77 \\
\hline \multicolumn{5}{|l|}{ Space Cooling } \\
\hline Electricity & 2.48 & 2.60 & 2.89 & 3.05 \\
\hline Natural Gas & 0.73 & 0.81 & 0.93 & 0.98 \\
\hline \multicolumn{5}{|l|}{ Water Heating } \\
\hline Electricity & 0.95 & 0.96 & 0.96 & 0.96 \\
\hline Natural Gas & 0.71 & 0.74 & 0.78 & 0.79 \\
\hline Distillate & 0.74 & 0.75 & 0.76 & 0.77 \\
\hline \multicolumn{5}{|c|}{ Ventilation (cfm per Btu) } \\
\hline Electricity & 0.39 & 0.40 & 0.42 & 0.42 \\
\hline \multicolumn{5}{|l|}{ Cooking } \\
\hline Electricity & 0.52 & 0.53 & 0.53 & 0.53 \\
\hline Natural Gas & 0.51 & 0.50 & 0.50 & 0.50 \\
\hline \multicolumn{5}{|c|}{ Lighting Efficacy (lumens per watt) } \\
\hline Electricity & 49.32 & 50.93 & 56.32 & 58.05 \\
\hline \multicolumn{5}{|l|}{ Refrigeration } \\
\hline Electricity & 1.28 & 1.29 & 1.30 & 1.30 \\
\hline
\end{tabular}




\subsubsection{Base}

The Base case from AEO2000 shows additional improvement in the energy efficiency of some equipment. Ventilation has the most improvement, rising 9\% over the Frozen case to 0.46 $\mathrm{cfm} /$ Btu. Space conditioning also improves, with efficiencies rising a further $6 \%$ over the Frozen case, to $3.21 \mathrm{Btu}$ Out/In for electricity and 1.04 for gas. Lighting increases an additional 3\%.

\subsubsection{Lowered Market Barriers}

Within NEMS each of the commercial sectors has a range of discount rates, representing the spectrum of preferences for businesses within that sector. Some businesses may have a very short focus or be very risk-averse, leading to a high discount rate. Other firms may be more energy conscious or willing to take risks, leading to a low discount rate. As a consequence a variety of equipment will be purchased for each sector.

As part of the analysis for the CEF study, the various market-related energy efficiency programs were converted to discount rate reductions and applied to the sectors. Lighting, water heating, and the heating, ventilation, and air conditioning (HVAC) end-uses were given different sets of discount rates, based upon the success of market programs.

Figure 5-4 shows the percentage of customers at each of the available discount rates. The AEO2000 used the same mix for all end-uses, with discount rates generally very high. Over one quarter of customers had an equivalent rate of 10 , or $1000 \%$. This says that these customers place essentially no value on ongoing costs (one dollar now is equivalent to $\$ 11$ next year.) They would consider almost totally the first costs of equipment. Rates of $55 \%$ and $153 \%$ also are high enough to make ongoing energy savings a relatively unimportant aspect in the decision process as well. Ten percent of customers have a discount rate of $20 \%$ or less.

In the CEF study, all customers had a discount rate of $14 \%$ for their HVAC equipment. Information, loans, or other market programs would lower their effective rate to this value. Water heating equipment would be somewhat higher, with $50 \%$ of customers at the $14 \%$ discount rate, and $25 \%$ of customers at $20 \%$ and $31 \%$ respectively. Lighting discount rates would be more evenly spread over those available in the model.

As a consequence of these lower rates, efficiency of equipment increases in most end-uses (Table 5-2). Natural gas cooling increases most significantly as better chillers and heat pumps are selected. Water heating improves as heat pump water heaters penetrate the market, raising efficiencies above 1.0 . 
Figure 5-4: Percentage of commercial customers with varying discount rates. The Base case has most customers at higher rates.

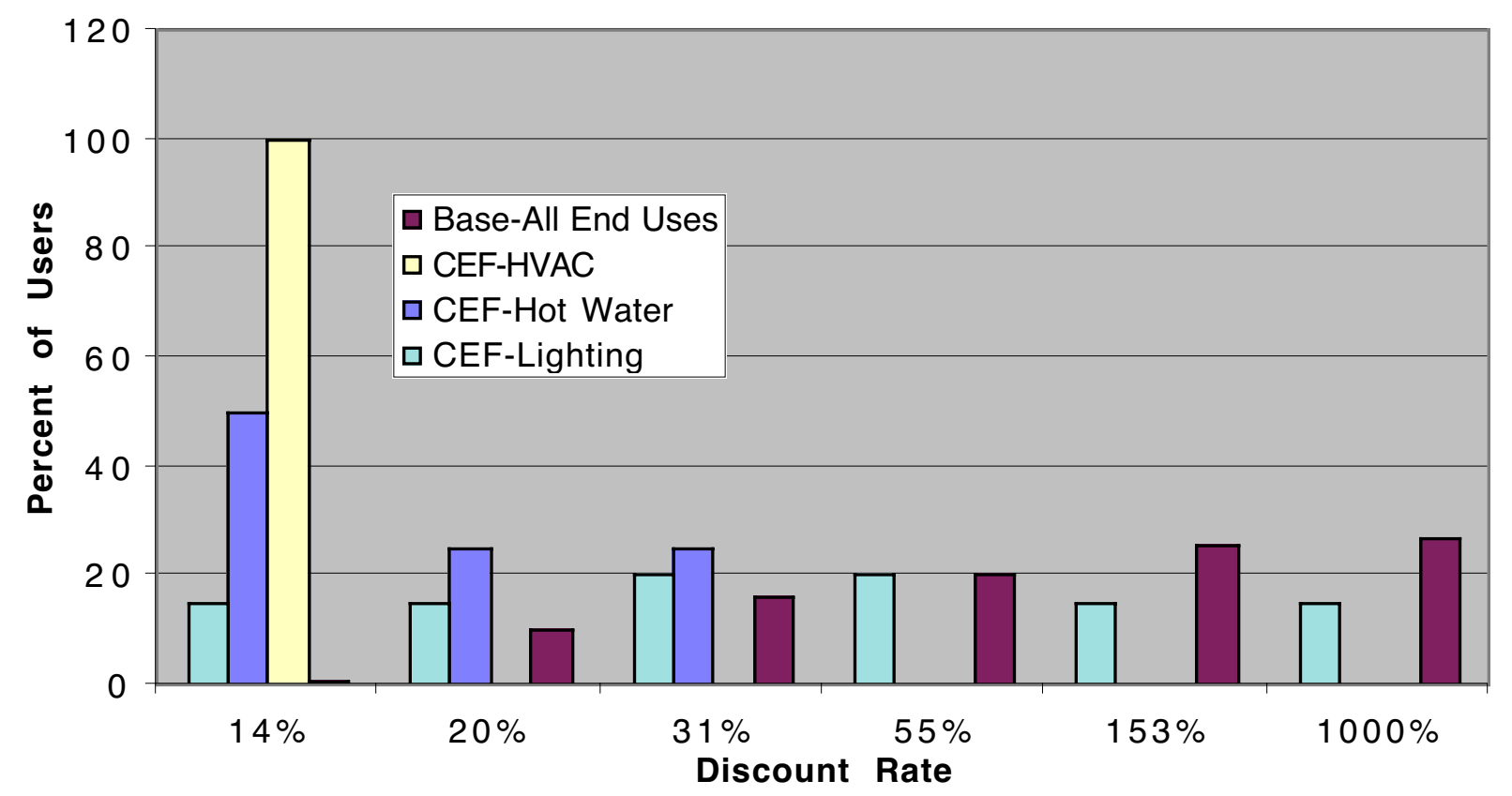

Table 5-2: Commercial equipment efficiency improvements with lowered discount rates (Btu out/Btu in)

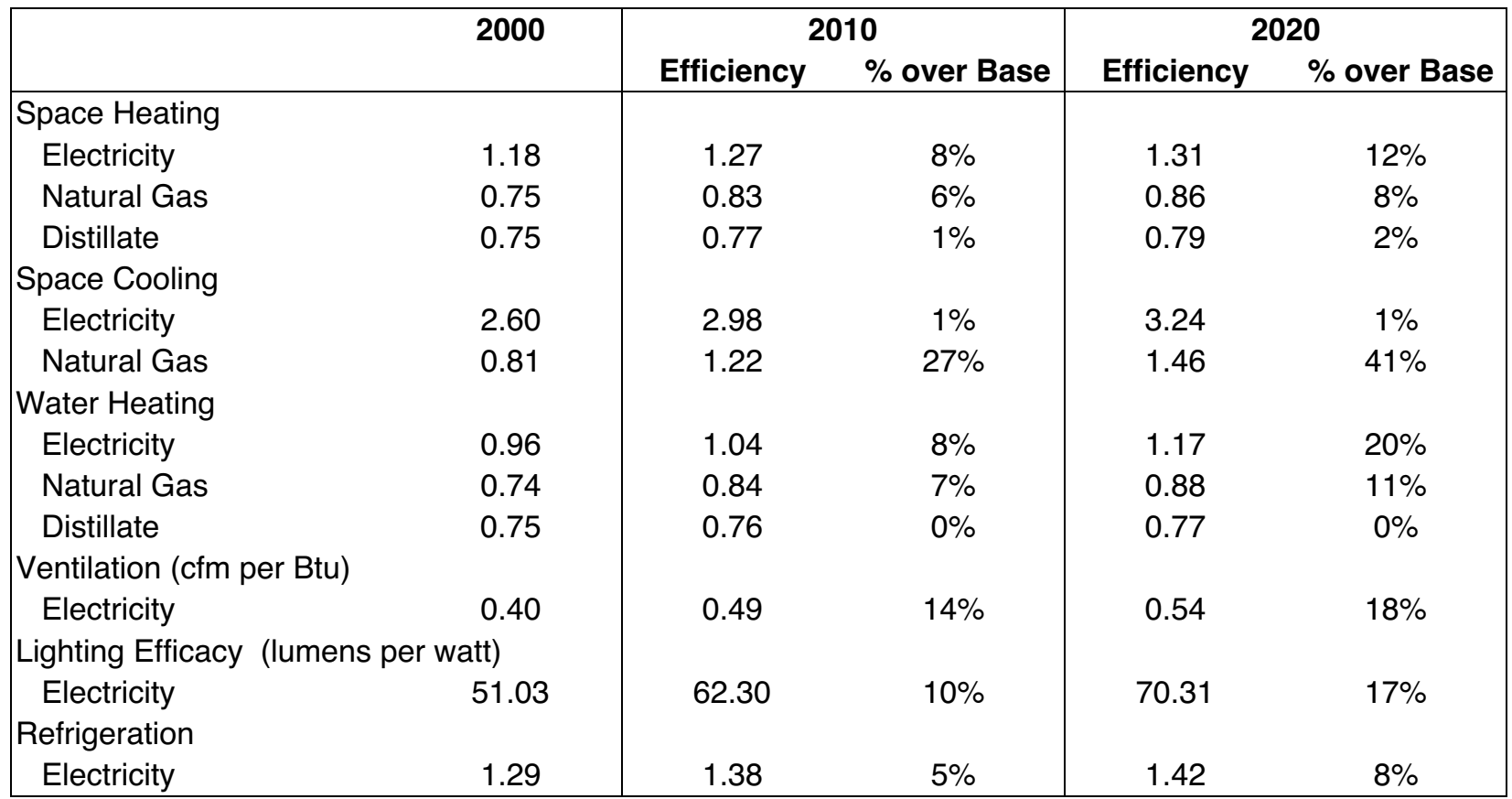


As a consequence of these efficiency improvements, energy use in the commercial sector drops 3.9\% from the amount in the Base case (Table 5-3). Electricity use drops 5.1\%. The major savings areas are in ventilation (12.4\%), lighting (12.3\%), electric water heating $(9.3 \%)$, and refrigeration $(7.5 \%)$. In terms of largest amount of energy saved, the major end-use is in gas space heating, followed by electric lighting.

Table 5-3: Iowa 2020 commercial energy use from Frozen, Base, and Lowered Discount Rate cases (trillion Btu)

\begin{tabular}{|c|c|c|c|c|}
\hline & Frozen & Base & $\begin{array}{c}\text { Lowered } \\
\text { Discount } \\
\text { Rate }\end{array}$ & $\begin{array}{l}\text { \% Change, } \\
\text { Lower Rate } \\
\text { from Base }\end{array}$ \\
\hline Space Heating & 36.7 & 36.6 & 34.8 & $-4.9 \%$ \\
\hline Electric & 1.7 & 1.7 & 1.6 & $-5.1 \%$ \\
\hline Gas & 33.8 & 33.7 & 32.0 & $-5.1 \%$ \\
\hline Distillate & 1.3 & 1.3 & 1.3 & $-0.3 \%$ \\
\hline Space Cooling & 3.7 & 3.6 & 3.5 & $-1.8 \%$ \\
\hline Electric & 3.1 & 3.0 & 2.9 & $-1.0 \%$ \\
\hline Gas & 0.6 & 0.6 & 0.6 & $-5.5 \%$ \\
\hline Water Heating & 11.0 & 11.0 & 10.3 & $-6.2 \%$ \\
\hline Electric & 1.2 & 1.2 & 1.1 & $-9.3 \%$ \\
\hline Gas & 9.4 & 9.4 & 8.8 & $-6.1 \%$ \\
\hline Distillate & 0.4 & 0.4 & 0.4 & $0.0 \%$ \\
\hline Ventilation & 2.1 & 1.9 & 1.7 & $-12.4 \%$ \\
\hline Cooking & 1.7 & 1.7 & 1.7 & $-1.1 \%$ \\
\hline Electric & 0.1 & 0.1 & 0.1 & $-1.9 \%$ \\
\hline Gas & 1.6 & 1.6 & 1.5 & $-1.0 \%$ \\
\hline Lighting & 12.4 & 12.1 & 10.6 & $-12.3 \%$ \\
\hline Refrigeration & 1.4 & 1.4 & 1.3 & $-7.5 \%$ \\
\hline Office Equipment (PC) & 1.5 & 1.5 & 1.5 & $-0.1 \%$ \\
\hline Office Equipment (non-PC) & 4.2 & 4.2 & 4.2 & $-0.1 \%$ \\
\hline Other Uses & 40.3 & 40.3 & 40.3 & $0.0 \%$ \\
\hline Electric & 13.6 & 13.6 & 13.6 & $0.0 \%$ \\
\hline Gas & 18.5 & 18.5 & 18.5 & $0.0 \%$ \\
\hline Distillate & 0.8 & 0.8 & 0.8 & $0.0 \%$ \\
\hline Other Fuel & 7.4 & 7.4 & 7.4 & $0.0 \%$ \\
\hline Total & 114.9 & 114.2 & 109.8 & $-3.9 \%$ \\
\hline Electric & 41.0 & 40.4 & 38.3 & $-5.1 \%$ \\
\hline Gas & 63.8 & 63.7 & 61.4 & $-3.7 \%$ \\
\hline Distillate & 2.5 & 2.5 & 2.5 & $-0.2 \%$ \\
\hline Other & 7.4 & 7.4 & 7.4 & $0.0 \%$ \\
\hline
\end{tabular}

Bold numbers indicate end-uses studied with significant savings

Electrical savings of $2.1 \mathrm{TBtu}$ translates into $605 \mathrm{GWh}$. Using an electrical price of $5.5 \mathrm{c} / \mathrm{kWh}$ gives a savings of $\$ 33$ million from electricity savings. In addition, 2.3 trillion Btu of natural gas saved at a price of $\$ 5.74 / \mathrm{MBtu}$ gives a savings of $\$ 13$ million. 


\section{Industrial}

Within Iowa, the industrial sector is the largest user of energy (Table 3-1). In 1997, Industrial energy use was over $360 \mathrm{TBtu}, 41 \%$ of the total end-use. There are a number of areas of potential savings. However, these must often be tailored to individual industry or business. Also, if a business is relatively energy-intensive then energy costs are often a significant and visible element of cost. This leads the business to take an active role in limiting energy expenditures, without government programs. Concerns over competitive information and privacy can also lower the participation. For these reasons, energy savings programs are often less successful in the industrial sector than in the residential or commercial sectors.

One major area that has shown potential for energy savings programs is in the industrial drive and motor systems. Industrial motor systems represent the largest single end use of electricity in the American economy-23\% of U.S. electricity consumption-and they present a very substantial energy-efficiency potential. Furthermore, motor systems are often used as a supporting operation to the creation of a business's product, rather than the focus of their activity. As a consequence, systems may be purchased based on specs related to the product need with less thought towards the energy use of the motor system itself.

DOE's Motor Challenge Program has identified many industries with the potential to reduce electricity use through more efficient electric motors and process improvements. The Motor Challenge Program is an industry/government partnership designed to help industry capture these significant energy and cost savings. One of the key elements in the Motor Challenge Program strategy is to encourage a systems approach to energy efficiency - that is, by installing new energy efficient motors, improving motor management practices, and optimizing motor systems. As part of the Motor Challenge program, a Market Assessment was undertaken to serve as a blueprint for the implementation of the Motor Challenge strategy.

The results of the recent market assessment involved on-site surveys of 265 industrial facilities. It documents that technologies offering a simple payback of 3 years or less can typically save businesses $11 \%$ to $18 \%$ of the energy used to drive motors (Xenergy, Inc., 1998). This survey provides information on the economic potential of the technologies rather than the market potential. As a consequence the amount of penetration by the new technologies into the market are not assessed.

The data from this survey was separated into the twenty most energy intensive SIC codes (McElhaney and Jallouk 1999). These can be applied to state-specific data to show the amount of energy used for motors in Iowa (Table 6-1). The amounts were calculated by dividing the survey's energy use/SIC code by the number of employees in each SIC code according to the 1996 Survey of Manufacturers (Department of Commerce 1996). The number of employees per SIC code is provided at the state level so the amount of motor energy use can be calculated assuming motor energy use per employee is roughly constant between states. Applying the percentage of savings available for each SIC code gives the amount of potential savings in GWh for each category. 
Table 6-1: Iowa industrial motor energy use and potential savings

\begin{tabular}{|c|c|c|c|c|c|c|}
\hline SIC & & $\begin{array}{c}\text { Motor Use } \\
\text { (GWh) }\end{array}$ & $\begin{array}{l}\% \text { of State } \\
\text { Motor Use }\end{array}$ & $\begin{array}{l}\text { Savings } \\
\text { (GWh) }\end{array}$ & $\begin{array}{c}\text { Savings } \\
\text { as \% of } \\
\text { Use }\end{array}$ & $\begin{array}{c}\text { Savings } \\
\text { as \% of } \\
\text { State }\end{array}$ \\
\hline 20 & Food and kindred products & 1114 & $17 \%$ & 138 & $12 \%$ & $15 \%$ \\
\hline 21 & Tobacco products & 0 & $0 \%$ & 0 & $0 \%$ & $0 \%$ \\
\hline 22 & Textile mill products & 34 & $1 \%$ & 5 & $15 \%$ & $1 \%$ \\
\hline 23 & Apparel and other textile products & 4 & $0 \%$ & 1 & $14 \%$ & $0 \%$ \\
\hline 24 & Lumber and wood products & 283 & $4 \%$ & 25 & $9 \%$ & $3 \%$ \\
\hline 25 & Furniture and fixtures & 39 & $1 \%$ & 5 & $13 \%$ & $1 \%$ \\
\hline 26 & Paper and allied products & 982 & $15 \%$ & 138 & $14 \%$ & $15 \%$ \\
\hline 27 & Printing and publishing & 90 & $1 \%$ & 11 & $12 \%$ & $1 \%$ \\
\hline 28 & Chemicals and allied products & 1351 & $20 \%$ & 218 & $16 \%$ & $23 \%$ \\
\hline 29 & Petroleum and coal products & 0 & $0 \%$ & 0 & $0 \%$ & $0 \%$ \\
\hline 30 & Rubber and misc. plastics products & 580 & $9 \%$ & 86 & $15 \%$ & $9 \%$ \\
\hline 31 & Leather and leather products & 7 & $0 \%$ & 1 & $12 \%$ & $0 \%$ \\
\hline 32 & Stone, clay, and glass products & 26 & $0 \%$ & 4 & $15 \%$ & $0 \%$ \\
\hline 33 & Primary metal industries & 1373 & $21 \%$ & 163 & $12 \%$ & $18 \%$ \\
\hline 34 & Fabricated metal products & 107 & $2 \%$ & 17 & $16 \%$ & $2 \%$ \\
\hline 35 & Industrial machinery and equipment & 161 & $2 \%$ & 25 & $15 \%$ & $3 \%$ \\
\hline 36 & Electronic and other electric equipment & 179 & $3 \%$ & 41 & $23 \%$ & $4 \%$ \\
\hline 37 & Transportation equipment & 289 & $4 \%$ & 43 & $15 \%$ & $5 \%$ \\
\hline 38 & Instruments and related products & 45 & $1 \%$ & 6 & $13 \%$ & $1 \%$ \\
\hline 39 & Miscellaneous manufacturing industries & 27 & $0 \%$ & 4 & $15 \%$ & $0 \%$ \\
\hline & Total & 6693 & $100 \%$ & 930 & $14 \%$ & $100 \%$ \\
\hline
\end{tabular}

Potential savings are calculated at $930 \mathrm{GWh}$, or $14 \%$ of motor system electrical use. This is equivalent to $3.2 \mathrm{TBtu}$. Comparing this to the total electrical use by industry (Table 3-1), the potential savings from motor and drive system improvements is $6 \%$ of total industrial electrical use. (Motor use represents $43 \%$ of total industrial electrical use.) Multiplying the savings by $5 \phi / \mathrm{kWh}$ gives savings of $\$ 46$ million per year. This value is higher than could be expected, both because industry typically pays less for electricity than residential or commercial sectors, and because this is potential savings, only a fraction of which can be expected to be implemented. The four industries with the largest potential for savings are Food, Paper, Chemicals, and Primary Metals. Combined they represent $71 \%$ of the potential savings in the state. Any savings programs may choose to focus on these industries. 


\section{Summary}

The purpose of this study was to explore the potential for energy savings in the state of Iowa. Several methods for determining savings were examined, including monitoring results of existing programs, surveys of technology and end-uses, savings calculators using databases of previously compiled information, and economic simulators. Each method has advantages and disadvantages, trading off between detail of information, accuracy of results, and scope. This paper concentrated on using economic simulation (the NEMS model) to determine market potential for energy savings for the residential and commercial sectors. The results of surveys were used to calculate the economic potential for savings in the industrial sector.

The NEMS model is used by the Energy Information Administration to calculate twenty year projections of energy use for every region of the country. The results of the Annual Energy Outlook 2000 were used as the Base case. Two alternative cases were used to simulate energy savings policies. Market-related programs were simulated by lowering the effective discount rates that end-users use when making decisions on equipment purchases. Standards programs in the Residential sector were simulated by eliminating the availability of low efficiency equipment in future years. The values for these programs were based on the Moderate scenario assumptions from the DOE Clean Energy Futures study. This scenario was based on analyses of a number of residential and commercial programs across the country. It assumed increased concern by society on energy efficiency but not to the point of fiscal policies such as taxes or direct subsidies.

The Residential sector's market potential for electrical energy savings was calculated to be $5.3 \%$ of expected electrical use, representing $850 \mathrm{GWh}$ by 2020 . Natural gas savings could be $2.4 \%$ of expected gas use, representing 2.1 trillion Btus. Using expected prices for energy in that year, these represent savings of $\$ 47$ million and $\$ 12$ million per year.

The Commercial sector's market potential for electrical energy savings was calculated to be $5.1 \%$ of its total expected electrical use, representing $605 \mathrm{GWh}$ of power by 2020. Natural gas savings were 2.3 trillion Btu, $3.7 \%$ of use. At the same prices as the residential sector $(5.5 \notin / \mathrm{kWh}$ and $\$ 5.74 / \mathrm{MBtu})$ the savings represent $\$ 33$ million and $\$ 13$ million per year, respectively.

Instead of performing a market simulation of the Industrial sector, a survey of potential savings from motor drive system improvements was used to calculate the economic potential savings. It found that motor systems are roughly $40 \%$ of electrical use within the industrial sector, and that $14 \%$ of this amount could be saved. This represents possible savings of 930 $\mathrm{GWh}$, or $\$ 46$ million per year at $5 ф / \mathrm{kWh}$.

In all three sectors only some of the potential savings were examined. For example, lighting and building envelope improvements in the residential sector, efficiency standards in commercial equipment, and distributed energy resources in the industrial sector were not examined. Expansion of studies into these areas may be useful in the future. Also, the growth of miscellaneous other energy uses such as electronics makes these a significant fraction of future demands and may warrant further investigation. Energy savings programs specific to these uses (such as Energy Star) may be helpful in slowing their growth. 
Overall, there is a good potential for saving at least $5 \%$ of energy use in Iowa through a combination of market programs and standards, representing over $\$ 100$ million savings per year. With the recent rise in energy costs, state residences and businesses have even greater incentive to save. Active state and utility programs should be able to achieve well over this amount, especially if applied to broader savings measures beyond just those studied here. 


\section{References}

Department of Commerce, 1996, Annual Survey of Manufacturers Geographic Area Statistics, M96(AS)-3, Washington DC.

EIA (Energy Information Administration) 1997, State Energy Data Report 1997, Consumption Estimates, DOE/EIA-0214(97),

EIA 1998, A Look at Commercial Buildings in 1995: Characteristics, Energy Consumption, and Energy Expenditures, DOE/EIA-625(95), U.S. Department of Energy, Washington, DC, November. http://www.eia.doe.gov/emeu/cbecs/cbecs95/index.html.

EIA 1999, A Look at Residential Energy Consumption in 1997, DOE/EIA-632(97), U.S. Department of Energy, Washington, DC, November. http://www.eia.doe.gov/emeu/recs/rescs97/index.html.

Dunn, Gordon 1999, Report on the Iowa Energy Efficiency Database - Part 3:Electric Energy Efficiency Programs - Potential Demand and Energy Savings, Iowa Utilities Board, Policy Development Section, December.

EIA 1999a, Annual Energy Outlook 2000: With Projections to 2020, DOE/EIA-0383 (00) Washington, DC: U.S. Department of Energy, December.

EIA 2000, Annual Energy Outlook 2001: With Projections to 2020, DOE/EIA-0383 (01) Washington, DC: U.S. Department of Energy, December.

EIA 2000a, National Energy Modeling System: An Overview 2000, DOE/EIA-0581 (2000) Washington, DC: U.S. Department of Energy, March.

Interlaboratory Working Group, 2000, Scenarios for a Clean Energy Future (Oak Ridge, TN; Oak Ridge National Laboratory and Berkeley, CA; Lawrence Berkeley National Laboratory), ORNL/CON-476 and LBNL-44029, November. http://www.ornl.gov/ORNL/Energy_Eff/CEF.htm

Iowa Department of Natural Resources-Energy Bureau 2000, Energy Programs, http://www.state.ia.us/dnr/energy/programs/index.htm.

LBL (Lawrence Berkeley Laboratory) 2000, Home Energy Save website, Livermore, CA, http://hes.lbl.gov/hes/vh.html.

McElhaney, K. L., Jallouk, P. A., 1999, State-by-State Estimated Potential Energy Savings Achievable from Implementation of Efficiency Measures and Practices Identified by the DOE Motor Challenge Program (draft), Oak Ridge National Laboratory, January. 
ORNL 1998, State Energy Program (SEP) Building Energy Projection Module, (draft), Oak Ridge National Laboratory.

Xenergy, Inc. 1998. United States Industrial Electric Motor Systems Market Opportunity Assessment, Burlington, MA, December, http://www.oit.doe.gov/bestpractices/explore library/pdfs/mtrmkt.pdf. 


\section{Appendix: Buildings implementation pathways from the Clean Energy Futures study}

Below is an excerpt from Chapter $4^{1}$ of the Clean Energy Futures report (Interlaboratory Working Group 2000). It explains the rationale behind the policy options studied in the report related to buildings technologies. It gives details on the policies modeled, first describing the barriers to adoption of energy efficiency, then describing the policies modeled and how they respond to the identified barriers. Lastly, the excerpt describes how these policies were modeled in the version of NEMS used by the study.

As mentioned in the body of this study on Iowa, only a portion of the policies identified in the CEF were used. Most notably, the CEF had two policy scenarios beyond the Business-As-Usual scenario: the Moderate and Advanced. The Iowa study only used policies from the Moderate Scenario. Some of the discussion on the Advanced scenario was removed from the excerpt below.

\section{Policy implementation pathways}

Students of end-use markets have long been puzzled by the lack of adoption of ostensibly costeffective energy efficiency technologies. A rich literature has developed around this question, and analyses of various barriers to adoption of efficiency technologies are widespread (DeCanio, 1993; DeCanio, 1998; Fisher and Rothkopf, 1989; Golove and Eto, 1996; Hirst and Brown, 1990; Howarth and Andersson, 1993; Jaffe and Stavins, 1994; Koomey, 1990; Koomey et al., 1996; Lovins, 1992; NPPC, 1989; Oster and Quigley, 1977; Sanstad and Howarth, 1994; Sanstad et al., 1993). Various policies have been implemented over the past twenty years to ameliorate or sidestep these barriers, and we develop our policy pathways based on that program experience supplemented by professional judgment. We develop both moderate and advanced pathways, as discussed below.

\subsection{Barriers to Adoption of Cost-Effective Efficiency Technologies}

The barriers that inhibit adoption of cost-effective technologies can be broken down into those faced by users, and those faced by manufacturers, builders, designers and suppliers of efficient products.

\subsubsection{Barriers faced by energy users}

Organizations and individuals face a variety of complex barriers to choosing the most costeffective efficiency option, which vary by user, technology, and end-use ${ }^{2}$. The list below is not comprehensive but illustrative of the kinds of constraints that users face. Each particular

\footnotetext{
${ }^{1}$ Authors: Jonathan G. Koomey, Carrie A. Webber, and Celina S. Atkinson, Lawrence Berkeley National Laboratory (LBNL); Andrew Nicholls and Brad Holloman, Pacific Northwest National Laboratory (PNNL).

${ }^{2}$ For a review of many of these reasons, see Stephen DeCanio, "Why do profitable energy-saving investment projects languish?" Journal of General Management, Vol. 20, No. 1 (Autumn 1994):62-71, and "Barriers within firms to energy-efficient investments," Energy Policy (September 1993): 906-914 .
} 
transaction is affected by different barriers, and this complexity has made it difficult for researchers to assess the effect of these barriers in a comprehensive way.

Not knowing. It is impossible for a utility customer, even one who carefully reads her bills, to determine the contribution of various appliances to the total bill (the bills do not separate the cost for lighting from that for refrigeration or cooking). Attaching individual electricity meters to particular appliances is extremely rare, so that the consumer finds herself in a "supermarket without prices:" the user collects all the purchases in their shopping cart and gets one lump-sum bill to pay at the end of the month, with no separate accounting. No consumer can optimize when she doesn't know the price of purchasing a service.

Universal metering by appliance is unlikely to come about any time soon, but the ENERGY STAR label and wide distribution of energy information can help ameliorate this problem. Efficiency standards also mitigate this problem to some degree. As information and metering technologies become more widespread, this problem will become less important, but it will be many years before these technologies will have a significant effect on ameliorating this barrier.

Not caring. In most cases, energy is a small part of the cost of owning and operating a device or building, so the potential energy savings will not "make or break" the firm or make a family rich $^{3}$. For example, before the advent of the ENERGY STAR television (TV) program, typical TVs with remote controls used 5 to 7 watts when turned off because a small amount of standby power is necessary to turn the TV on. TVs that qualify for ENERGY STAR must achieve standby power of three watts or less, a savings of roughly 50\%. About ten major manufacturers now offer such TVs. When Sony examined their TV models, the company was able to reduce their standby power from 7-8 watts to about 0.6 watts. While a large savings in percentage terms, even this $90+\%$ reduction will only save about $\$ 5$ per year per TV. If implemented for all TVs across the U.S., the total savings would be hundreds of millions of dollars per year, but the cost per TV is so low that it would be hard to imagine consumers lobbying TV manufacturers to reduce the standby power of their units.

Since energy costs are typically small on an individual basis, it is easy (and rational) for consumers to ignore them in the face of information gathering and transaction costs. However, the potential energy, dollar, and emissions savings can be important when summed across all consumers, which is why government agencies like EPA and DOE work directly with manufacturers to improve the efficiency of their products. A little work to influence the source of mass-produced products can pay off in significant efficiency improvements and emissions reduction that rapidly propagate through the economy due to mass production and distribution. These programs eliminate the information and transaction costs that impede adoption of efficiency technologies without the program.

Unable to find out. Wise purchases are based on reliable and easily accessible information. Determining which energy efficient products are cost-effective and reliable is not a trivial task. Consumers and managers have limited time and attention, and they are not generally energy experts, so it's difficult for them to separate the winners from the losers. While these costs are a

\footnotetext{
${ }^{3}$ Of course, for low-income families, the cost of energy can be a very significant part of their income. In this case, capital constraints and information are more important barriers to promoting energy efficiency than "not caring".
} 
normal part of markets, they can be reduced or eliminated by centralized information collection and dissemination by a credible source (such as EPA, DOE, non-profit organizations, state energy offices, Consumer Reports, or electric utilities).

Can't raise the money. Many consumers and industries face capital constraints in pursuing those energy efficiency improvements that require additional incremental investment. These constraints surface as short payback time requirements for investments (2-3 years), or an inability to even consider investing due to lack of money. Creating attractive financing options that improve the consumer's monthly cash flow is one strategy that has proven successful in promoting the EPA's ENERGY STAR new homes program to builders and consumers.

Split incentives. Whenever the purchaser or operator of an appliance is not the same person who pays for the electricity, the incentive for considering efficiency can be diluted or eliminated. Landlords who pay the energy bills have no control over their tenants' energy use. Alternatively, if tenants pay the bills, then landlords will likely invest in improving energy efficiency only if it will improve tenant retention, justify higher rents, or increase the value of the property upon resale. For these latter conditions to hold there needs to be an objective way to measure the energy efficiency of a building, a situation that only exists in the few jurisdictions where home energy ratings are commonplace, and is rarer still in commercial buildings. Split incentives are particularly difficult to ameliorate, but minimum efficiency standards have been effective in counteracting them. In residential buildings, about one-third of all households rent. About $90 \%$ of all multifamily households rent, which makes this barrier particularly important in this segment of the market.

\subsubsection{Barriers faced by manufacturers, builders, designers, and suppliers}

Energy-aware consumers may never even be offered energy-efficient products if manufacturers choose not to produce them, so it's important to understand the barriers manufacturers face in producing such goods. By the same token, a lack of consumer demand can also inhibit manufacturers from incorporating more efficiency into their products (If the customers don't ask for it, why deliver it?). This lack of demand can be a direct result of the long list of consumer barriers reviewed above. This "chicken and egg" problem is one that can be influenced by policies.

Reluctance to change. An important barrier is inertia. If a TV's power supply has worked well for ten or twenty years, why "rock the boat" with a new design, especially when the public is not clamoring for change? The introduction of ENERGY STAR, however, created a different dynamic. The marketing advantage of having a "green" product is brought to the attention of the marketing branch of the corporation, and these marketers become the advocates within that company for design changes that will make their jobs easier. As long as the new technology is at least as reliable and capable as that it replaces (and there's no reason why it shouldn't be) then the ENERGY STAR method for removing barriers can work well. In fact, reexamining time-honored choices about product design usually leads to increased product functionality and cost savings as well. 
Inability to capture all benefits of research and development. If a company spends money on research and development (R\&D) to create new products, they can reap some, but not all of the benefits from such innovation. As soon as the company creates a new product, competitors can copy those designs, without having to spend their own money on R\&D. This situation leads to under-investment in R\&D from society's perspective, which is the main justification for government sponsored R\&D. This problem afflicts all sectors of the economy, and it is widely recognized by economists and public policy analysts around the world.

The problem is especially pronounced when an industry is as fragmented as the design and construction industries (Brambley et al. 1988). Oster and Quigley (1977), discussing R\&D in the residential construction industry, state that

"Small scale may be particularly problematic if many of the potential innovations in the industry are in organization, systems design, and in the integration of housing components. Here the minimum efficient scale for R\&D activity is presumably rather large, and, more importantly, the returns to R\&D are not easily captured by a single firm."

Fragmentation of the industry is also a problem in the commercial buildings sector, with the design and engineering of buildings split between many small design firms.

In addition, there is a longer-term public-purpose aspect to R\&D. Certain kinds of long-term basic and applied research is unlikely to be funded by industry, because the payoff will be so far into the future. Government R\&D can and does focus on many technologies that will not be cost effective for years, yet may be strategically important decades hence. Historical support for fuel cells and photovoltaics falls into this category.

Design and production cycles. Product design cycles can also slow the pace of innovation. Until a product has "run its course" and repaid the initial investment, most manufacturers are justifiably reluctant to modify production lines. These cycles have become shorter and shorter in recent years due to the growing impact of information technology, but they can be important in particular instances. By working with manufacturers to accommodate their design cycles, EPA has successfully encouraged dozens of them to incorporate efficiency into their next product cycle, while minimizing any transition costs for altering products.

Perverse fee structures. Lovins (1992) describes how typical fee structures for engineers and architects penalize efficiency. Lovins interviewed more than fifty design professionals and analysts of the design process, and documented a market rife with inefficiency and "perverse" incentives. These inefficiencies are driven mainly by the difficulty of creating optimized, custom-built buildings systems in the face of persistent institutional failures.

Lovins analyzes the prevailing fee structures of building design engineers, which are explicitly or implicitly based on a percentage of the capital cost of the project. The reason why fee structures like this one are pernicious is because good design for heating, ventilation, and air-conditioning (HVAC) systems will allow substantial reductions in capital costs and operating costs. Such design requires additional expenditures beyond the typical "rule-of-thumb" equipment sizing that most engineers do, which results in a net penalty for designers of efficient systems: 
"Designers who do extra work to design and size innovative HVAC systems exactly right, thereby cutting their client's capital and operating costs, are directly penalized by lower fees and profits as a result, in two different ways: they are getting the same percentage of a smaller cost, and they are doing more work for that smaller fee, hence incurring higher costs and retaining less profit (Lovins, 1992)."

The innovation stifling effects of such fee structures are reinforced by the obligations of professionals, as codified in law. Burnette (1979a, 1979b) points out that the judgement of a particular professional "need not be infallible, just reasonable within the norms established by the judgements and practices of other qualified professionals." Such a standard (and associated litigation) "leads to defensive design and institutionalized conformity" (Lovins, 1992). Use of inaccurate rules of thumb regarding equipment sizing 4 , as well as those related to setting fees, are both expressions of that conformity.

Lovins shows how, even though this type of fee structure has been strongly discouraged in the U.S. since the early 1970s (through the threat of anti-trust action against the professional associations), the practice has been eliminated in name only: "both the designer and procurer of design services still generally base their fee negotiation on percentage-of-cost curves, just as if nothing had changed. In low-rise office projects, for example, $70 \%$ of U.S. designers estimate their fees as a percentage of project cost, even though only $15 \%$ bid them in that form; for lowrise hotels, $100 \%$ vs. 50\%; for apartments, $50 \%$ vs. $5 \%$."

\subsection{Policies to Remove Barriers}

Policies to remove barriers and reduce energy costs, energy use, and carbon emissions in buildings fall into nine general categories: voluntary programs, building efficiency standards, equipment efficiency standards, state market transformation programs, financing, government procurement, tax credits, accelerated $R \& D$, and carbon trading systems. Each policy may affect residential buildings, commercial buildings or both, and each ameliorates specific market barriers that inhibit the adoption of cost-effective efficiency improvements. Tables A-1 and A-2 (below) summarize which barriers and end-uses (respectively) can be affected by each policy. Not all policies discussed here are used in our scenarios.

Voluntary Programs. Major voluntary buildings-sector programs in the U.S. include the ENERGY STAR programs operated by EPA and DOE, and the Building America and Rebuild America programs run by DOE. Programs exist for both residential and commercial products and buildings. The ENERGY STAR product programs are structured as labeling programs. Identifying high efficiency products for consumers is only one aspect of the program, however. The programs has also been effective in working with manufacturers to convince them to promote existing and develop new energy-efficient products.

ENERGY STAR's residential programs are all structured as labeling programs, even the ENERGY STAR new homes program for residential buildings. In this program, EPA works with builders to increase the construction of high efficiency homes, which can then be marketed using the

\footnotetext{
${ }^{4}$ Since HVAC systems are typically oversized by factors of two and three, these rules of thumb (coincidentally or not) increase the designers profits because of fee structures based on the capital costs of the project.
} 
ENERGY STAR label. Residential products covered by ENERGY STAR programs include residential HVAC equipment, insulation, windows, residential lighting fixtures, clothes washers, dishwashers, room air conditioners, refrigerators, televisions, VCRs, home audio equipment, and home computers. Future product programs may include other consumer electronics and water heaters. Also in development is a program aimed at existing homes.

Table A-1 Carbon Mitigation Policies and Which Barriers They Can Affect

\begin{tabular}{|c|c|c|c|c|c|c|c|c|c|}
\hline \multirow[t]{2}{*}{ Barrier } & \multicolumn{9}{|c|}{ Policy Type } \\
\hline & 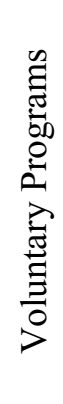 & 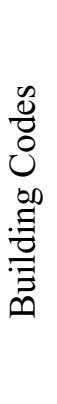 & 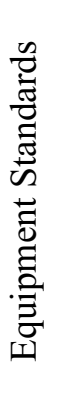 & 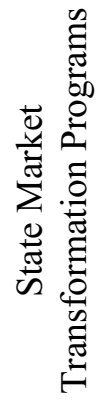 & 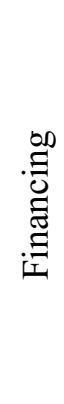 & 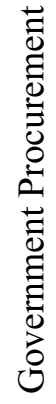 & 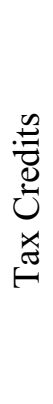 & 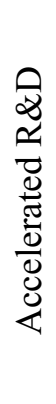 & 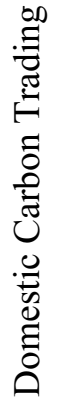 \\
\hline SCENARIO & B & $\mathrm{B}$ & B & B & $\mathrm{B}$ & $\mathrm{B}$ & $\mathrm{B}$ & $\mathrm{B}$ & A \\
\hline \multicolumn{10}{|l|}{ Barriers faced by users } \\
\hline Not knowing & $X$ & $X$ & $X$ & $\mathrm{X}$ & & & $X$ & & \\
\hline Not caring & $\mathrm{X}$ & $X$ & $\mathrm{X}$ & $\mathrm{X}$ & & & & & \\
\hline Unable to find out & $\mathrm{X}$ & $\mathrm{X}$ & $\mathrm{X}$ & $\mathrm{X}$ & & & $\mathrm{X}$ & & \\
\hline $\begin{array}{r}\text { Can't raise the money } \\
\text { Split incentives }\end{array}$ & & & & $\mathrm{X}$ & $\mathrm{X}$ & & $\mathrm{X}$ & & \\
\hline \multicolumn{10}{|l|}{$\begin{array}{l}\text { Barriers faced by manufacturers, } \\
\text { builders, designers, \& product } \\
\text { suppliers }\end{array}$} \\
\hline Reluctance to change & $\mathrm{X}$ & $\mathrm{X}$ & $\mathrm{X}$ & & & $\mathrm{X}$ & & & $\mathrm{X}$ \\
\hline $\begin{array}{r}\text { Inability to capture all benefits of } \\
\text { R\&D }\end{array}$ & & & & & & & & $\mathrm{X}$ & \\
\hline Design and production cycles & $\mathrm{X}$ & & & & & & & $\mathrm{X}$ & \\
\hline Perverse fee structures & & & & & $\mathrm{X}$ & & $\mathrm{X}$ & & \\
\hline
\end{tabular}

(1) "B" under scenario signifies "both," "M" signifies Moderate Scenario only, "A" signifies Advanced Scenario only. 


\section{Table A-2 Carbon Mitigation Policies and Which End-Uses and Technologies They Can Affect}

\begin{tabular}{|c|c|c|c|c|c|c|c|c|c|}
\hline \multirow[t]{2}{*}{ End-Use/Technology } & \multicolumn{9}{|c|}{ Policy Type } \\
\hline & 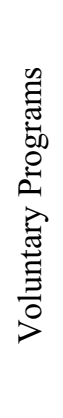 & $\begin{array}{l}\frac{0}{0} \\
0 \\
0 \\
: 00 \\
: 0 \\
: 0 \\
0 \\
0\end{array}$ & 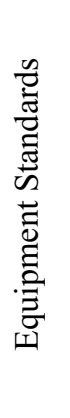 & 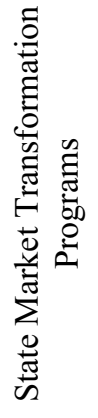 & $\begin{array}{l}\text { D0 } \\
\text { : } \\
\text { E్ } \\
\text { : }\end{array}$ & 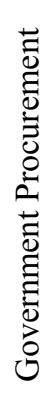 & 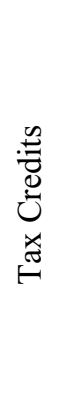 & 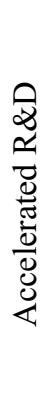 & 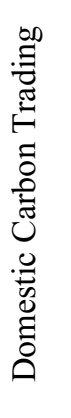 \\
\hline SCENARIO & B & $\mathrm{B}$ & B & B & $\mathrm{B}$ & $\mathrm{B}$ & B & B & A \\
\hline Thermal Shell-Res. Retrofits & $\mathrm{X}$ & $\mathrm{X}$ & & $\mathrm{X}$ & $\mathrm{X}$ & $\mathrm{X}$ & $\mathrm{X}$ & $\mathrm{X}$ & $\mathrm{X}$ \\
\hline Thermal Shell-Res. New & $\mathrm{X}$ & $\mathrm{X}$ & & $\mathrm{X}$ & $\mathrm{X}$ & & $\mathrm{X}$ & $\mathrm{X}$ & $\mathrm{X}$ \\
\hline Thermal Shell-Comml Retrofits & $\mathrm{X}$ & $\mathrm{X}$ & & & $\mathrm{X}$ & & $\mathrm{X}$ & $\mathrm{X}$ & $\mathrm{X}$ \\
\hline Thermal Shell-Comml New & $\mathrm{X}$ & $\mathrm{X}$ & & & $\mathrm{X}$ & & $\mathrm{X}$ & $\mathrm{X}$ & $\mathrm{X}$ \\
\hline Residential HVAC equipment & $\mathrm{X}$ & & $\mathrm{X}$ & $\mathrm{X}$ & $\mathrm{X}$ & & $\mathrm{X}$ & $\mathrm{X}$ & $\mathrm{X}$ \\
\hline Commercial HVAC equipment & $\mathrm{X}$ & $\mathrm{X}$ & $\mathrm{X}$ & $\mathrm{X}$ & $\mathrm{X}$ & $\mathrm{X}$ & $\mathrm{X}$ & $\mathrm{X}$ & $\mathrm{X}$ \\
\hline Residential Ducts & & & & $\mathrm{X}$ & $\mathrm{X}$ & & $\mathrm{X}$ & $\mathrm{X}$ & $\mathrm{X}$ \\
\hline Commercial Ducts & & & & & $\mathrm{X}$ & & $\mathrm{X}$ & $\mathrm{X}$ & $\mathrm{X}$ \\
\hline Residential Water Heating & $\mathrm{X}$ & & $\mathrm{X}$ & $\mathrm{X}$ & $\mathrm{X}$ & & $\mathrm{X}$ & $\mathrm{X}$ & $\mathrm{X}$ \\
\hline Commercial Water Heating & $\mathrm{X}$ & $\mathrm{X}$ & $\mathrm{X}$ & & $\mathrm{X}$ & $\mathrm{X}$ & $\mathrm{X}$ & $\mathrm{X}$ & $\mathrm{X}$ \\
\hline Residential Refrigeration & $\mathrm{X}$ & & $\mathrm{X}$ & $\mathrm{X}$ & & & & $\mathrm{X}$ & $\mathrm{X}$ \\
\hline Commercial Refrigeration & $\mathrm{X}$ & $\mathrm{X}$ & & $\mathrm{X}$ & & $\mathrm{X}$ & & $\mathrm{X}$ & $\mathrm{X}$ \\
\hline Cooking Equipment & & & $\mathrm{X}$ & & & & & $\mathrm{X}$ & $\mathrm{X}$ \\
\hline Laundry & $\mathrm{X}$ & & $\mathrm{X}$ & $\mathrm{X}$ & & & & $\mathrm{X}$ & $\mathrm{X}$ \\
\hline Dishwashers & $\mathrm{X}$ & & $\mathrm{X}$ & & & & & $\mathrm{X}$ & $\mathrm{X}$ \\
\hline Residential Lighting & $\mathrm{X}$ & & & $\mathrm{X}$ & & & & $\mathrm{X}$ & $\mathrm{X}$ \\
\hline Commercial Lighting & $\mathrm{X}$ & $\mathrm{X}$ & $\mathrm{X}$ & $\mathrm{X}$ & & $\mathrm{X}$ & & $\mathrm{X}$ & $\mathrm{X}$ \\
\hline Televisions & $\mathrm{X}$ & & & & & & & & $\mathrm{X}$ \\
\hline PCs & $\mathrm{X}$ & & & & & $\mathrm{X}$ & & & $\mathrm{X}$ \\
\hline Office Equipment (not PCs) & $\mathrm{X}$ & & & & & $\mathrm{X}$ & & & $\mathrm{X}$ \\
\hline Motors & $\mathrm{X}$ & $\mathrm{X}$ & $\mathrm{X}$ & $\mathrm{X}$ & & $\mathrm{X}$ & & $\mathrm{X}$ & $\mathrm{X}$ \\
\hline Transformers & $\mathrm{X}$ & & $\mathrm{X}$ & & & & & $\mathrm{X}$ & $\mathrm{X}$ \\
\hline Water Conservation Measures & & $X$ & $\mathrm{X}$ & & & & $\mathrm{X}$ & & $\mathrm{X}$ \\
\hline Residential Miscellaneous & $\mathrm{X}$ & & & $\mathrm{X}$ & & & & $\mathrm{X}$ & $\mathrm{X}$ \\
\hline Commercial Miscellaneous & $\mathrm{X}$ & & $\mathrm{X}$ & $\mathrm{X}$ & & $\mathrm{X}$ & & $\mathrm{X}$ & $\mathrm{X}$ \\
\hline $\begin{array}{l}\text { District Energy Systems with } \\
\text { Combined Heat and Power }\end{array}$ & & & & $\mathrm{X}$ & & $\mathrm{X}$ & $\mathrm{X}$ & $\mathrm{X}$ & $\mathrm{X}$ \\
\hline Fuel cells & & & & $\mathrm{X}$ & & $\mathrm{X}$ & $\mathrm{X}$ & $\mathrm{X}$ & $\mathrm{X}$ \\
\hline
\end{tabular}

(1) "B" under scenario signifies "both", "M" signifies Moderate Scenario only, "A" signifies Advanced Scenario only.

(2) Fuel cells, district energy systems, shell retrofits, and state market transformation programs for new residential shells are not included in current scenarios.

Commercial products covered by the ENERGY STAR labeling programs include PCs, monitors, copiers, printers, fax machines, multi-function devices, exit signs and transformers. Some commercial sector ENERGY STAR programs operate differently from equipment labeling 
programs, relying on high level corporate commitments and public recognition of participating corporations to promote cost-effective efficiency investments. The commitment of the chief executive of a company to these programs allows program champions within the organization to beat back institutional inertia and cut through red tape to make these investments happen. ENERGY STAR's commercial buildings programs are the ENERGY STAR Building program and the ENERGY STAR Small Business program, which focus on improving the energy efficiency of existing buildings by working with and educating building managers and business owners.

The DOE's Building America program is a private/public partnership that applies a systemsengineering approach to the design and construction of production housing. The goals of the partnership include producing homes on a community scale that use $30 \%$ to $50 \%$ less energy than those built to code at no incremental cost, reducing construction time and waste by as much as $50 \%$, and improving builder productivity. The systems engineering approach considers the interaction between the building site, envelope, and mechanical systems, as well as other factors. It recognizes that features of one component in the house can greatly affect others and it enables the teams to incorporate energy-saving strategies at no extra first cost.

Rebuild America is a voluntary program that stimulates energy efficiency upgrades in existing commercial buildings, new education buildings, and existing high rise residential buildings. DOE supplies technical support and State Energy Offices supply limited financial support. Its goal is to reduce energy use and bills in such buildings by $20-30 \%$.

Building Codes. The most important efficiency code for new low-rise residential buildings is the International Code Council's Model Energy Code, which is periodically reviewed and updated. In residential buildings, the focus is primarily on the building shell, although codes may also affect HVAC equipment and lighting.

The most important energy conservation standard for new high-rise residential and commercial buildings is that issued by the American Society of Heating, Refrigerating and Air-Conditioning Engineers (ASHRAE) and by the Illuminating Engineering Society of North America (IESNA). In the summer and fall of 1999, these organizations approved a new standard for commercial and high-rise residential buildings, ASHRAE/IESNA Standard 90.1-1999. This standard, which will be published in February 2000, will then be available for adoption by federal, state and local government agencies into building codes. Standard 90.1-1999 is an update of the previous Standard, ASHRAE/IESNA Standard 90.1-1989, (issued in 1989), and will produce substantial savings relative to it, according to ASHRAE.

In our analysis, however, our "baseline" energy standard is the 1989 version, the operative commercial building standard available to us while this report was being written. (ASHRAE issued final approval of the 1999 version in late October 1999). The 1989 standard is referenced in the Energy Policy Act of 1992, which directs the states to demonstrate that its commercial energy codes meet or exceed ASHRAE Standard 90.1-1989.

For the Moderate and Advanced scenarios, we developed an altogether different commercial standard to capture the energy savings potential inherent in commercial building standards. We didn't use ASHRAE/IESNA 90.1-1999, because most of its energy savings potential, which is in 
lighting, will be captured first by another policy instrument, namely the promulgation of minimum efficiency standards for fluorescent ballasts in 2004 (as we assume in our Moderate and Advanced scenarios). ${ }^{5}$ Instead, we assume in our Moderate and Advanced scenarios that a new commercial standard is developed and adopted that features a 15\% "whole building" reduction target. This standard, by design, is not prescriptive, and allows builders and designers maximum flexibility in reaching the target. Advances in handheld computer technology will facilitate adoption of and compliance with this new standard.

Equipment Standards. Equipment standards require that all new equipment sold meet minimum energy-efficiency standards. Water conservation measures, such as low-flow showerheads and faucets, are also considered since they reduce water-heating energy. The appliance standards considered here are based on three pieces of legislation: the National Appliance Energy Conservation Act of 1987 (NAECA), which addresses primarily residential appliances, the 1988 amendments to NAECA, which address magnetic fluorescent ballasts, and the Energy Policy Act of 1992 (EPACT), which primarily addresses commercial products.

In the residential sector, NAECA standards are currently in place for residential refrigerators and freezers, water heaters (gas, oil and electric), clothes washers, clothes dryers, dishwashers, heat pumps, central air conditioners, room air conditioners, furnaces (gas and oil), and boilers (gas and oil). EPACT set water conservation standards for showerheads and faucets that reduce residential hot water use. DOE periodically updates NAECA standards. Tighter standards are anticipated for residential clothes washers, water heaters, heat pumps and central air conditioners between 2000 and 2006, with some updates to follow in 2010 .

In the commercial sector, EPACT set standards for lamps (4- and 8-foot fluorescent lamps and incandescent reflector lamps), motors (1-200 horsepower), and commercial heating and cooling, including packaged air-cooled air conditioners and heat pumps, packaged water-cooled air conditioners and heat pumps, packaged terminal air conditioners and heat pumps, water heaters, furnaces and boilers. The showerhead and faucet standard also affects commercial hot water use. The only commercial products covered under NAECA, fluorescent lamp ballasts, currently are subject to a standard that prevents sales of the lower efficiency core-coil magnetic ballasts (highefficiency magnetic ballasts can still be sold). We assume in our scenarios that DOE will enact a revised standard for ballasts that takes effect in 2004.

\section{State Market Transformation Programs Funded Through "Public Benefits (Line or pipe)} Charges." State Market Transformation programs are quite diverse. As implemented in states that are experimenting with deregulation, they involve a small charge (1-2\%) on every $\mathrm{kWh}$ that is transmitted across the grid (they could also in principle be applied to natural gas as well). Payment of the charge would be a precondition for interconnecting with the grid. This money then goes into a fund to pay for energy efficiency and renewable technology implementation programs.

\footnotetext{
${ }^{5}$ In Fall 1999 (after the analysis for this study had been completed), efficiency advocates and ballast manufacturers negotiated an agreement that would result in an efficiency standard eliminating most U.S. magnetic ballast manufacturing by April 1, 2005 (except for ballasts manufactured as replacements for existing equipment), and eliminating all such manufacturing by July 1 , 2010. The U.S. Department of Energy accepted this negotiated agreement in its Congressionally mandated standards-setting process.
} 
Such programs can focus on new construction or on retrofits and replacements. State new construction programs can affect the thermal shell, HVAC, water heating and lighting, and may influence fuel choice for HVAC, water heating, cooking, and dryers. For existing homes, utilities have weatherization programs focusing on the building shell, rebates for high-efficiency HVAC, appliances and lighting. Rebates may also be used to subsidize fuel switching for hot water heating or conversion from electric resistance central furnaces to heat pumps.

Financing. An important subset of State Market Transformation Programs and some ENERGY STAR programs is special financing to spread the incremental investment costs over time and reduce the first cost impediment to adoption of energy efficient technologies. The ENERGY STAR new homes program, for example, already offers preferential financing that improves monthly cash-flow for purchasers of ENERGY STAR homes. These financing packages can apply to those end-uses that are structural parts of the building, like HVAC, thermal shell, and water heating.

In commercial buildings, Energy Savings Performance Contracting (ESPC) is another way to use creative financing to promote efficiency investments. In such contracts, an energy service company guarantees a fixed amount of energy cost savings throughout the life of the contract (typically 5 to 12 years, and up to 25 years for Federal government contracts) and is paid directly from those cost savings. The organization that owns the facility retains the remainder of the energy cost savings for itself.

Government Procurement. Procurement policies have the potential to accelerate the adoption of new technologies, and also directly save money for the government. Procurement can reduce costs for new technologies by allowing manufacturers to acquire production experience with them and hence "move down the learning curve". In 1997 the Federal Acquisition Regulations were amended, directing that "agencies shall implement cost-effective contracting preference programs favoring the acquisition of...products that are in the upper 25 percent of energy efficiency for all similar products" (FAR, sec. 23.704). In addition, EPA and DOE are currently working to encourage state and local governments to reform their own purchasing practices to encourage adoption of more energy efficient devices. Another program that falls under this general category is the Federal Low Income Weatherization Program, which improves the energy efficiency of qualifying residences. We treat procurement policies as a key enabling program (particularly for ENERGY STAR) that are implicit in the Moderate and Advanced Scenarios, but we do not explicitly estimate their effects.

Tax Credits. We consider the effect of tax credits for high-efficiency equipment, as described in President Clinton's Climate Change Technology Initiative. This initiative, first laid out in January 1998 and updated in Spring 1999, proposed tax incentives for efficient natural gas water heaters, electric central air conditioners, electric heat pumps, residential-sized heat-pump water heaters, and natural gas heat pumps. It also proposed tax credits for fuel cells, new homes with efficiencies that significantly exceed current building standards, rooftop photovoltaic systems, and solar water heating systems. 


\subsection{Definition of Pathways}

Our policy pathways combine many (but not all) of the policies discussed above in both Moderate and Advanced Scenarios. The Moderate Scenario presumes modest progress in implementing those policies and programs. The content of these scenarios [used in the Iowa study] is summarized in Table A-3.

Creating scenarios entails judgment. No one can forecast the future with certainty, and many of the relevant parameters are simply not known. We made judgments that we felt were plausible, based on the analysis teams' considerable experience in this area. Penetration rates in particular were usually developed in this manner, after reviewing the literature on experience with related programs and policies. We documented our assumptions in the appendices.

\section{Methodology for analyzing impacts}

We rely on a three-step process for creating our analysis: first, we assess the potential impact of individual policies on energy demand in detailed spreadsheets. Then we change hurdle rates (implicit discount rates) and other parameters inside the buildings sector modules of CEF-NEMS (our version of the National Energy Modeling System) so that the model mimics the energy savings calculated from the spreadsheets when these modules are run in stand-alone mode (equipment efficiency standards were implemented directly in the CEF-NEMS modules). This procedure follows that used in the earlier study by Koomey et al. (1998).

Table A-3 Buildings Sector Policies

\begin{tabular}{|l|l|}
\hline$>$ & $\begin{array}{l}\text { Expand voluntary labeling and deployment programs such as } \\
\text { ENERGY STAR, Building America, PATH, Rebuild America } \\
\text { to increase the penetration of efficient technologies in the } \\
\text { market and to raise the efficiency level for certain programs. }\end{array}$ \\
\hline$>$ & Increase enforcement and adoption of current building codes \\
$>$ & $\begin{array}{l}\text { Implement new efficiency standards for equipment beyond } \\
\text { those already planned. }\end{array}$ \\
\hline$>$ & Implement tax credits as proposed by Clinton Administration \\
\hline$>$ & $\begin{array}{l}\text { Government procurement assumed to increase in scope over } \\
\text { current efforts. Increase DOE's Federal Energy management } \\
\text { Program (FEMP) efficiency goals by executive order. Adopt } \\
\text { renewable power purchase requirement for Federal facilities. (1) }\end{array}$ \\
\hline
\end{tabular}

(1) Unlike other policies enumerated here, we do not explicitly model government procurement policy in this analysis. However, we recognize it here as an important and strategic enabling policy that is essential for the voluntary programs to achieve their estimated penetration levels. 


\title{
2.1 Overall Approach
}

The most challenging part of this analysis is estimating the impact of policies on the market penetration of technologies under our Moderate and Advanced scenarios over the next two decades. To accomplish this difficult task, we use our best qualitative judgment, based on our collective experience with buildings efficiency programs, because there is simply no "scientific" means for predicting the precise impacts of most policy measures.

With respect to research and development, for example, the predictive challenge is aptly captured by the President's Committee of Advisors on Science and Technology (PCAST) in their report, Federal Energy Research and Development for the Challenges of the Twenty-First Century (PCAST 1997). PCAST frames the challenges as follows:

\begin{abstract}
"how much can energy R\&D contribute to (national goals)... as a function of time and in relation to the sums invested? It is difficult, indeed impossible, to offer any precise answers to this question, not least because the answers depend strongly on the outcomes of R\&D (by the nature of such activity) which cannot be predicted in detail.” (page 1-16)
\end{abstract}

But while the precise prediction is not possible, the basic relationship between resources and outcomes is evident: "The evidence from all of these historical approaches supports the proposition that the leverage of R\&D, against the challenges facing the energy system, is likely to be large." (PCAST, page 1-17) And the empirical record of Federal buildings energy efficiency research is compelling, with development of a number of high-performance technologies, including low-emissivity window coatings, high-efficiency refrigerator compressors, and fluorescent lamp electronic ballasts, all of which are widespread products in today's marketplace.

With respect to predicting the future impacts of voluntary information programs on consumer choice, there is also great uncertainty. As a recent U.S. DOE report observes of information and education policies:

"...the ability of information programs to induce actual changes...depends on three factors: the extent to which the information is applicable to the decisions at hand and considered reliable, the extent to which the information identifies previously unknown cost-effective opportunities or positive product attributes, and the extent to which it is acted upon." (US DOE 1996, p. 3-17).

Establishing robust parameters for any one of those factors is challenging, but it is especially daunting to establish a firm causal link between the information provided, "and the extent to which it is acted upon."

Nonetheless, to illustrate the potential impacts of policies in the year 2015 such as advanced technology tax credits for heat pump water heaters, ENERGY STAR buildings, and accelerated research and development, one must make transparent, well-documented, and defensible assumptions about program impacts, and that is what we did. 


\subsection{Details of the Analysis of Policies Outside of CEF-NEMS}

Our spreadsheet analysis of the buildings sector relies for its basic structure on the spreadsheet analysis documented in the study Scenarios of U.S. Carbon Reductions: Potential Impacts of Energy Technologies by 2010 and Beyond (Interlaboratory Working Group 1997). We updated the spreadsheets to reflect some of the improvements in the NEMS Annual Energy Outlook forecast since that study was published, including detailed breakdowns of the residential and commercial miscellaneous end-uses, explicit accounting for halogen torchieres in lighting, and extension of the analysis period to 2020 .

The spreadsheets rely on careful stock accounting for buildings and equipment, and detailed characterizations of the technoeconomic potential for efficiency improvements by end-use, based on the latest technology data. Efficiency improvements are characterized in terms of the percentage savings that are cost effective relative to typical new equipment purchased in 2000, and a cost of conserved energy $(\$ / \mathrm{kWh}$ or $\$ / \mathrm{Mbtu})$ for purchasing those efficiency options.

The technology and program effectiveness data for the building sector relies on a huge variety of sources. We combine information from these sources with experience and judgment to create the policy scenarios.

The calculations are carried through for each technology at a low level of disaggregation. Estimated energy savings per unit for each appliance are multiplied by the number of efficient units expected to be shipped in a given year, accounting for expected program penetrations and retirements and growth in the number of households and floor area of commercial buildings. These savings are then aggregated over all the end-uses to estimate the total savings for a given fuel type in each scenario. Details on the assumptions and calculation methods are contained in Appendices B-1 and C-1 [of the Clean Energy Futures study (Interlaboratory Working Group 2000)]. Because of their importance to the overall results, we summarize equipment efficiency standards included in our scenarios in Table A-4.

In the real world, only some fraction of this technoeconomic potential can be captured with real programs and policies. The original interlaboratory analysis of buildings used overall achievable fractions of $35 \%$ and $65 \%$ for the efficiency and high-efficiency/low carbon cases, respectively, implying that $35 \%$ or $65 \%$ of the technoeconomic potential could be captured in practice by 2010. In this analysis, we derive these implementation fractions by end-use by explicitly characterizing the pathways for specific policies. We also derive a program implementation cost, based on recent program experience. These key data are summarized in Table A-5. The details of these calculations are contained in Appendices B-1 and C-1, and an end-use by end-use breakdown of these results is shown in Appendix D-1 [of the Clean Energy Futures study (Interlaboratory Working Group 2000)].

The achievable fractions in 2010 for residential and commercial buildings are about one-quarter in the Moderate Scenario. By 2020, as a result of stock turnover and advances in technology brought about by policies and programs, the achievable fraction goes up to around forty percent in the Moderate Scenario. 
Table A-4 Summary of New Equipment Efficiency Standards by Scenario

\begin{tabular}{|c|c|c|c|c|c|c|}
\hline Sector & Equipment type & Year & $\begin{array}{c}\text { Efficiency/ } \\
\text { Energy } \\
\text { units }\end{array}$ & $\begin{array}{l}\text { Baseline } \\
\text { efficiency }\end{array}$ & $\begin{array}{l}\text { Standard } \\
\text { efficiency }\end{array}$ & Scenario \\
\hline \multirow[t]{6}{*}{ Residential } & $\begin{array}{c}\text { CAC } \\
\text { ASHP heating } \\
\text { ASHP cooling } \\
\text { RAC } \\
\text { RAC }\end{array}$ & $\begin{array}{l}2006 \\
2006 \\
2006 \\
2001 \\
2010\end{array}$ & $\begin{array}{c}\text { SEER } \\
\text { HSPF } \\
\text { SEER } \\
\text { EER } \\
\text { EER }\end{array}$ & $\begin{array}{c}10.42 \\
7.17 \\
10.89 \\
9.1 \\
9.7\end{array}$ & $\begin{array}{c}12 \\
7.4 \\
12 \\
9.7 \\
10.5\end{array}$ & $\begin{array}{l}\text { M,A } \\
\text { M,A } \\
\text { M,A } \\
\text { M,A } \\
\text { M,A }\end{array}$ \\
\hline & $\begin{array}{c}\text { Refrigerator/freezer } \\
\text { Refrigerator/freezer } \\
\text { Freezers } \\
\text { Freezers }\end{array}$ & $\begin{array}{l}2010 \\
2010 \\
2010 \\
2010\end{array}$ & $\begin{array}{l}\text { kWh/year } \\
\text { kWh/year } \\
\text { kWh/year } \\
\text { kWh/year }\end{array}$ & $\begin{array}{l}665 \\
495 \\
455 \\
391\end{array}$ & $\begin{array}{l}495 \\
421 \\
391 \\
290\end{array}$ & $\begin{array}{l}\text { M,A } \\
\text { A } \\
\text { M,A } \\
\text { A }\end{array}$ \\
\hline & Gas water heater & 2004 & $\mathrm{EF}$ & 0.54 & 0.62 & M,A \\
\hline & Dishwasher & 2010 & $\mathrm{kWh} /$ year & 496 & 431 & A \\
\hline & Televisions & 2010 & $\mathrm{kWh} /$ year & 184 & 146 & A \\
\hline & $\begin{array}{l}\text { Clothes washer } \\
\text { Clothes washer } \\
\text { Clothes washer }\end{array}$ & $\begin{array}{l}2004 \\
2007 \\
2004\end{array}$ & $\begin{array}{l}\text { Modified EF } \\
\text { Modified EF } \\
\text { Modified EF }\end{array}$ & $\begin{array}{l}0.817 \\
0.961 \\
0.817\end{array}$ & $\begin{array}{l}0.961 \\
1.362 \\
1.362\end{array}$ & $\begin{array}{l}\mathrm{M} \\
\mathrm{M} \\
\mathrm{A}\end{array}$ \\
\hline Commercial & $\begin{array}{c}\text { Packaged AC } \\
\text { Packaged AC } \\
\text { Packaged AC } \\
\text { Fluorescent } \\
\text { Ballasts }\end{array}$ & $\begin{array}{l}2005 \\
2005 \\
2010 \\
\\
2004\end{array}$ & $\begin{array}{l}\text { EER } \\
\text { EER } \\
\text { EER }\end{array}$ & $\begin{array}{c}9.4 \\
9.4 \\
10.3 \\
\\
\text { Typical in } 2000\end{array}$ & $\begin{array}{c}10.3 \\
10.3 \\
11 \\
\text { Electronic }\end{array}$ & $\begin{array}{c}\mathrm{M} \\
\mathrm{A} \\
\mathrm{A} \\
\mathrm{M}, \mathrm{A}\end{array}$ \\
\hline
\end{tabular}

(1) $\mathrm{CAC}=$ Central Air Conditioner, ASHP $=$ Air Source Heat Pump, RAC $=$ Room Air Conditioner, AC $=$ Air Conditioner, $\mathrm{SEER}=$ Seasonal Energy Efficiency Ratio, HSPF = Heating Seasonal Performance Factor, EF = Energy Factor.

(2) The baseline efficiency shown above is the average efficiency of new units in 2000, except for the 2010 standards for RACs, Refrigerator/freezers, and Freezers, where the baseline efficiency is the previous standard level. The projected efficiency of average new units in the year a particular standard comes into force is correctly analyzed in our scenario calculations, but for simplicity's sake, we show the year 2000 new unit efficiency in this table.

(3) Standard for televisions affects standby power only, reducing it to $3 \mathrm{~W}$.

(4) In Scenario column, 'M' stands for Moderate and 'A' stands for Advanced.

(5) The standard levels and timing of equipment efficiency standards shown in this table represent the authors' best judgment of feasible and cost effective standards for the two main scenarios considered in the study. They should in no way be construed to represent the position of the U.S. DOE on these standards, which will only be officially determined after appropriate rulemaking procedures are followed. 
Table A-5 Summary of Buildings Sector Program Effectiveness and Costs, by Scenario and Fuel

\begin{tabular}{|c|c|c|c|c|c|c|}
\hline \multirow[b]{2}{*}{ Sector \& fuel } & \multicolumn{2}{|c|}{$\begin{array}{l}\text { Technoeconomic } \\
\text { potential \% savings } \\
\text { relative to business } \\
\text { as usual case }\end{array}$} & \multicolumn{2}{|c|}{$\begin{array}{c}\text { Achievable } \\
\text { percentage of } \\
\text { technoeconomic } \\
\text { potential }\end{array}$} & \multicolumn{2}{|c|}{ Technology cost } \\
\hline & 2010 & 2020 & 2010 & 2020 & 2010 & 2020 \\
\hline Residential--Moderate & $28 \%$ & $37 \%$ & $28 \%$ & $45 \%$ & 600 & 5.46 \\
\hline Natural gas & $5 \%$ & $12 \%$ & $21 \%$ & $22 \%$ & 2.11 & 2.27 \\
\hline Oil & $6 \%$ & $13 \%$ & $0 \%$ & $0 \%$ & N/A & N/A \\
\hline LPG & $6 \%$ & $13 \%$ & $0 \%$ & $0 \%$ & $\mathrm{~N} / \mathrm{A}$ & $\mathrm{N} / \mathrm{A}$ \\
\hline Other & $0 \%$ & $0 \%$ & N/A & $\mathrm{N} / \mathrm{A}$ & N/A & N/A \\
\hline Total & $14 \%$ & $21 \%$ & $24 \%$ & $36 \%$ & 5.23 & 4.88 \\
\hline Commercial--Moderate & & & & & & \\
\hline Electricity & $19 \%$ & $26 \%$ & $37 \%$ & $54 \%$ & 7.45 & 7.53 \\
\hline Natural gas & $16 \%$ & $26 \%$ & $22 \%$ & $25 \%$ & 1.60 & 1.43 \\
\hline Oil & $16 \%$ & $26 \%$ & $0 \%$ & $0 \%$ & N/A & N/A \\
\hline Other & $0 \%$ & $0 \%$ & N/A & $\mathrm{N} / \mathrm{A}$ & N/A & N/A \\
\hline Total & $17 \%$ & $25 \%$ & $27 \%$ & $37 \%$ & 6.13 & 6.19 \\
\hline
\end{tabular}

(1) Technology cost is the total incremental investment cost for the more efficient option, annualized and expressed as a Cost of Conserved Energy (CCE). CCEs are calculated using a real discount rate of 7\% and lifetimes as shown in Appendix C-1.

(2) Technoeconomic potential savings and CCEs for electricity are expressed in terms of site energy at $3412 \mathrm{Btus} / \mathrm{kWh}$, so no electricity supply side effects are included.

(3) All costs are in 1997 dollars.

(4) Program implementation costs of $\$ 0.6 / \mathrm{MBtu}$ of fuel and $\$ 1.7 / \mathrm{Mbtu}$ of site electricity are used (corresponding to $\$ 0.6 / \mathrm{Mbtu}$ of primary energy for electricity), as described in Chapter 1.

\subsection{Modeling the Scenarios in CEF-NEMS}

The revised analysis spreadsheets incorporate these parameters, and then yield energy savings by end-use in 2010 and 2020 for residential and commercial buildings in the Moderate and Advanced Scenarios. To match the CEF-NEMS projection in our scenarios to our detailed spreadsheet forecasts of energy savings by end-use and technology, we changed hurdle rates, technology costs, and growth trends for each end-use. We directly input the equipment efficiency standards to the CEF-NEMS buildings sector modules. These changes reflect the effect of a variety of non-energy-price policies that eliminate many of the barriers to investing in costeffective efficiency technologies.

We match the CEF-NEMS run for each building sector module run in "stand-alone" mode against the spreadsheet results. The fuel price interactions in the integrated runs would make it difficult to exactly match against the spreadsheets. Running the CEF-NEMS modules in standalone mode eliminates this complexity. Appendix A-1 [of the Clean Energy Futures study 
(Interlaboratory Working Group 2000)] contains information on how we modified the CEFNEMS input files and code to reproduce the energy savings from the spreadsheets.

On the demand side, NEMS interprets a series of "hurdle rates" (sometimes referred to as "implicit discount rates") as a proxy for all the various reasons why people don't purchase apparently cost-effective efficiency technologies in the building sector. They include constraints for both the consumer (purchasing) and for the supplier (product manufacturing and distribution). Among the constraints are transaction costs, manufacturer aversion to innovation, information-gathering costs, hassle costs, misinformation, and information processing costs. The hurdle rates embody the consumers' time value of money, plus all of the other factors that prevent the purchase of the more efficient technologies. In this regard, the NEMS modeling framework follows a long and rich history in the economics of energy efficient technology adoption (DeCanio 1998, Howarth and Andersson 1993, Howarth and Sanstad 1995, Koomey et al. 1996, Meier and Whittier 1983, Ruderman et al. 1987, Sanstad et al. 1993, Train 1985).

In the residential and commercial sectors, for example, the financial component of the reference case hurdle rate is about 15 percent (in real terms) with the other institutional and market factors pushing such rates to well above 100 percent for some end-uses. In our scenarios, we reduce the hurdle rates as appropriate for many end-uses to reflect the policies described above. When we reduce the hurdle rates in the CEF-NEMS model, we are increasing the responsiveness of the model to changes in energy prices. This change accurately (though indirectly) reflects a world in which aggressive programs and policies remove barriers to adoption of energy-efficient technologies.

\section{Appendix References}

Brambley, M.R. , D.B. Crawley, D.D. Hostetler, R.C. Stratton, M.S. Addison, J.J. Deringer, J.D. Hall, and S.E. Selkowitz. 1988. Advanced Energy Design and Operation Technologies Research: Recommendations for a U. S. Department of Energy Multiyear Program Plan. Battelle, Pacific Northwest Laboratory. PNL-6255. December 1988.

Burnette, Charles Hamilton. 1979a. The Architect's Access to Information: Constraints on the Architect's Capacity to Seek, Obtain, Translate, and Apply Information. The AIA Research Corporation and The National Bureau of Standards. NBS GCR 78-153. March.

Burnette, Charles Hamilton. 1979b. Making Information Useful to Architects: An Analysis and Compendium of Practical Forms for the Delivery of Information. The AIA Research Corporation and The National Bureau of Standards. NBS GCR 78-154. March.

DeCanio, Stephen. 1993. "Barriers within firms to energy-efficient investments." Energy Policy. vol. 21, no. 9. pp. 906.

DeCanio, Stephen J. 1998. "The efficiency paradox: bureaucratic and organizational barriers to profitable energy-saving investments." Energy Policy. vol. 26, no. 5. April. pp. 441-454.

Fisher, Anthony C., and Michael H. Rothkopf. 1989. "Market Failure and Energy Policy: A Rationale for Selective Conservation." Energy Policy. vol. 17, no. 4. August. pp. 397-406. 
Golove, William H., and Joseph H. Eto. 1996. Market barriers to energy efficiency: A critical reappraisal of the rationale for public policies to promote energy efficiency. Berkeley, CA: Lawrence Berkeley Laboratory. LBL-38059. March.

Hirst, E., and M. Brown. 1990. "Closing the Efficiency Gap: Barriers to the Efficient Use of Energy." Resources, Conservation, and Recycling. vol. 3, no. pp. 267-281.

Howarth, Richard B., and Bo Andersson. 1993. "Market Barriers to Energy Efficiency." Energy Economics. vol. 15, no. 4. October. pp. 262-272.

Howarth, Richard B., and Alan H. Sanstad. 1995. "Discount Rates and Energy Efficiency." Contemporary Economic Policy. vol. 13, no. 3. pp. 101.

Interlaboratory Working Group. 1997. Scenarios of U.S. Carbon Reductions: Potential Impacts of Energy-Efficient and Low-Carbon Technologies by 2010 and Beyond. Oak Ridge, TN and Berkeley, CA: Oak Ridge National Laboratory and Lawrence Berkeley National Laboratory. ORNL-444 and LBNL-40533. September.

Interlaboratory Working Group, 2000, Scenarios for a Clean Energy Future (Oak Ridge, TN; Oak Ridge National Laboratory and Berkeley, CA; Lawrence Berkeley National Laboratory), ORNL/CON-476 and LBNL-44029, November.

http:/www.ornl.gov/ORNL/Energy_Eff/CEF.htm

Jaffe, Adam B., and Robert N. Stavins. 1994. "Energy-Efficiency Investments and Public Policy." The Energy Journal. vol. 15, no. 2. pp. 43.

Koomey, Jonathan. 1990. Energy Efficiency Choices in New Office Buildings: An Investigation of Market Failures and Corrective Policies. PhD Thesis, Energy and Resources Group, University of California, Berkeley.

Koomey, Jonathan, Alan H. Sanstad, and Leslie J. Shown. 1996. "Energy-Efficient Lighting: Market Data, Market Imperfections, and Policy Success." Contemporary Economic Policy. vol. XIV, no. 3. July (Also LBL-37702.REV). pp. 98-111.

Koomey, Jonathan G., R. Cooper Richey, Skip Laitner, Robert J. Markel, and Chris Marnay. 1998. Technology and greenhouse gas emissions: An integrated analysis using the LBNL-NEMS model. Berkeley, CA: Ernest Orlando Lawrence Berkeley National Laboratory. LBNL-42054. September.

Lovins, Amory B. 1992. Energy-Efficient Buildings: Institutional Barriers and Opportunities. ESource. Strategic Issues Paper. December.

Meier, Alan, and J. Whittier. 1983. "Consumer Discount Rates Implied by Purchases of EnergyEfficient Refrigerators." Energy. vol. 8, no. 12. pp. 957-962.

NPPC, Northwest Power Planning Council. 1989. Regulatory Barriers to Conservation. NPPC. Issue Paper 89-10. March 9.

Oster, S.M. , and J.M. Quigley. 1977. "Regulatory Barriers to the Diffusion of Conservation: Some Evidence From Building Codes." Bell Journal of Economics. vol. 8, no. 2. pp. 361-77. 
PCAST. 1997. Federal Energy Research and Development for the Challenges of the TwentyFirst Century. Washington, DC: President's Committee of Advisors on Science and Technology. November.

Ruderman, Henry, Mark D. Levine, and James E. McMahon. 1987. "The Behavior of the Market for Energy Efficiency in Residential Appliances Including Heating and Cooling Equipment." The Energy Journal. vol. 8, no. 1. pp. 101-124.

Sanstad, Alan H., and Richard Howarth. 1994. "'Normal' Markets, Market Imperfections, and Energy Efficiency." Energy Policy. vol. 22, no. 10. October. pp. 826-832.

Sanstad, Alan H., Jonathan G. Koomey, and Mark D. Levine. 1993. On the Economic Analysis of Problems in Energy Efficiency: Market Barriers, Market Failures, and Policy Implications. Lawrence Berkeley Laboratory. LBL-32652. January.

Train, Kenneth. 1985. "Discount Rates in Consumers' Energy-Related Decisions: A Review of the Literature." Energy. vol. 10, no. 12. pp. 1243-1253.

US DOE. 1996. Policies and Measures for Reducing Energy Related Greenhouse Gas Emissions: Lessons from Recent Literature. Washington, DC: Office of Office of Policy and International Affairs, U.S. Department of Energy. DOE/PO-0047. July. 


\section{INTERNAL DISTRIBUTION}

1. S. W. Hadley

2. B. J. Kirby

3. J. E. Christian

4. W. G. Craddick

5. T. R. Curlee

6. R. B. Shelton

7. M. A. Brown

8. Central Research Library

9-20. D. H. Daniels

21. Dr. Stephen G. Hildebrand

\section{EXTERNAL DISTRIBUTION}

22. Dr. Lilia A. Abron, President, PEER Consultants, P.C., 1460 Gulf Blvd. Apt. 1103, Clearwater, Florida 33767

23. Dr. Douglas C. Bauer, Executive Director, Commission on Engineering and Technical Systems, National Research Council, Harris 280, 2001 Wisconsin Ave NW, Washington, D.C. 20007

24. Dr. Susan L. Cutter, Professor and Chair, Director, Hazards Research Lab, Department of Geography, University of South Carolina, Columbia, South Carolina 29208

25. Mr. P. Richard Rittelmann, FAIA, Executive Vice President, Burt Hill Kosar Rittelmann Associates, 400 Morgan Center, Butler, Pennsylvania 16001-5977

26. Dr. Susan F. Tierney, The Economic Resource Group, Inc., One Mifflin Place, Cambridge, Massachusetts 02138

27. Dr. C. Michael Walton, Ernest H. Cockrell Centennial Chair In Engineering, Department of Civil Engineering, University of Texas at Austin, Austin, Texas 78712-1076 